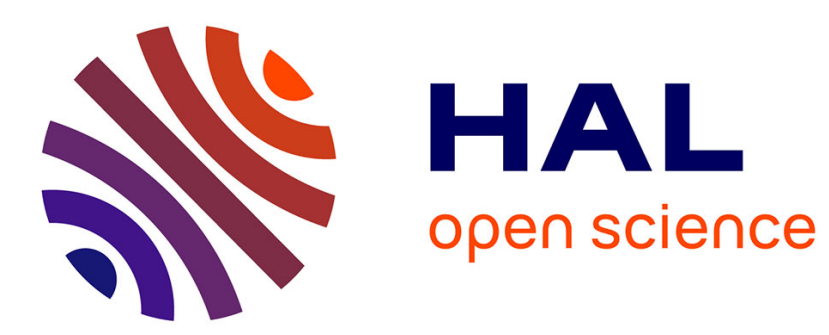

\title{
Cheating in the Lab Predicts Fraud in the Field: An experiment in public transportations
}

\author{
Zhixin Dai, Fabio Galeotti, Marie Claire Villeval
}

\section{To cite this version:}

Zhixin Dai, Fabio Galeotti, Marie Claire Villeval. Cheating in the Lab Predicts Fraud in the Field: An experiment in public transportations. Management Science, 2018, 64 (3), pp. 1081-1100. 10.1287/mnsc.2016.2616 . halshs-01348517v2

\section{HAL Id: halshs-01348517 \\ https://shs.hal.science/halshs-01348517v2}

Submitted on 26 Mar 2020

HAL is a multi-disciplinary open access archive for the deposit and dissemination of scientific research documents, whether they are published or not. The documents may come from teaching and research institutions in France or abroad, or from public or private research centers.
L'archive ouverte pluridisciplinaire HAL, est destinée au dépôt et à la diffusion de documents scientifiques de niveau recherche, publiés ou non, émanant des établissements d'enseignement et de recherche français ou étrangers, des laboratoires publics ou privés. 


\title{
Cheating in the Lab Predicts Fraud in the Field
}

\section{An Experiment in Public Transportations}

\author{
Zhixin Dai ${ }^{\mathrm{a}}$,Fabio Galeotti ${ }^{\mathrm{a}}$, and Marie Claire Villeval ${ }^{\mathrm{a}, \mathrm{b}, \mathrm{c}}$
}

This version: 18 May 2016

\begin{abstract}
We conduct an artefactual field experiment using a diversified sample of passengers of public transportations to study attitudes towards dishonesty. We find that the diversity of behavior in terms of dis/honesty in laboratory tasks and in the field correlate. Moreover, individuals who have just been fined in the field behave more honestly in the lab than the other fare-dodgers, except when context is introduced. Overall, we show that simple tests of dishonesty in the lab can predict moral firmness in life, although fraudsters who care about social image cheat less when behavior can be verified ex post by the experimenter.
\end{abstract}

Keywords: Dishonesty, fare-dodging, field experiment, external validity, public transportations

JEL codes: B41, C91, C93, K42

${ }^{a}$ Université de Lyon, Lyon, F-69007, France; CNRS, GATE Lyon Saint-Etienne, 93 Chemin des Mouilles, Ecully, F-69130, France; dai@gate.cnrs.fr, galeotti@gate.cnrs.fr, villeval@gate.cnrs.fr

${ }^{\mathrm{b}}$ IZA, Bonn, Germany

${ }^{\mathrm{c}}$ Department of Public Finance, University of Innsbruck

Acknowledgments: We are extremely grateful to P. Jacquesson, R. Sauter and F. German from Keolis and to D. Aubaret and L. Clerc-Gagnoux from Kisio for enabling the realization of this experiment with passengers of the public transportation company in Lyon. We thank A. Cohn, E. Fehr, S. Shalvi, R. Weber and seminar participants at the University of Chicago, ADRES conference in Paris, IMEBESS Meeting in Toulouse, ESA World Meeting in Sydney, ESA European meeting in Heidelberg, the $6^{\text {th }}$ ASFEE Conference in Paris, the $12^{\text {th }}$ Workshop on social economy for young economists at the University of Bologna, the $5^{\text {th }}$ Zurich Workshop in Economics in Lucerne, the GATE-LAB Workshop on Social Norms and Moral Norms in Lyon, the BEE Lyon-Toulouse workshop, for very useful comments. We thank Q. Thevenet for programming the experiment and S. Belhadj, L. Charroin, and A. Solda for valuable research assistance. This research has been supported by a grant from Keolis, a grant of the French National Research Agency (ANR, FELIS Grant, ANR-14-CE28-0010-01), and funding from the European Commission (Marie Skłodowska-Curie Individual Fellowship, 661645 - IDEA MSCA-IF-EF-ST). It was performed within the framework of the LABEX CORTEX (ANR-11-LABX-0042) of Université de Lyon, within the program Investissements d'Avenir (ANR-11-IDEX-007) operated by the French National Research Agency (ANR). 


\section{INTRODUCTION}

Fraud is a major concern in many spheres of economic life, from the financial sector to public transports, from sports to politics and academia, and it is responsible of enormous costs for society. For example, the overall gross tax gap in the U.S. represents more than $16 \%$ of the estimated actual tax liability (IRS) and insurance fraud is estimated to be around $10 \%$ of all claim expenditures in the U.S. (Mazar et al., 2008). The recent Panama Papers scandal has focused the attention on the importance of evasion in tax heavens. Corporate scandals (e.g., Enron, Société Générale, Volkswagen) entail immediate repercussions on the stock market and may durably undermine consumers' trust. Understanding better the determinants of the attitudes toward fraud is undoubtedly a major challenge to develop more effective policies.

The lack of reliable data on activities that are, by definition, secretive contributes to explain the recent booming of laboratory experiments studying dishonesty. ${ }^{1}$ These experiments have renewed considerably our knowledge by challenging the standard economics-of-crime approach (Becker, 1968). In particular, they have revealed a large diversity in the attitudes towards cheating, showing that the decision to engage or not in fraud does not result only from an evaluation of benefits and costs (e.g., Erat and Gneezy, 2012; Fischbacher and Föllmi-Heusi, 2013; Gibson et al., 2013; Abeler et al., 2014). ${ }^{2}$ However, although the advantages of using the laboratory to study dishonesty are many, one potential limitation arises from the fact that this setting is highly artificial and the results may not generalize to real settings. This issue, i.e. the generalizability of lab evidence, is a major source of debates and the discussion is still ongoing in the profession (see e.g., Levitt and List, 2007; Falk and Heckman, 2009; Camerer, 2015; Fréchette and Schotter, 2015; Charness and Fehr, 2015).

The main aim of this study is analyzing whether the diversity of attitudes towards cheating that has been identified by means of various laboratory tasks is correlated with the dishonesty of individuals in real life. We study to what extent the findings of laboratory experiments on dishonesty are externally

\footnotetext{
${ }^{1}$ Irlenbusch and Villeval (2015) review almost 60 articles related to dishonesty published in economic journals between 2012 and early 2015. The meta-analysis of Abeler et al. (2016) includes 58 studies on lying based on the reports of random draws (coins or dice). Of course, there is an older experimental literature on tax evasion (for a review, see Torgler, 2007) and cheap talk games with strategic information transmission (e.g., Crawford and Sobel, 1982, Gneezy, 2005; Sutter, 2009) or promises about future behavior (e.g., Charness and Dufwenberg, 2006).

${ }^{2}$ Subjects frequently do not deceive or lie in a way that maximize their earnings (Gneezy, 2005; Shalvi et al., 2011; Fischbacher and Föllmi-Heusi, 2013). Possible explanations are that people want to preserve a good selfor social image (Mazar et al., 2008; Gino et al., 2009; Shalvi et al., 2011; Fischbacher and Föllmi-Heusi, 2013) or they follow moral norms (Vanberg, 2008; Lundquist et al., 2009; Pruckner and Sausgruber, 2013). Subjects also condition their decision to lie on the effect that their behavior will have on others (Brandts and Charness, 2003; Charness and Dufwenberg, 2006; Ellingsen et al., 2010; Maggian and Villeval, 2016), suggesting a role for social preferences and guilt. Dishonesty is also sensitive to occupational norms (Cohn et al., 2014), and incentive schemes (e.g., Conrads et al., 2013, 2014; Charness et al., 2014). Gächter and Schultz (2016) have demonstrated that individual dishonesty in the lab is also directly influenced by the prevalence of rule violations in the society.
} 
valid with an ordinary population. To achieve this aim, we compare the cheating behavior of similar people in the field and in the laboratory by means of an artefactual field experiment (in the sense of Harrison and List, 2004) using a diversified sample of 279 passengers of a public transport service in France.

Levitt and List (2007) identify five main threats to generalizability in a typical laboratory experiment due to the fact that decision-making involves economic but also moral and ethical considerations: the scrutiny of actions by others, a lack of anonymity, the context in which the decision is embedded, the self-selection of participants, and the stakes of the game. When studying dishonesty, some of these threats may be exacerbated, making generalizability even more challenging. In particular, the fear of scrutiny may induce subjects to resist the temptation of cheating because observability increases the moral and ethical costs of cheating. Dishonesty also possesses different facets and is likely to be context-dependent; thus, decisions may differ if they are taken in or outside the lab. This leaves open the question of whether economists are able, by means of a lab experiments, to make general claims about dishonesty which hold across different contexts. Moreover, if more prosocial individuals tend to self-select in participating in experiments, and if social preferences are correlated with a higher moral firmness, lab experiments may underestimate dishonesty or overestimate the impact of interventions. Although Falk and Heckman (2009) and Camerer (2015) address very thoughtfully the limitations to the generalizability of such critiques, our study has been designed such as to avoid each of these potential issues.

We chose to study dishonesty in public transportations because fare evasion is a non-trivial offence, ${ }^{3}$ is widespread in all countries, costs billions of dollars worldwide (see e.g., Donohue, 2010; Fürst, 2012; Cour des Comptes, 2016), but is surprisingly understudied. ${ }^{4}$ In a "policy view" (in the terms of Camerer, 2015), it is crucial to determine whether the lab can be convincingly used to investigate the determinants of fare evasion in the field and how it reacts to various interventions. Our study focuses on small-scale dishonesty that is more prevalent in day-to-day life with dramatic consequences for society (Mazar and Ariely, 2006) and, therefore, globally relevant from an economic point of view. The level of stakes associated with fare evasion at the individual level is comparable

\footnotetext{
${ }^{3}$ Fare-dodging and fare evasion are used interchangeably throughout the paper. They are considered as a crime and are defined as using public transports without purchasing the required ticket or without validating one's ticket at the machine.

${ }^{4}$ Surprisingly, economic studies on fare evasion are very few (Boyd et al., 1989; Kooreman, 1993; Nikiforakis, 2007; Bucciol et al., 2013; Buehler et al., 2014). More can be found in criminology (e.g., van Andel, 1989; Hauber et al., 1996; Smith and Clarke, 2000; Kilias et al., 2009). Data from the field are usually not made available by companies. Fragmented information comes from newspapers but data are difficult to compare. A report of the French Auditing Court ("Cour des Comptes") released in 2016 on transportations in the region Paris-Ile de France indicates that the fraud rate on buses and tramways has increased from about $9 \%$ in 2009 to about 14\% in 2014 but acknowledges that these percentages are underestimated. It indicates that in 2013, the number of trips without a valid ticket amounts to 14 million trips on the RER, 23 millions on tramways, 84 millions in the metro and 123 millions in the buses.
} 
with the low stakes in the games used in the lab, which reduces the risk of making inaccurate inference from the experimental findings due to too different levels of stakes.

Another advantage in terms of generalizability of studying fare-dodging is the opportunity to observe the dishonesty of ordinary people, and the accessibility of the targeted population. Indeed, a very large fraction of the population uses public transports in France, with a huge variety in terms of age, income level, occupation, residential location. This contrasts with other recent studies of dishonesty in the lab and in the field which target much more specific populations (open air sellers in List, 2009; bankers in Cohn et al., 2014; prisoners in Cohn et al., 2015; graders in Armantier and Boly, 2013; nurses in Hanna and Wang, 2015). Regarding the risk of self-selection, comparisons with data collected by the operator (Keolis) indicate that our sample is relatively similar in terms of individual characteristics and that our proportion of fraudsters is not below the estimates of the company.

Our methodology combines standard laboratory and field measures of dishonesty to test whether our measures of dishonesty generalize across contexts. Precisely, studying fare evasion allowed us to collect three field measures. The first two are based on whether subjects could at the end of the experiment display a validated ticket in exchange for a new one (similar to Bucciol et al., 2013), and on self-reports. ${ }^{5}$ For the third measure we recruited a sub-sample of passengers just after they paid a fine. The core of our paper consists of correlating these measures of dishonesty in the field to dishonesty in the lab, as measured in both an abstract task - a die-under-cup task inspired from Fischbacher and Föllmi-Heusi (2013) and Shalvi et al. (2011), that eliminates any possible scrutiny ${ }^{6}$ , and a contextualized task - a public transportation game where subjects decide to buy or not a ticket to use a fictional bus. We introduced this public transportation game because it allows us to measure cheating behavior at the individual level, whereas the die task only allows us to compare the distribution of all subjects' reports to the theoretical distribution of random draws. Note that behavior may differ in this game compared to the die task for at least two psychological reasons. Since the experimenter is able to identify ex post in the data who has cheated in this game, a feeling of scrutiny may affect negatively the decision to lie (if subjects experience a disutility from being exposed as a cheater in the experimenter's eyes). On the other hand, introducing a public transportation context may prime the identity of passengers, which may reinforce the fare-dodgers' willingness to cheat. Our

\footnotetext{
${ }^{5}$ Economists are typically reluctant to use self-reports. In our case, this measure is used as a complement and can be correlated with our objective measure of fraud. Moreover, studies in psychology show a correlation between self-reports on unethical tendencies and actual lying (Halevy et al., 2014; Zimerman et al., 2014).

${ }^{6}$ People may not reveal their true preferences if their behavior can be observed. To circumvent this problem, economists and psychologists developed recently simple techniques to measure dishonesty in total privacy. Besides reporting the outcome of a dice roll in private (e.g., Shalvi et al., 2011; Fischbacher and Föllmi-Heusi, 2013; Hao and Houser, 2013; Gächter and Schultz, 2016), they include coin flips (e.g., Bucciol and Piovesan, 2011; Houser et al., 2012; Abeler et al., 2014), reports on real-effort outcomes (e.g., Mazar et al., 2008; Rosaz and Villeval, 2012). In mind games, the experimenter knows the result of the random draw, but payment depends on the self-reported accuracy of a prior prediction (Jiang, 2013; Kajackaite and Gneezy, 2015).
} 
objective, however, is not to compare cheating in the two tasks, but to test whether the correlation between behavior in the field and in the lab holds in these two different environments.

As a robustness test, we conducted a complementary study with a standard students-subject pool. ${ }^{7}$ To get a field measure of dishonesty, we overpaid these subjects at the end of the session and checked whether they reported or not the error (like Gneezy et al., 2013, and Potters and Stoop, 2016).

Our contribution and novelty are fourfold. First, by presenting the first study comparing the behavior of actual fare-dodgers and non-fare-dodgers across experimental tasks, we are able to investigate whether or not the same persons cheat in different contexts and to validate the external validity of lab measures of dishonesty with and without context. ${ }^{8}$ This constitutes a test of the generalizability of lab findings on dishonesty to the field that does not rely on priming methods (such as Cohn et al., 2014, 2015) but on direct observation, and that involves ordinary people. Second, we can study the consistency of objective measures of cheating with self-reports and whether lab measures correlate more with objective measures or with self-reports. Deviations allow us to identify image concerns. Third, we provide the first study able to measure the immediate impact of a fine in the field on subsequent dishonesty in the lab, by testing whether fare-dodgers who have just paid a fine fraud more or less than others when given a new opportunity to cheat. Fourth, we contribute to a better knowledge of fare-dodgers, their moral norms and their individual characteristics.

Our results show that the lab measures of dishonesty correlate with rule violation in real life. The proportion of fully dishonest subjects in the die task is higher among passengers who do not hold a validated ticket, while the proportion of incomplete liars is the highest among those who hold a valid ticket but self-report as occasional fare-dodgers. Our study with students confirms the correlation between field and lab measures of dishonesty. Moreover, fare-dodgers who had just paid a fine behave more honestly than the other fare-dodgers in the die task but not when context is introduced, which suggests a priming effect of context. Behavior in the contextualized task is essentially consistent with behavior in the die task and with our field measures of dishonesty, except for passengers without a ticket who, however, self-report as non-fraudsters. Indeed, when decisions can be verified ex post, selfimage concerned people cheat less than when scrutiny is impossible. Overall, we show that simple tests of dishonesty in the lab are able to capture individual attributes that predict rule violation by ordinary people in real life. Showing the external validity of the die-under-cup task is a major finding given the large interest for this experimental paradigm in the recent literature on dishonesty. More generally, this constitutes a major step in the validation of the use of the laboratory to study how

\footnotetext{
${ }^{7}$ By diversifying their subject pool, some studies on dishonesty found substantial differences between students and non-student subjects (Utikal and Fischbacher, 2013; Cohn et al., 2014), while others found no difference (Abeler et al., 2014). This suggests that more investigation is needed.

${ }^{8}$ This is old debated topic in psychology. Hartshorne and May (1928) claim that cheating in one context cannot predict cheating in other contexts, while more recent studies defend the generality of moral behavior (Burton, 1963).
} 
dishonesty reacts to policy interventions. Caution must however be taken when behavior can be verified by the experimenter since it may underestimate the dishonesty of image-concerned individuals.

The remainder of this paper is as follows. Section 2 reviews the related literature. Section 3 describes the experimental design and procedures. Section 4 details our results and Section 5 presents our replication study. Section 6 discusses the results and concludes.

\section{RELATED LITERATURE}

This section briefly reviews the various methods used by previous experimental studies to investigate the link between dishonesty in the field and in the laboratory and characterizes how we differ from these studies.

One approach consists of examining how societal norms across countries shape individuals' intrinsic standards of honesty and ethical values, as measured in the lab. With a lab experiment conducted in 23 countries, Gächter and Schultz (2016) have demonstrated that individual dishonesty is directly influenced by the prevalence of rule violations (such as tax evasion, political fraud and corruption) in the society. In contrast, our study examines the correlation between the behavior of the same persons in the field and in the lab in a given culture.

Another approach consists of priming the identity of people with a presumed or proven culture of cheating. Cohn et al. (2014) show that bank employees, when their professional identity is primed, behave more dishonestly in a coin tossing task compared to control groups. This study demonstrates the impact of business culture but cannot relate directly (unobserved) individual dishonesty in the field to that observed in the lab. Cohn et al. (2015) identify a causal effect of criminal identity on dishonesty. Indeed, inmates behave more dishonestly when their criminal identity is primed compared to regular citizens, and that the dishonesty of primed and non-primed prisoners, pooled together, is correlated to the offences committed in prison. This provides evidence of the external validity of a coin tossing task, but with a very peculiar population characterized by persons who committed serious crimes. In addition, a large proportion of the inmates were convicted for crimes which are not necessarily linked to dishonesty. In contrast, our study focuses on the day-to-day dishonesty of ordinary people, which involves small-scale cheating, and we replace priming with a direct observation of individual dishonesty in a real setting. ${ }^{9}$

A different approach consists of replicating the same experiment in field and lab settings. Conducting a field experiment and two lab experiments on bribing, Armantier and Boly (2013) obtain

\footnotetext{
${ }^{9}$ Indeed, priming methods may have some limitations. For example, the behavior change observed under priming may not occur actually in the real world. This is the case if the priming manipulation induces an experimenter demand effect (Zizzo, 2012). Moreover, the effect induced by priming does not tell whether the task is, in the first place, able to capture differences in dishonesty in the field.
} 
analogous treatment effects, both in terms of direction and magnitude. However, since bribing involves joint dishonesty, it may be partly motivated by social preferences and what works for corruption may not work for other forms of dishonesty. More importantly, while the authors uncover a clear parallelism between the lab and the field, they do not test whether corrupt individuals in the lab would adopt the same behavior in the real world. The same applies to Alm et al. (2015) who show the similarity of tax evasion decisions of actual taxpayers, students, and non-student subjects in comparable field and lab settings, and to Choo et al. (2014) who find a lower compliance of students. By measuring the behavior of identical individuals in the field and in the lab, we believe that we provide a stronger test of the generalizability of lab experiments on dishonesty.

Indeed, another method consists of observing the dishonest behavior of identical individuals both in a naturally-occurring environment and in the lab. A secondary result of a study by List (2009) on open air markets is that cheating, intended as maintaining collusive promises between sellers, correlates between a natural and a framed field experiment, whereas little correlation is found between cheating rates in the lab and in the other environments when no context is introduced. This last result is, however, based on a small sample of 17 dishonest sellers. In the spirit of List (2009), we compare the behavior of identical persons in a naturally-occurring situation and in the lab, we manipulate the context of the games, and we conduct a similar study with student-subjects. In contrast, our subjects are aware of participating in an experiment. Our approach, based on a larger and more general population and on a standard lying task, can be very useful to complement previous research and provide substantial evidence on the external validity of lab findings. ${ }^{10}$

The experiment most closely related to our study is that of Hanna and Wang (2015), run in India. It shows that nurses who report more favorable outcomes in a die rolling task are more likely to be absent from work. ${ }^{11}$ Like us, the authors aim to validate a laboratory measure of dishonesty using a non-student subject pool by correlating it with a field measure of dishonesty -fraudulent absenteeism. In contrast, our study involves a more generic sample of the general population, uses monetary incentives, compares different measures of dishonesty in the field, and test the predictive value of alternative lab measures with and without context. It thus provides a more complete framework to understand whether dishonesty can be reliably measured in the lab. ${ }^{12}$

\footnotetext{
${ }^{10}$ Using a similar approach, Cohn and Maréchal (2015) show that cheating in a coin tossing task predicts school misbehavior of middle and high-school students. A major difference with our study is that the violation of behavioral rules differs from dishonesty. Other differences include the fact that we compare different tasks.

${ }^{11}$ They also show that students with above median dice score are more likely to be willing to work in the public sector where corruption is high. Barfort et al. (2015) find the opposite in Denmark. However, the latter do not observe dishonesty in the field.

${ }^{12}$ Hanna and Wang (2015) look at a very specific population, composed mainly of women (95\%), and pay subjects with candies. The fact that some nurses have been exposed to a biometric monitoring with the goal of reducing absenteeism may also have affected the measurement of dishonesty in the experimental task.
} 


\section{EXPERIMENTAL PROCEDURES AND DESIGN}

In this section, we first present our recruitment methods and experimental procedures. Then, we describe the content of the experiment. Next, we explain our measures of dishonesty in the laboratory and in the field. Finally, we describe our sample of subjects.

\subsection{Recruitment and procedures}

The experiment was conducted in Lyon (France) during nine consecutive days (excluding Sundays) from $11 \mathrm{am}$ to $7 \mathrm{pm}$. Recruiters wore a badge (with the word "survey"-"enquête"-written on it) in order to prevent being perceived as inspectors. They were instructed to invite subjects at the precise arrival of trams and buses at the "Gare Part-Dieu" stop, located in front of the biggest shopping mall in the city center and the main train station. The procedure consisted of randomly approaching passengers who were getting off the vehicle by asking them whether they were holding a monthly pass. The invitation to participate was extended only to passengers without a pass in order to maximize the number of potential fare-dodgers participating in the experiment. ${ }^{13}$ The experiment was presented as a study ran by researchers from the University about means of transportation. Potential participants were told that the duration of the study was about 45 minutes, that they would have to answer questions, that the study was anonymous and did not require any particular knowledge, and that a minimum of 25 Euros would be paid in gift vouchers immediately at the end of the study. The recruiters were not informed about the aim of the study and if someone asked about its content, they were instructed to tell that they did not know. Once a passenger agreed to participate, he was asked to keep his used ticket if he had one because it would be replaced with a new one at the end of the experiment.

The 244 subjects who agreed to participate were escorted to a building located 60 meters from the stop, where we had installed our mobile lab (see Appendix 1). Upon arrival, each subject signed a consent form, received a tablet and was assigned to a desk. Each desk was isolated by means of mobile partitions. Since the experiment was based on individual decisions, we had a permanent inflow of participants with a maximum of nine subjects at the same time. We answered questions in private. Once a subject completed the experiment, he was escorted to a separate room and paid out in gift vouchers. After giving the vouchers, the assistant asked the subject whether he had a validated ticket in the purpose of exchanging it with a free day-pass since the ticket was no longer valid.

In order to measure the immediate impact of a sanction on honesty, we also recruited 35 subjects from the Fine Collection Office (FCO, hereinafter) where passengers who are caught to travel without a valid ticket and do not pay their fine on the spot can pay their fine. These subjects were invited immediately after paying their fine. The rest of the procedure was similar to that used with the other

\footnotetext{
${ }^{13}$ Recruiters were also instructed not to invite both members of the same couple or several friends simultaneously. They were told not to recruit people who spontaneously offered themselves to take part in the study to avoid potential contamination from subjects having already participated.
} 
passengers. The experimenter knew when a person was coming from the FCO because he was escorted by different recruiters than those who were at the bus and tram stop. This information was recorded by a code entered in the tablet.

A total of 279 subjects participated. To get a sample of passengers as representative as possible, participants were sampled based on a stratified random procedure which followed a compulsory survey conducted by the local public transport agency TCL-Sytral in Lyon in 2014. Appendix 2 compares our subject pool with the population of this representative survey. Our sample differs mainly in terms of age (we excluded passengers younger than 18, we slightly over-represent passengers from 18 to 24 years old, and under-represent passengers older than 60) and status (we over-represent unemployed people and under-represent white collars and retirees).

\subsection{Content of the experiment}

The experiment consists of four parts and a final questionnaire. It is fully computerized, including the instructions that are displayed on the tablet at the beginning of each part (see Appendix 3). For the purpose of this paper, we only focus on the first three parts. ${ }^{14}$

First part: Elicitation of attitudes towards risk, ambiguity, and losses. We used Eckel and Grossman's (2008) method with the representation proposed by Eckel et al. (2012). Precisely, subjects have to choose one lottery in each of four successive sets of six binary lotteries displayed on a ring in different screens. The expected payoff of each lottery increases as one moves clockwise, from $28 €$ to $36 €$, as well as the variance of payoffs. The first set of lotteries is used to elicit risk attitudes in the gain domain. Each lottery offers two outcomes, each with an equal likelihood. The second set offers the same choices but in the domain of losses. To hold expected earnings constant across tasks, subjects receive an initial endowment of $€ 40$. The comparison of the choices made in these two tasks gives a measure of the subjects' degree of loss aversion. The next two sets of lotteries offer the same possible outcomes in the domain of gains, first, and of losses, next. Like in Cardenas and Carpenter (2013), the probability of each outcome is, however, uncertain, with a minimum of $30 \%$ and a maximum of $70 \%$. Comparing choices in the first and the third (second and fourth, respectively) sets gives a measure of ambiguity aversion in the gain (loss) domain.

Second part: Die-under-cup task. To elicit the subjects' proneness to lying, we adapted the procedure of Fischbacher and Föllmi-Heusi (2013). Subjects are first asked to fill out a brief questionnaire. ${ }^{15}$ They are then told that, for answering these questions, they can earn 0,3 or 5 Euros,

\footnotetext{
${ }^{14}$ For the third part, in this paper we only consider the first period. The fourth part consisted of a dynamic public transportation game in which subjects had to decide on whether buying or not a ticket and in which we manipulated the frequency and regularity of audits, and the information about the future occurrence of audits. The results of this fourth part are reported in Dai et al. (2016).

${ }^{15}$ Subjects have to report whether they are fully prepared to take risks or whether they prefer to avoid risks on a scale between 0 ("not at all willing to take risks") and 10 ("very willing to take risks"), using the Dohmen et al. (2011) procedure. The second question is similar but in the context of financial decisions.
} 
depending on a die roll. The die is inside a sealed cup that allows only the subject to see the die, as in Shalvi et al. (2011). We use a six-faced die with three colors rather than numbers. The die can give three possible outcomes (red, yellow, blue) with equal probability (1/3). Subjects are instructed to privately roll the die twice, and report the outcomes of the two rolls in the tablet. The first roll determines the earnings of the task: $€ 0$ if the color reported is blue, $€ 3$ if yellow and $€ 5$ if red. The second roll does not give rise to any payment. ${ }^{16}$ To avoid any error, the text above each reporting screen on the tablet reminds the subjects whether his report determines payment or not. This task allows us to collect information on full honesty, partial and full dishonesty at the aggregate level, without losing too much statistical power since we have only three possible outcomes rather than six, in contrast to previous die-rolling experiments.

Third part: Public transportation game. This part departs from the abstract environment of the die task to move closer to a naturally-occurring situation of public transportation. The task is depicted as a decision on whether to buy or not a ticket for using an imaginary bus. Seven destinations can be reached, each described as a subsequent stop of the bus. For every possible final destination (stops 17), the subject has to decide whether to buy a ticket or not. One decision, chosen at random at the end of the experiment, is relevant for payment. The price of the ticket equals $€ 1.70$ irrespective of the destination (equivalent to the actual tariff). Subjects benefit from using the bus, which is explained in terms of time saved. We used two treatments. In the "Variable treatment" (144 subjects), the benefit increases in the distance between the departure point and the final destination, in increments of $€ 2$ per stop, with an expected benefit of $€ 8$. In the "Constant treatment" (135 subjects), the benefit is $€ 8$, irrespective of the destination. The Variable treatment aimed to test whether lies are more likely when their relative benefit increases (i.e., when the distance is shorter) rather than when it is fixed (i.e., in the Constant treatment). It turns out that there is not much of a difference between the two treatments (people cheat more on shorter distances in both treatments), and, thus, we pool them in the data analysis. To preserve some comparability with the die task, in period 1 subjects are informed that there is no ticket control on the line. Thus, it is clear that lying cannot be punished. ${ }^{17}$ Since previous studies have shown that the introduction of context in a protocol can affect behavior (Cooper et al., 1999) or matters for ecological validity (Frechette, 2015), this part allows us to test whether the difference in attitudes toward dishonesty between actual fare-dodgers and non fare-dodgers is larger in the contextualized game than in the abstract die task. More importantly, this task allows us to measure dishonesty at the individual level, in contrast to the die task. The counterpart is that some subjects may feel scrutinized since it is possible for the experimenter to check ex post whether they lied or not.

\footnotetext{
${ }^{16}$ The second roll is presented as allowing the subjects to check that the die is fair.

${ }^{17}$ After playing period 1, subjects discovered four subsequent periods in this game. In periods 2 to 5 , which we do not consider in this paper, we introduced various common knowledge probabilities of being controlled and fined. The results of the other periods are available upon request.
} 
Final questionnaire. At the end of the experiment, subjects fill in a final questionnaire where we collect information about the demographic and socio-economic characteristics of the subjects (age, gender, income category, status, residence), their usage of public transport (frequency, time), and, finally, their beliefs and opinion about fare evasion. A full list of the items used in this questionnaire can be found in Appendix 3.

Payments. We paid the earnings of one randomly selected lottery choice in part 1 , those associated to the reported outcome in part 2, and either the earnings of one decision in one period of part 3 or the earnings of three randomly selected periods in part 4 . Subjects received between $€ 25$ and $€ 110$, and, on average, $€ 60$.

\subsection{Measures of dishonesty}

We collected in total two experimental and three field measures of dishonesty. One experimental measure comes from the die task and the other one is given by the public transportation game. In part 2 , we can assess the extent to which our subjects are dishonest by comparing the distribution of the reported outcomes of the die roll with the uniform distribution of a fair die roll. In part 3, we measure whether and how often subjects do not buy a ticket in the game. While the first measure cannot be evaluated for each individual but only for clusters of subjects, the second one is calculated individually.

Turning to the field measures of dishonesty, one is based on whether a subject is able to display or not a validated ticket at the end of the experiment (like in Bucciol et al., 2013). We believe that this measure is quite reliable. Subjects were, at the recruitment stage, told to keep their ticket with them for replacement with a new one. The motivation was credible since the company uses a time-based pricing system and a ticket is valid only within one hour; therefore, it makes sense to compensate a ticket-holder with a new ticket for the time spent in the study. ${ }^{18}$ Even if a passenger does not plan to continue his journey, it is attractive to get a free day-pass that can be used any time in exchange for a used ticket. The advantage of this measure is that we can convincingly classify subjects who are not able to display a valid ticket as fare-dodgers. One limitation, however, is that it is instantaneous; it only captures subjects who evaded the fare on that specific day. ${ }^{19}$

Our second field measure is based on self-reports in a final questionnaire. Subjects were asked to report how many times, on average, they travel without a ticket out of 10 trips. We classify as cheaters

\footnotetext{
${ }^{18}$ It is unlikely that subjects trashed their ticket in the bus/tram before being approached by the recruiters since this behavior is extremely unusual in Lyon. One can argue that some subjects might have thrown out their ticket on the way to the lab. Although we cannot entirely exclude this possibility, we believe it is very unlikely. Subjects had to walk only 60 meters from the stop, and had been just advised not to trash the ticket. None of the recruiters reported such behavior. Finally, even if few subjects did trash their ticket and were wrongly classified as dishonest, it would only make more difficult to detect differences in behavior between ticket holders and nonticket holders, and, therefore, it would strengthen our results.

${ }^{19}$ As mentioned earlier, this only reduces the distinction between ticket and non-ticket holders, making any difference we detect even stronger.
} 
those who report to evade at least once out of 10 trips. The advantage of this measure is that subjects who admit to travel without a ticket can be credibly classified as fare-dodgers since they have no reason to lie. The disadvantage is that image-concerned fare-dodgers may not be willing to admit that they are a cheater. ${ }^{20}$

Finally, the subjects recruited at the FCO have, by definition, acted dishonestly at least once, since they have been caught during an inspection. We classify them as fare-dodgers but we expect them to behave differently in the experiment from the other recruited fare-dodgers. On the one hand, they may act more honestly. Indeed, paying a fine may have an "educative" effect on immediate behavior because these people have just been reminded that violating the rules leads to punishment. Faredodgers who pay the fine may also, in general, be more honest than other fare dodgers (as a large fraction of detected fraudsters who do not pay on the spot never pay their fine). On the other hand, they may behave less honestly because of loss repair: they may try to recover the amount of the fine by cheating in the experiment (Kastlunger et al., 2009; Dai et al., 2015). For these reasons, these subjects are classified as standalone category and their behavior is analyzed separately.

\subsection{Self-selection of subjects}

One might be concerned that evaders are less willing to take part in a study on public transports than passengers who used to pay their fare, and that the fare-dodgers who agree to participate are those who are the least embarrassed by a violation of the honesty norm (although they are not aware of the aim of the study). We explain why we believe that these two sources of selection bias have not plagued our study. Table 1 reports the distribution of the subjects based on our measures of fraud in the field.

Table 1. Distribution of subjects, by measure of fraud in the field

\begin{tabular}{lcccccc}
\hline \hline & \multicolumn{3}{c}{ Number of trips without a ticket, out of } & & & \\
& \multicolumn{4}{c}{ 10 trips (self-reported) } & \multirow{2}{*}{ Total } & \multirow{2}{*}{ Percentages } \\
\cline { 2 - 5 } & 0 & 1 or 2 & 3 or more & & & \\
\hline Ticket holders & $77(54.23)$ & $43(30.28)$ & $22(15.49)$ & $142(100)$ & 58.20 & 50.90 \\
Non-ticket holders & $33(32.35)$ & $28(27.45)$ & $41(40.20)$ & $102(100)$ & 41.80 & 36.56 \\
Total (exc. FCO) & $110(45.08)$ & $71(29.10)$ & $63(25.82)$ & $244(100)$ & 100 & - \\
FCO & $13(37.14)$ & $9(25.72)$ & $13(37.14)$ & $35(100)$ & - & 12.54 \\
Total (all) & $123(44.09)$ & $80(28.67)$ & $76(27.24)$ & $279(100)$ & - & 100 \\
\hline
\end{tabular}

Notes: Percentages in parentheses. FCO: Fine Collection Office.

First, Table 1 indicates a high share of fare-dodgers among the participants. Excluding the FCO, $41.80 \%$ of the subjects were not able to display a validated ticket ${ }^{21}$ and $54.92 \%$ reported travelling without a ticket at least once every 10 trips. The representatives of the operator confirmed that our

\footnotetext{
${ }^{20} \mathrm{We}$ believe that allowing people to provide a non-binary answer to this question reduces the number of subjects who self-report as non-fraudsters when they are actually fraudsters.

${ }^{21}$ We cannot provide these statistics for the FCO subjects since they may have not used public transports.
} 
values are consistent with their measures for passengers without a pass on the lines where we recruited our subjects. ${ }^{22}$ This indicates that fare-dodgers did not self-select out of our study.

Second, in the final questionnaire we asked subjects to indicate how they perceive a passenger who does not pay his fare on a scale from 1 for "I very strongly disapprove" and 7 for "I very strongly approve". $39.20 \%$ of the non-ticket holders and $27.56 \%$ of the self-reported fraudsters report a value lower than 4 (more or less disapprove), while $24.80 \%$ and $26.54 \%$, respectively, report a value higher than 4 (more or less approve). The corresponding percentages are $59.84 \%$ and $18.18 \%$, respectively, for the ticket holders and $64.23 \%$ and $15.45 \%$ for the self-reported non-fraudsters. If only fare-dodgers with no shame self-selected in our study, we should expect a higher approval rate among these subjects. Moreover, a fraction of the subjects unable to show us a validated ticket self reported as non-fraudsters, which suggests that these subjects care about their image.

\section{RESULTS}

In this section, we first consider the general prevalence of cheating in the die task to test whether we are able to replicate previous findings. We then divide subjects in categories based on our field measures of dishonesty to study whether behavior in the die task is related to dishonesty in the field. Next, we investigate whether the relationship between dishonesty in the field and behavior in the lab holds in the contextualized transportation game. We then test the extent to which the lab behavior of our different categories of subjects differs between the public transportation game and the die task. Finally, we report the results of our complementary study ran with students.

\subsection{Diversity of attitudes towards lying in the die-under-cup task}

As in previous studies, we find that the distribution of the reported outcomes of the first die roll (the one that determines payoffs) is significantly different from a uniform distribution ( $\chi^{2}$ goodness-of-fit test, $p<0.001) .{ }^{23}$ Indeed, $11.11 \%$ of the subjects report the lowest outcome (blue, that pays $€ 0$ ) and $51.97 \%$ report the highest outcome ( $r e d$, that pays $€ 5$ ), both being significantly different from the expected value of $33 \%$ (binomial tests, $p<0.001$ ). $36.92 \%$ of the subjects report the medium outcome (yellow, that pays $€ 3$ ), which does not differ significantly from $33 \%(p=0.205)$.

\footnotetext{
${ }^{22}$ The high fraud rate is also due to the recruitment of passengers without a monthly pass. Recruiting metro users would have also led to a much lower fraud rate because the access to metro is protected by barriers. The rate of self-reported fraud is consistent with a 2011 survey conducted by OpinionWay in Lyon where it was found that $55 \%$ of respondents reported to sometimes travel without a valid ticket (Keolis, 2014). These statistics can also be compared to the percentage of non-ticket holders (42.88\%) found by Bucciol et al. (2013) in a medium-sized city in Italy. Italy and France display amongst the highest rate of fare evasion in Europe (Bonfanti and Wagenknecht, 2010).

${ }^{23}$ Throughout the paper, statistical tests are two-sided, unless specified otherwise. Each subject gives one independent observation. To compare the distributions of the reported outcomes with the theoretical distributions, we use $\chi^{2}$ goodness-of-fit tests. Kolmogorov-Smirnov tests (available upon request) give similar results but they are less desirable since they assume continuous distributions.
} 
Assuming that subjects never misreport an outcome when it is not beneficial for them, we can non-parametrically estimate the percentages of dishonest and honest people in our subject pool (for a derivation of these estimations, see Appendix 4). The estimated percentage of honest subjects is $33 \%$, while the percentage of income maximizers -who lie by reporting the highest outcome- is $28 \%$ at maximum. These values are consistent with the estimates of Fischbacher and Föllmi-Heusi (2013) who found respectively $39 \%$ and $22 \%$, using a six-sided die. We can further estimate the percentages of partially and fully dishonest subjects. Fully dishonest subjects are those who report the most favorable outcome regardless of the actual outcome. We consider two definitions of partial dishonesty. The lower bound of partial dishonesty is given by the subjects who report the medium outcome when they roll the worst one, assuming that only a fully dishonest subject reports the highest outcome when it is not true. The upper bound is that partially dishonest subjects always lie a bit by reporting the next superior outcome (yellow when getting blue, and red when getting yellow). This assumes that both fully and partially dishonest subjects may lie by reporting the highest outcome. Based on these definitions, the percentage of fully dishonest subjects lies in between $0 \%$ and $28 \%$, and that of partially dishonest subjects between $39 \%$ and $67 \%$.

To sum up, consistently with previous studies we find a considerable diversity of attitudes towards lying: a non-trivial fraction of subjects are fully honest in the die task, while the majority behave dishonestly but not in a way that maximizes their earnings.

\subsection{Dishonesty in the field and lying in the die-under-cup task}

We now examine the links between dishonesty in the field and behavior in the die task. Figure 1 and Table 2 summarize the distribution of reported outcomes of the first die roll for different categories of subjects: self-reported fraudsters who do not hold a validated ticket (69 subjects), self-reported fraudsters who hold a validated ticket (65), self-reported non-fraudsters who do not hold a validated ticket (33), and self-reported non-fraudsters who hold a validated ticket (77). They also report the significance of two-sided binomial tests that the observed percentages differ from the expected 33\% and Table 2 displays the $p$-value of a $\chi^{2}$ test that the observed distribution differs from the expected uniform distribution. These statistics are used as supports for our main results. 


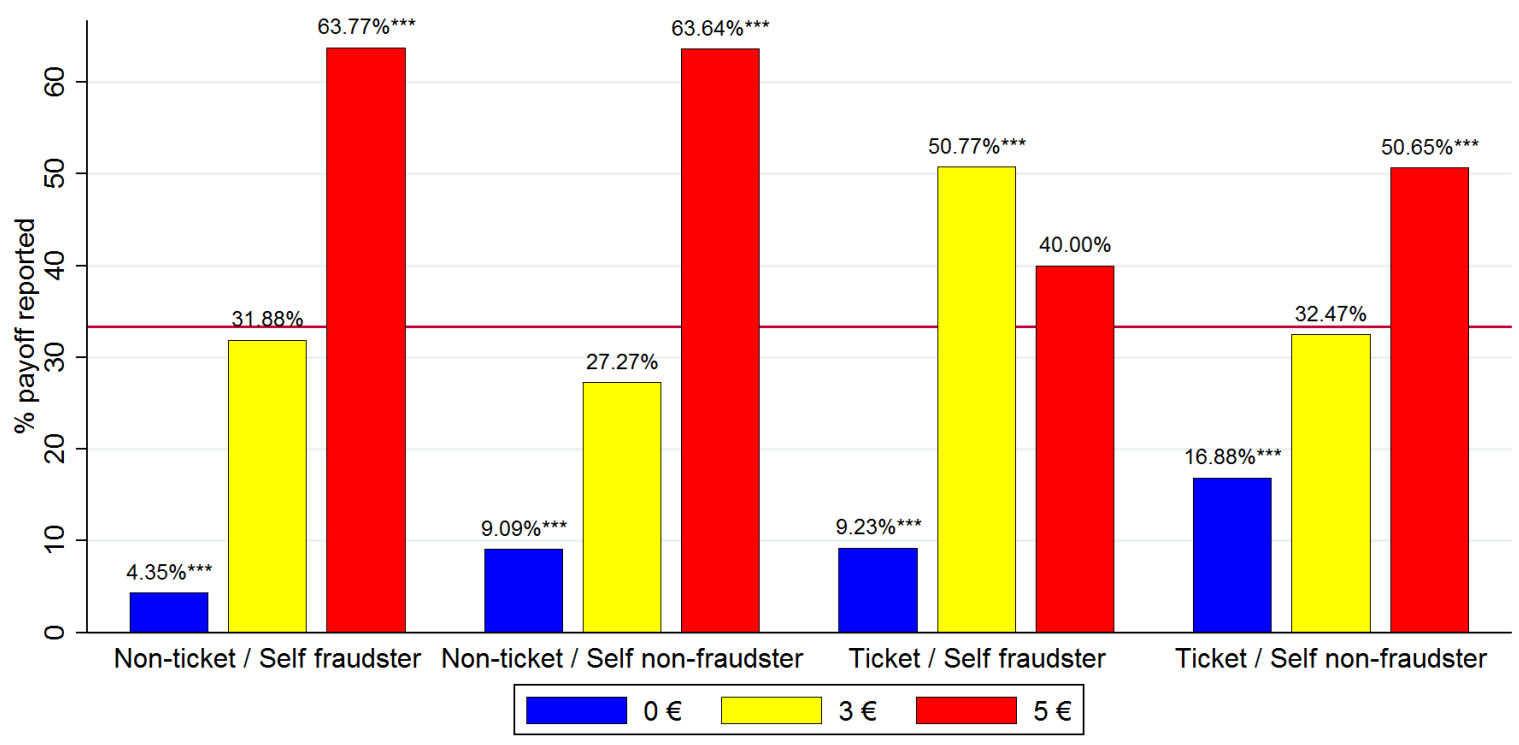

Notes: The horizontal line identifies the uniform distribution and is located at $33.33 \%$. $* p<0.1, * * p<0.05, * * *$ $p<0.01$ (two-sided binomial tests that the observed percentage differs from $33.33 \%$.).

Figure 1. Reported outcomes of the first die roll, by category of subjects

Table 2. Summary of the distribution of reported outcomes of the first die roll, by category of subjects

\begin{tabular}{lccccc}
\hline \hline Reported outcome & $\begin{array}{c}\text { Blue } \\
(€ 0)\end{array}$ & $\begin{array}{c}\text { Yellow } \\
(€ 3)\end{array}$ & $\begin{array}{c}\text { Red } \\
(€ 5)\end{array}$ & $\begin{array}{c}\text { Avg. } \\
\text { payoff }\end{array}$ & $\chi^{2}$ test \\
\hline All subjects & $11.11(<0.001)$ & $36.92(0.205)$ & $51.97(<0.001)$ & 3.71 & $<0.001$ \\
Fine Collection Office & $17.14(0.048)$ & $40.00(0.473)$ & $42.86(0.281)$ & 3.34 & 0.124 \\
Ticket holders & $13.38(<0.001)$ & $40.85(0.062)$ & $45.77(0.002)$ & 3.51 & $<0.001$ \\
Non-ticket holders & $5.88(<0.001)$ & $30.39(0.600)$ & $63.73(<0.001)$ & 4.10 & $<0.001$ \\
\hline Self-reported non-fraudsters & $14.55(<0.001)$ & $30.91(0.615)$ & $54.55(<0.001)$ & 3.66 & $<0.001$ \\
Self-reported fraudsters & $6.72(<0.001)$ & $41.04(0.066)$ & $52.24(<0.001)$ & 3.84 & $<0.001$ \\
$\quad$ or 2 frauds/10 trips & $9.86(<0.001)$ & $42.25(0.130)$ & $47.89(0.012)$ & 3.66 & $<0.001$ \\
3 or more frauds/10 trips & $3.17(<0.001)$ & $39.68(0.287)$ & $57.14(<0.001)$ & 4.05 & $<0.001$ \\
\hline Non-ticket/Self fraudsters & $4.35(<0.001)$ & $31.88(0.899)$ & $63.77(<0.001)$ & 4.15 & $<0.001$ \\
Non-ticket/Self non-fraudsters & $9.09(0.002)$ & $27.27(0.580)$ & $63.64(0.001)$ & 4.00 & $<0.001$ \\
Ticket/Self fraudsters & $9.23(<0.001)$ & $50.77(0.004)$ & $40.00(0.292)$ & 3.52 & $<0.001$ \\
Ticket/Self non-fraudsters & $16.88(0.002)$ & $32.47(1.000)$ & $50.65(0.002)$ & 3.51 & 0.001 \\
\hline
\end{tabular}

Note: The first three columns display the percentage of subjects who report the corresponding outcome, and, in parentheses, the $p$-value of binomial tests that the percentage differs from $33.33 \%$. The last column displays the $p$-value of a $\chi^{2}$ goodness-of-fit test that the observed distribution differs from the uniform distribution.

We state our first result as follows:

Result 1. Irrespective of which field measure of dishonesty we employ, both fraudsters and nonfraudsters over-report the best outcome and under-report the worst one in the die task.

Support for Result 1. Figure 1 shows that both fraudsters and non-fraudsters tend to misreport the first die roll to their advantage. More specifically, the distributions of the outcomes reported by ticket holders, non-ticket holders, self-reported fraudsters, and self-reported non-fraudsters differ significantly from a uniform distribution (see $\chi^{2}$ tests in Table 2). For each category, the percentage of reds (blues) is significantly above (below) the expected value of $33 \%$ (see binomial tests in Table 2). 
The percentage of yellows is weakly significantly above $33 \%$ only for those who hold a ticket and self report as fraudsters. The fact that ticket holders who self report as non-fraudsters report more reds than expected by a uniform distribution is not that surprising since this category also includes a fraction of fare-dodgers who lied about their status. This leads to our second result:

Result 2. a) Fare evasion in the field is associated with more dishonesty in the die task. b) The relationship is stronger when we consider actual rather than self-reported fare evasion.

Support for Result 2. Comparing the distributions of the outcomes reported by fraudsters and nonfraudsters in the field reveals that non-ticket holders lie significantly more than ticket holders (Fisher's exact test, $p=0.013)$, and self-reported fraudsters lie more than self-reported non-fraudsters $(p=0.067)$. In particular, non-ticket holders report the best outcome significantly more often than ticket holders ( $p=0.006)$, and the worst outcome significantly less often (0.085). Self-reported fraudsters report the worst outcome significantly less often than self-reported non-fraudsters $(p=0.056)$, but report a similar proportion of reds as self-reported non-fraudsters $(p=0.797)$. Since self-reported fare evasion also gives an indication of the intensity of dishonesty in public transportations, we explore further the link between self-reports and dishonesty in our task; this leads to our third result:

Result 3. a) Subjects who report cheating more frequently in the field more often misreport the outcome of the die roll, especially when they roll the least profitable outcome. b) Occasional fare dodgers (i.e., ticket holders who confess to cheat sometimes) tend to lie partially rather than fully.

Support for Result 3. The distribution of die outcomes reported by those subjects who tell they never travel without a ticket is significantly different from that of those who confess cheating thrice or more every 10 trips (Fisher's exact test, $p=0.047$ ), but not from those who report cheating only once or twice ( $p=0.274$ ). Subjects who cheat thrice or more report blue in only $3.17 \%$ of the cases, a percentage significantly below the proportion of blue outcomes (14.55\%) reported by subjects who report they never travel without a ticket $(p=0.020)$.

As shown by Figure 1 and the $\chi^{2}$ tests in Table 2, the percentage of reds is significantly above $33 \%$ for each category of subjects, except the self-reported fraudsters holding a ticket. Binomial tests in Table 2 indicate that in this latter category, subjects report significantly more yellows, and not reds, than expected, which gives evidence of less frequent full dishonesty in this group. Pairwise comparisons show that non-ticket holders display a similar lying behavior irrespectively of whether they self report as fraudsters or non-fraudsters (Fisher's exact test, $p=0.564$ ), and they in general lie more than ticket holders. ${ }^{24}$ In contrast, among ticket holders, the distribution of reported outcomes differs significantly between self-reported fraudsters and non-fraudsters $(p=0.077)$. The self-reported

\footnotetext{
${ }^{24}$ Self-reported fraudsters without a ticket report significantly higher outcomes than self-reported fraudsters and non-fraudsters with a ticket ( $p=0.039$ and 0.018 , respectively). Self-reported non-fraudsters without a ticket report higher outcomes than self-reported fraudsters $(p=0.068)$.
} 
fraudsters holding a ticket are probably occasional fare dodgers as they admit to sometimes travel without a ticket but they carry a valid one on the day of the experiment.

Finally, we consider the behavior of the subjects who have just paid a fine.

Result 4. Subjects who have just paid a fine cheat less in the die task than the other subjects who do not hold a validated ticket.

Support for Result 4. The subjects from the FCO can be classified as fare-dodgers. Yet, interestingly, their behavior in the die task follows a uniform distribution (see $\chi^{2}$ test in Table 2). If the percentage of blues differs significantly from the expected value of $33 \%$, this is not the case for the percentages of reds and yellows (see binomial tests in Table 2). The distribution of outcomes reported by these subjects is similar to that of ticket holders (Fisher's exact test, $p=0.841$ ), and it differs from that of non-ticket holders $(p=0.017)$. In particular, the FCO subjects report a similar proportion of reds, blues, and yellows as non-fare-dodgers ( $p>0.1)$, but more blues and less reds than other fare-dodgers ( $p=0.076$ and 0.046 , respectively).

Additional support for Results 2 to 4 . Table 3 displays the percentages of honest, fully and partially dishonest subjects in each category, as estimated non-parametrically. It confirms that there are less fully dishonest and more honest people among ticket holders and subjects who have just paid a fine. The largest (smallest) percentage of fully dishonest (honest) people is among subjects who travelled without a ticket the day of the experiment. Subjects who self-report as fraudsters tend to be mostly partially dishonest, especially those who were able to display a validated ticket (i.e., occasional fraudsters).

Table 3. Percentages of honest and (partially and fully) dishonest subjects (die task)

\begin{tabular}{|c|c|c|c|c|c|c|}
\hline \multirow{2}{*}{$\begin{array}{l}\text { Categories of subjects } \\
\text { in the field }\end{array}$} & \multirow{2}{*}{$\begin{array}{l}\text { Fully } \\
\text { honest }\end{array}$} & \multirow{2}{*}{$\begin{array}{l}\text { Income } \\
\text { maximizers }\end{array}$} & \multicolumn{2}{|c|}{ Partially dishonest } & \multicolumn{2}{|c|}{ Fully dishonest } \\
\hline & & & $\begin{array}{l}\text { Lower- } \\
\text { bound }\end{array}$ & $\begin{array}{l}\text { Upper- } \\
\text { bound }\end{array}$ & $\begin{array}{l}\text { Lower- } \\
\text { bound }\end{array}$ & $\begin{array}{l}\text { Upper- } \\
\text { bound }\end{array}$ \\
\hline All & $33 \%$ & $28 \%$ & $39 \%$ & $67 \%$ & $0 \%$ & $28 \%$ \\
\hline Fine Collection Office & $51 \%$ & $14 \%$ & $34 \%$ & $49 \%$ & $0 \%$ & $14 \%$ \\
\hline Ticket holders & $40 \%$ & $19 \%$ & $41 \%$ & $60 \%$ & $0 \%$ & $19 \%$ \\
\hline Non-ticket holders & $18 \%$ & $46 \%$ & $37 \%$ & $74 \%$ & $9 \%$ & $46 \%$ \\
\hline Self-reported non-fraudsters & $44 \%$ & $32 \%$ & $25 \%$ & $49 \%$ & $7 \%$ & $32 \%$ \\
\hline Self-reported fraudsters & $20 \%$ & $28 \%$ & $51 \%$ & $80 \%$ & $0 \%$ & $28 \%$ \\
\hline 1 or 2 frauds $/ 10$ trips & $30 \%$ & $22 \%$ & $49 \%$ & $70 \%$ & $0 \%$ & $22 \%$ \\
\hline 3 or more frauds $/ 10$ trips & $10 \%$ & $36 \%$ & $55 \%$ & $90 \%$ & $0 \%$ & $36 \%$ \\
\hline Non-ticket/Self fraudsters & $13 \%$ & $46 \%$ & $41 \%$ & $83 \%$ & $4 \%$ & $46 \%$ \\
\hline Non-ticket/Self non-fraudsters & $27 \%$ & $45 \%$ & $27 \%$ & $55 \%$ & $18 \%$ & $45 \%$ \\
\hline Ticket/Self fraudsters & $28 \%$ & $10 \%$ & $62 \%$ & $72 \%$ & $0 \%$ & $10 \%$ \\
\hline Ticket/Self non-fraudsters & $51 \%$ & $26 \%$ & $23 \%$ & $47 \%$ & $3 \%$ & $26 \%$ \\
\hline
\end{tabular}

Additional support for these results comes from a regression analysis in which we control for the socioeconomic and behavioral characteristics of the subjects, and their beliefs and moral norms about honesty, since they may drive the differences in behavior between fare-dodgers and non-fare-dodgers. Indeed, we have found that the sample of fare-dodgers differs from the sample of non-fare-dodgers in 
many respects. ${ }^{25}$ Table 4 reports marginal effects in four multinomial logit regressions with robust standard errors in which the dependent variable is the reported outcome of the first die roll. ${ }^{26}$ In model (1), the independent variables include a dummy for holding a ticket, one for self reporting as a nonfare-dodger, and one for being recruited at the FCO. Model (2) controls for individual characteristics (being a male, age, having a monthly income of less than $€ 1000$, being a student, being employed, having a high school education or lower, living in the city center, living in an upper class neighborhood, number of social networks), attitudes toward risk (risk attitude, loss aversion, and ambiguity aversion, as measured in the first part of the experiment), usage of public transportation (frequency of trips in the previous month, whether the subject travel after $7 \mathrm{pm}$, whether the mean duration of the trips is less than 15 minutes, whether the subject uses exclusively the bus, the tram or both bus and tram). We also control for moral norms (degree of approval on fare evasion, minimum proportion of trips without a ticket to be considered a fare-dodger) and beliefs (belief on the mean fraud rate in transportation, belief on the mean probability of control, whether the subject overestimates the fine, whether he underestimates it). Models (3) and (4) are similar to (1) and (2), respectively, except that we distinguish between the four categories of subjects, taking the non-ticket holders who acknowledge they are fraudsters as the omitted category.

Table 4 confirms that a subject without a ticket is more likely to report the highest die outcome, red, even after controlling for individual characteristics. A self-reported fraudster is more likely to report yellow, and less likely to report blue especially if he does not hold a ticket. Finally, a subject who has just paid a fine reports more honestly than a non-ticket holder. ${ }^{27}$

\subsection{Dishonesty in the field and evasion in the public transportation game}

Our contextualized public transportation game confirms the general relationship between dishonesty in the lab and in the field with some differences with the die task, which we summarize in Result 5.

Result 5. Dishonesty in the public transportation game is associated with dishonesty in the field but, contrary to the die task: a) The association is stronger when we consider self-reported dishonesty rather than holding or not a ticket. b) Among self-reported non-fraudsters, non-ticket holders behave as honestly as ticket holders. c) Subjects who have just paid a fine do not behave more honestly than nonticket holders.

\footnotetext{
${ }^{25}$ Being a male, having an income lower than $€ 1000$, having a high school education or lower, leaving in the center or in a lower class neighborhood all increase the probability to be a fare-dodger (non ticket holders and/or self-report fraudsters). Actual fare-dodgers have also weaker moral norms of honesty (higher approval, more flexibility in the definition of dishonesty, higher beliefs about the fraud rate in public transportation in Lyon) (see Appendix 5).

${ }^{26}$ Ordered logit regressions give qualitatively similar results. They are reported in Appendix 10.

${ }^{27}$ In Appendix 7, we complement this study with an analysis of self-justification in the die task. In other words, we investigate whether subjects use the information on the second die roll as a self-justification to lie by reporting the best outcome of the two die rolls (see Shalvi et al., 2011).
} 
Table 4. Determinants of the $1^{\text {st }}$ roll outcome reported in the die task (multinomial logit regressions)

\begin{tabular}{|c|c|c|c|c|c|c|c|c|c|c|c|c|}
\hline & \multicolumn{6}{|c|}{$(1)$} & \multicolumn{6}{|c|}{$(2)$} \\
\hline & \multicolumn{2}{|c|}{ Blue $(€ 0)$} & \multicolumn{2}{|c|}{ Yellow (€ 3) } & \multicolumn{2}{|c|}{ Red $(€ 5)$} & \multicolumn{2}{|c|}{ Blue $(€ 0)$} & \multicolumn{2}{|c|}{ Yellow $(€ 3)$} & \multicolumn{2}{|c|}{ Red $(€ 5)$} \\
\hline & $\mathrm{dy} / \mathrm{dx}$ & se & $\mathrm{dy} / \mathrm{dx}$ & se & $\mathrm{dy} / \mathrm{dx}$ & se & $\mathrm{dy} / \mathrm{dx}$ & se & $\mathrm{dy} / \mathrm{dx}$ & se & $\mathrm{dy} / \mathrm{dx}$ & se \\
\hline Ticket holder & 0.069 & 0.048 & $0.124 *$ & 0.064 & $-0.193 * * *$ & 0.063 & $0.092 *$ & 0.051 & $0.127 *$ & 0.068 & $-0.218 * * *$ & 0.069 \\
\hline Self-reported non-fraudster & 0.069 & 0.043 & $-0.132 * *$ & 0.063 & 0.063 & 0.065 & $0.146^{* *}$ & 0.059 & $-0.186^{* *}$ & 0.074 & 0.04 & 0.08 \\
\hline Fine Collection Office & $0.139 * *$ & 0.063 & 0.051 & 0.094 & $-0.190 * *$ & 0.096 & $0.127 * *$ & 0.053 & 0.020 & 0.092 & -0.146 & 0.094 \\
\hline Individual characteristics & \multicolumn{2}{|c|}{ No } & \multicolumn{2}{|c|}{ No } & \multicolumn{2}{|l|}{ No } & \multicolumn{2}{|c|}{ Yes } & \multicolumn{2}{|c|}{ Yes } & \multicolumn{2}{|c|}{ Yes } \\
\hline Number of observations & \multicolumn{6}{|c|}{279} & \multicolumn{6}{|c|}{279} \\
\hline Pseudo R2 & \multicolumn{6}{|c|}{0.031} & \multicolumn{6}{|c|}{0.145} \\
\hline Df & \multirow{2}{*}{\multicolumn{6}{|c|}{6}} & \multicolumn{6}{|c|}{58} \\
\hline \multirow[t]{4}{*}{ Prob $>$ F } & & & & & & & \multicolumn{6}{|c|}{0.002} \\
\hline & \multicolumn{6}{|c|}{$\frac{0.02}{3(3)}$} & & & \multirow{2}{*}{\multicolumn{2}{|c|}{$\frac{(4)}{\text { Yellow }(€ 3)}$}} & & \\
\hline & \multicolumn{2}{|c|}{ Blue $(€ 0)$} & \multicolumn{2}{|c|}{ Yellow $(€ 3)$} & \multicolumn{2}{|c|}{ Red $(€ 5)$} & \multicolumn{2}{|c|}{ Blue $(€ 0)$} & & & \multicolumn{2}{|c|}{ Red $(€ 5)$} \\
\hline & $\mathrm{dy} / \mathrm{dx}$ & se & $\mathrm{dy} / \mathrm{dx}$ & se & $\mathrm{dy} / \mathrm{dx}$ & $\mathrm{se}$ & $\mathrm{dy} / \mathrm{dx}$ & se & $\mathrm{dy} / \mathrm{dx}$ & se & $\mathrm{dy} / \mathrm{dx}$ & se \\
\hline $\begin{array}{l}\text { No ticket and self non- } \\
\text { fraudster }\end{array}$ & 0.077 & 0.082 & -0.065 & 0.107 & -0.012 & 0.107 & 0.128 & 0.078 & -0.044 & 0.106 & -0.085 & 0.11 \\
\hline Ticket and self fraudster & 0.079 & 0.07 & $0.161 * *$ & 0.08 & $-0.240 * * *$ & 0.083 & 0.086 & 0.075 & $0.209 * *$ & 0.085 & $-0.295 * * *$ & 0.092 \\
\hline Ticket and self non-fraudster & $0.142 * *$ & 0.065 & -0.009 & 0.081 & -0.133 & 0.082 & $0.234 * * *$ & 0.068 & -0.063 & 0.088 & $-0.171 *$ & 0.09 \\
\hline Fine Collection Office & $0.144 * *$ & 0.072 & 0.069 & 0.098 & $-0.213 * *$ & 0.1 & $0.122 * *$ & 0.059 & 0.055 & 0.094 & $-0.178^{*}$ & 0.097 \\
\hline Individual characteristics & \multicolumn{2}{|c|}{ No } & \multicolumn{2}{|c|}{ No } & $\mathrm{No}$ & & $\mathrm{Ye}$ & & & & $\mathrm{Ye}$ & \\
\hline Number of observations & & & & & & & & & & & & \\
\hline Pseudo R2 & & & & & & & & & & & & \\
\hline Df & & & & & & & & & & & & \\
\hline Prob $>$ F & & & & & & & & & & & & \\
\hline
\end{tabular}

Notes: Multinomial logit regressions with robust standard errors. The Table reports the marginal effects. Independent variables include individual characteristics, attitudes towards risk, usage of public transportation, norms, beliefs. The full regressions are contained in Appendix 6. In models (3) and (4) the omitted category is "No Ticket and self-reported fraudster". * $p<0.1, * * p<0.05, * * * p<0.01$. 
Support for Result 5. Since we have multiple observations per subject (one for each of the seven destinations), we measure dishonesty in this game as the rate of ticket fraud, i.e. the proportion of times out of all destinations a subject is willing to travel without a ticket knowing that no control is exerted (we get one independent observation per subject). Since we find no difference in fraud rates between the Variable and the Constant treatments (Mann-Whitney test, $p=0.167$ ), we pool the data together. Table 5 displays the fraud rate and the percentages of fully honest, partially and fully dishonest subjects in the game, for the whole sample and for each field category. Subjects who always buy a ticket in the game are classified as fully honest; those who never buy one as fully dishonest; and those who do not buy a ticket at least once but not systematically as partially dishonest. Contrary to the die task, observing individual behavior gives us precise values for each category.

Table 5. Fraud rate and percentages of honest and (partially and fully) dishonest subjects (Public transportation game)

\begin{tabular}{lcccc}
\hline \hline & $\begin{array}{c}\text { Mean rate of } \\
\text { ticket fraud }\end{array}$ & $\begin{array}{c}\text { Fully } \\
\text { honest }\end{array}$ & $\begin{array}{c}\text { Partially } \\
\text { dishonest }\end{array}$ & $\begin{array}{c}\text { Fully } \\
\text { dishonest }\end{array}$ \\
\hline All & $0.36(0.37)$ & $38 \%$ & $45 \%$ & $16 \%$ \\
Fine Collection Office & $0.42(0.41)$ & $37 \%$ & $40 \%$ & $23 \%$ \\
\hline Ticket holders & $0.28(0.34)$ & $45 \%$ & $44 \%$ & $11 \%$ \\
Non-ticket holders & $0.45(0.38)$ & $29 \%$ & $49 \%$ & $22 \%$ \\
Self-reported non-fraudsters & $0.18(0.31)$ & $68 \%$ & $25 \%$ & $7 \%$ \\
Self-reported fraudsters & $0.50(0.35)$ & $14 \%$ & $63 \%$ & $22 \%$ \\
$\quad$ l or 2 frauds/10 trips & $0.37(0.32)$ & $20 \%$ & $68 \%$ & $13 \%$ \\
3 or more frauds/10 trips & $0.64(0.32)$ & $8 \%$ & $59 \%$ & $33 \%$ \\
Non-ticket/Self fraudsters & $0.55(0.37)$ & $14 \%$ & $57 \%$ & $29 \%$ \\
Non-ticket/Self non-fraudsters & $0.23(0.33)$ & $61 \%$ & $33 \%$ & $6 \%$ \\
Ticket/Self fraudsters & $0.44(0.32)$ & $14 \%$ & $71 \%$ & $15 \%$ \\
Ticket/Self non-fraudsters & $0.15(0.29)$ & $71 \%$ & $21 \%$ & $8 \%$ \\
\hline
\end{tabular}

Note: Column (1) displays standard deviations in parentheses.

Focusing on significant results, we find that, compared to ticket holders, non-ticket holders in the field display a higher rate of ticket fraud in the game ( 0.45 vs. 0.28 , Mann-Whitney test, $p=0.001)$; they are more fully dishonest (Fisher's exact test, $p=0.033)$ and less fully honest $(p=0.016)$. Similarly, compared to self-reported non-fraudsters, self-reported fraudsters have a higher rate of fraud ( $0.50 \mathrm{vs.}$ $0.18, p<0.001)$; they are more fully $(p=0.001)$ and partially $(p<0.001)$ dishonest, but less fully honest $(p<0.001)$. The fraud rate in the game is significantly larger for subjects who report more frequent frauds in the field ( 3 or more, 0.64$)$ compared to those who report less frequent frauds $(0.37)$ or no fraud at all $\left(p<0.001\right.$ in both cases) ${ }^{28}$

Non-ticket holders who self-report as fraudsters are more dishonest in the game than any other category (fraud rate $=0.55, p<0.001$ for each pairwise comparison), followed by ticket holders who selfreport as fraudsters $(0.44, p<0.001)$. The remaining two categories, i.e. ticket and non-ticket holders who self-report as non-fraudsters, display similar rates of fraud ( 0.15 and 0.23 , respectively, $p=0.211$ );

\footnotetext{
${ }^{28}$ These differences across subject categories hold when analyzing the other periods of this game when we introduce positive probabilities of detection. Results are available upon request.
} 
these rates are smaller than for the other categories $(p<0.001)$. The proportion of fully dishonest subjects is higher amongst non-ticket holders who self-report as fraudsters compared to non-ticket holders who do not admit they are fraudsters, and ticket holders who self-report as fraudsters or as non-fraudsters ( $p=0.009,0.065$ and 0.001 , respectively). Both non-ticket and ticket holders who self-report as fraudsters are more partially dishonest and less fully honest than non-ticket holders who self-report as non-fraudsters, and ticket holders who self-report as non-fraudsters $(p<0.05)$. Interestingly, ticket and non-ticket holders who self-report as non-fraudsters display similar proportions of fully honest, partially and fully dishonest subjects $(p>0.1)$.

Finally, subjects from the FCO have a higher fraud rate (0.42) than self-reported non-fraudsters $(p<0.001)$, irrespectively of whether the latter hold a validated ticket $(p<0.001)$ or not $(p=0.038)$; they are also more fully $(p=0.025)$ and partially dishonest $(p=0.001)$. Their fraud rate is smaller $(p=0.082)$ and they are less partially dishonest $(p=0.004)$ and more fully honest $(p=0.088)$ than non-ticket holders who admit they are fraudsters.

To test the robustness of these results, we estimate four logit regressions in which the dependent variable is the decision to not buy a ticket for a given destination. Since we have multiple observations for each subject, we cluster the standard errors at the individual level. ${ }^{29}$ The independent variables are the same as in Table 4, except that we include a dummy for the Variable treatment and a control variable for the number of stops needed to reach the destination (from 1 to 7 ). Table 6 reports marginal effects and standard errors.

Table 6. Determinants of fraud in the public transportation game (Logit regressions)

\begin{tabular}{|c|c|c|c|c|}
\hline & \multicolumn{2}{|c|}{ (1) } & \multicolumn{2}{|c|}{ (2) } \\
\hline & $\mathrm{dy} / \mathrm{dx}$ & se & $\mathrm{dy} / \mathrm{dx}$ & se \\
\hline Ticket holder & $-0.093 * *$ & 0.042 & -0.063 & 0.043 \\
\hline Self-reported non fraudster & $-0.292 * * *$ & 0.040 & $-0.155 * * *$ & 0.050 \\
\hline Fine Collection Office & -0.096 & 0.069 & $<0.001$ & 0.064 \\
\hline Controls for individual characteristics & \multicolumn{2}{|c|}{ No } & \multicolumn{2}{|c|}{ Yes } \\
\hline Controls for the treatment variables & \multicolumn{2}{|c|}{ Yes } & \multicolumn{2}{|c|}{ Yes } \\
\hline Number of observations & \multicolumn{2}{|c|}{1953} & \multicolumn{2}{|c|}{1953} \\
\hline Pseudo R2 & \multicolumn{2}{|c|}{0.113} & \multicolumn{2}{|c|}{0.220} \\
\hline Df & \multicolumn{2}{|c|}{5} & \multicolumn{2}{|c|}{31} \\
\hline \multirow[t]{3}{*}{ Prob $>F$} & \multicolumn{2}{|c|}{$<0.001$} & \multicolumn{2}{|c|}{$<0.001$} \\
\hline & \multicolumn{2}{|c|}{ (3) } & \multicolumn{2}{|c|}{ (4) } \\
\hline & $\mathrm{dy} / \mathrm{dx}$ & se & $\mathrm{dy} / \mathrm{dx}$ & se \\
\hline No Ticket and self-reported non-fraudster & $-0.286^{* * *}$ & 0.072 & $-0.173 * * *$ & 0.066 \\
\hline Ticket and self-reported fraudster & $-0.090 *$ & 0.048 & -0.073 & 0.053 \\
\hline Ticket and self-reported non-fraudster & $-0.386 * * *$ & 0.054 & $-0.214 * * *$ & 0.066 \\
\hline Fine Collection Office & -0.094 & 0.071 & -0.004 & 0.065 \\
\hline Controls for individual characteristics & \multicolumn{2}{|c|}{ No } & \multicolumn{2}{|c|}{ Yes } \\
\hline Controls for the treatment variables & \multicolumn{2}{|c|}{ Yes } & \multicolumn{2}{|c|}{ Yes } \\
\hline Number of observations & \multicolumn{2}{|c|}{1953} & \multicolumn{2}{|c|}{1953} \\
\hline Pseudo R2 & \multicolumn{2}{|c|}{0.113} & \multicolumn{2}{|c|}{0.220} \\
\hline Df & \multicolumn{2}{|c|}{6} & \multicolumn{2}{|c|}{32} \\
\hline Prob $>$ F & \multicolumn{2}{|c|}{$<0.001$} & \multicolumn{2}{|c|}{$<0.001$} \\
\hline
\end{tabular}

${ }^{29}$ Random-effects logit models give qualitatively similar results (available upon request). 
Notes: Logit regressions with clustered standard errors. The Table reports the marginal effects. Independent variables include individual characteristics, attitudes towards risk, usage of public transportation, norms, beliefs. The full regressions are contained in Appendix 8. In models (3) and (4) the omitted category is "No ticket and self-reported fraudster". * $p<0.1, * * p<0.05, * * * p<0.01$.

Table 6 reveals that self-reported fraud in the field is a better predictor of dishonesty in this game than not holding a ticket. Compared to self-reported fraudsters, the non-ticket holders who self-report as non-fraudsters behave as honestly as the ticket holders who self-report as non-fraudsters. The coefficients of the two variables relative to self-reported non-fraudsters (holding or not a ticket) differ neither in model (3) nor in model (4) ( $p=0.233$ and $p=0.562$, respectively). In contrast, the effect of holding $v s$. not holding a ticket reduces the probability of fraud in model (1), but not in model (2) where we control for individual characteristics. These results differ partly from the die task. Our interpretation is that the two games do not differ only in terms of context but also in terms of possible feeling of scrutiny. Indeed, even if anonymity is preserved, individual behavior can be, ex post, verified by the experimenter. This is a crucial difference with the die task where information about the true outcome of the die rolls remains private. This difference might explain that the subjects who do not hold a ticket but inconsistently self-report as non-fraudsters in the field lie a lot in the die task but not in the public transportation game. Image concerns may explain that these non-ticket holders do not acknowledge they are fraudsters and that they cheat less when they anticipate that we will be able to check behavior ex post.

\subsection{Comparison between dishonesty in the die task and in the public transportation game}

As mentioned earlier, the primary objective of our study is not to compare the cheating behavior in the die task and public transportation game, but to test whether the correlation between behavior in the field and in the lab holds in these two different environments. The two laboratory tasks in fact differ in many respects - most notably in the way dishonesty is measured (at group level in the die task and at individual level in the public transportation game) and whether context is used. Therefore, a direct comparison would be too noisy. That said, it is still useful to provide some tests on how behavior in the public transportation game relates to the one in the die task. In the remaining of this section, we will attempt to statistically quantify the extent to which the lab behavior of our different categories of subjects differs between the public transportation game and the die task. ${ }^{30}$

To make the two measures of lab dishonesty comparable, we construct a standardized measure of dishonesty which is based on the payoffs consequences of subjects' decisions. ${ }^{31} \mathrm{We}$ first compute the

\footnotetext{
${ }^{30}$ In Appendix 9, we report additional analysis on the correlation between behavior in the public transportation game and in the die task.

${ }^{31}$ This analysis builds upon some of the original techniques used in a recent meta study by Abeler et al. (2016).
} 
expected payoff from fully honest behavior $(\bar{\pi})$, the highest possible payoff ( $\pi^{\max }$ ), and the lowest possible payoff $\left(\pi^{\min }\right){ }^{32}$ We then calculate the standardized measure of dishonesty $\left(d^{S}\right)$ as follows:

$$
d^{S}= \begin{cases}\frac{\pi-\bar{\pi}}{\bar{\pi}-\pi^{\min }}, & \pi<\bar{\pi} \\ \frac{\pi-\bar{\pi}}{\pi^{\max }-\bar{\pi}}, & \pi \geq \bar{\pi}\end{cases}
$$

where $\pi$ is the realized payoff.

This standardized measure can take values from -1 (when $\pi=\pi^{\min }<\bar{\pi}$ ) to +1 (when $\pi=$ $\pi^{\max }$ ), and is equal to 0 when the realized payoff coincides with the expected payoff from fully honest behavior (i.e. $\pi=\bar{\pi}$ ). The average standardized measure, computed for a group of subjects, measures how much more money they make compared to a benchmark group of fully honest subjects. In particular, the more $d^{S}$ is greater than zero, the more dishonest their behavior is.

We can now compare this standardized measure of dishonesty across our categories of subjects and between our two laboratory tasks by means of a regression analysis. We employ OLS regressions with standard errors clustered on each subject to control for the dependence of the decisions between the die task and the public transportation game. Explanatory variables include all those used in previous regressions, a dummy variable for the task (die task $=0$; public transportation game $=1$ ), and interactions between this dummy and the field measures of dishonesty. Table 7 reports the results of these regressions. Figure 2 displays the average marginal effects for our different categories of subjects distinguishing between behavior in the die task and in the public transportation game. More specifically, Panel A reports the average marginal effects for ticket holders, non-ticket holders, self-reported fraudsters, and self-reported non-fraudsters, while Panel B displays the average marginal effects for self-reported fraudsters who do not hold a validated ticket, self-reported fraudsters who hold a validated ticket, self-reported non-fraudsters who do not hold a validated ticket, and self-reported non-fraudsters who hold a validated ticket.

The results support our previous findings. In particular, while not holding a ticket is a good predictor of lab behavior, especially in the die task but also in the public transportation game, selfreported fraud in the field is a good predictor of lab dishonesty only in the public transportation game. ${ }^{33}$

\footnotetext{
${ }^{32}$ In the die task, fully honest behavior is equivalent to truthfully reporting the outcome of the die. Hence, the expected payoff from fully honest behavior is equal to $\frac{0+3+5}{3}=€ 2.6 \overline{7}$. The highest (lowest) possible payoff is equal to $€ 5(€ 0)$. In the public transportation game, since subjects make repeated decisions, we consider average payoffs. Fully honest behavior means always buying the ticket. The expected payoff from this behavior is equal to $8-1.7=€ 6.3$, where 8 is the average benefit from using the fictional bus and 1.7 the cost of the ticket. The highest (lowest) possible payoff is equal to $€ 8$ ( 66.3 ).

${ }^{33}$ In previous regressions (see Table 4), we find that, in the die task, self-reported fradusters tend to overreport the middle outcome compared to self-reported non-fraudsters, suggesting that they are slightly more dishonest than self-reported non-fraudsters. We do not find this in Table 7.
} 
In addition, we confirm that, in the public transportation game, non-ticket holders who self-report as non-fraudsters behave as honestly as the ticket holders who self-report as non-fraudsters. All this supports our interpretation that scrutiny matters for image-concerned subjects (i.e. those who did not hold a valid ticket and are uncomfortable to admit they are fraudsters).

Table 7. Regressions on the standardized measure of dishonesty

\begin{tabular}{|c|c|c|c|c|}
\hline & \multicolumn{2}{|l|}{$(1)$} & \multicolumn{2}{|l|}{ (2) } \\
\hline & $\mathrm{dy} / \mathrm{dx}$ & se & $\mathrm{dy} / \mathrm{dx}$ & se \\
\hline Ticket holder & $-0.235 * * *$ & 0.081 & $-0.244 * * *$ & 0.088 \\
\hline Self-reported non fraudster & -0.019 & 0.085 & 0.005 & 0.091 \\
\hline Public transportation game & -0.084 & 0.070 & -0.084 & 0.072 \\
\hline Fine Collection Office & $-0.314 * *$ & 0.136 & $-0.249 *$ & 0.129 \\
\hline Ticket holder $\times$ Public transportation game & 0.139 & 0.094 & 0.139 & 0.097 \\
\hline Self-reported non fraudster $\times$ Public transportation game & $-0.280 * * *$ & 0.098 & $-0.280 * * *$ & 0.100 \\
\hline Fine Collection Office $\times$ Public transportation game & 0.191 & 0.150 & 0.191 & 0.154 \\
\hline Controls for individual characteristics & \multicolumn{2}{|l|}{ No } & \multicolumn{2}{|l|}{ Yes } \\
\hline Number of observations & \multicolumn{2}{|l|}{558} & \multicolumn{2}{|l|}{558} \\
\hline Pseudo R2 & \multicolumn{2}{|c|}{0.079} & \multicolumn{2}{|l|}{0.144} \\
\hline Df & \multicolumn{2}{|c|}{7} & \multicolumn{2}{|l|}{33} \\
\hline Prob $>$ F & \multicolumn{2}{|c|}{$<0.001$} & \multicolumn{2}{|c|}{$<0.001$} \\
\hline & \multicolumn{2}{|c|}{ (3) } & \multicolumn{2}{|l|}{ (4) } \\
\hline & $\mathrm{dy} / \mathrm{dx}$ & se & $\mathrm{dy} / \mathrm{dx}$ & se \\
\hline No Ticket and self-reported non-fraudster & -0.055 & 0.127 & -0.061 & 0.135 \\
\hline Ticket and self-reported fraudster & $-0.260 * * *$ & 0.099 & $-0.291 * * *$ & 0.104 \\
\hline Ticket and self-reported non-fraudster & $-0.256 * *$ & 0.106 & $-0.239 * *$ & 0.114 \\
\hline Fine Collection Office & $-0.325 * *$ & 0.138 & $-0.269 * *$ & 0.130 \\
\hline Public transportation game & -0.089 & 0.075 & -0.089 & 0.077 \\
\hline No Ticket and self-reported non-fraudster $\times$ Public transportation game & $-0.266^{*}$ & 0.152 & $-0.266 *$ & 0.156 \\
\hline Ticket and self-reported fraudster $\times$ Public transportation game & 0.148 & 0.113 & 0.148 & 0.116 \\
\hline Ticket and self-reported non-fraudster $\times$ Public transportation game & -0.141 & 0.121 & -0.141 & 0.124 \\
\hline Fine Collection Office $\times$ Public transportation game & 0.195 & 0.152 & 0.195 & 0.156 \\
\hline Controls for individual characteristics & \multicolumn{2}{|l|}{ No } & \multicolumn{2}{|l|}{ Yes } \\
\hline Number of observations & \multicolumn{2}{|l|}{558} & \multicolumn{2}{|l|}{558} \\
\hline Pseudo R2 & \multicolumn{2}{|l|}{0.08} & \multicolumn{2}{|l|}{0.146} \\
\hline Df & \multicolumn{2}{|c|}{9} & \multicolumn{2}{|c|}{35} \\
\hline Prob $>$ F & \multicolumn{2}{|c|}{$<0.001$} & \multicolumn{2}{|c|}{$<0.001$} \\
\hline
\end{tabular}

Notes: OLS regressions with clustered standard errors. Independent variables include individual characteristics, attitudes towards risk, usage of public transportation, norms, beliefs. The full regressions are available from the authors upon request. In models (3) and (4) the omitted category is "No ticket and self-reported fraudster". * $p<$ $0.1, * * \mathrm{p}<0.05, * * * \mathrm{p}<0.01$

Panel A
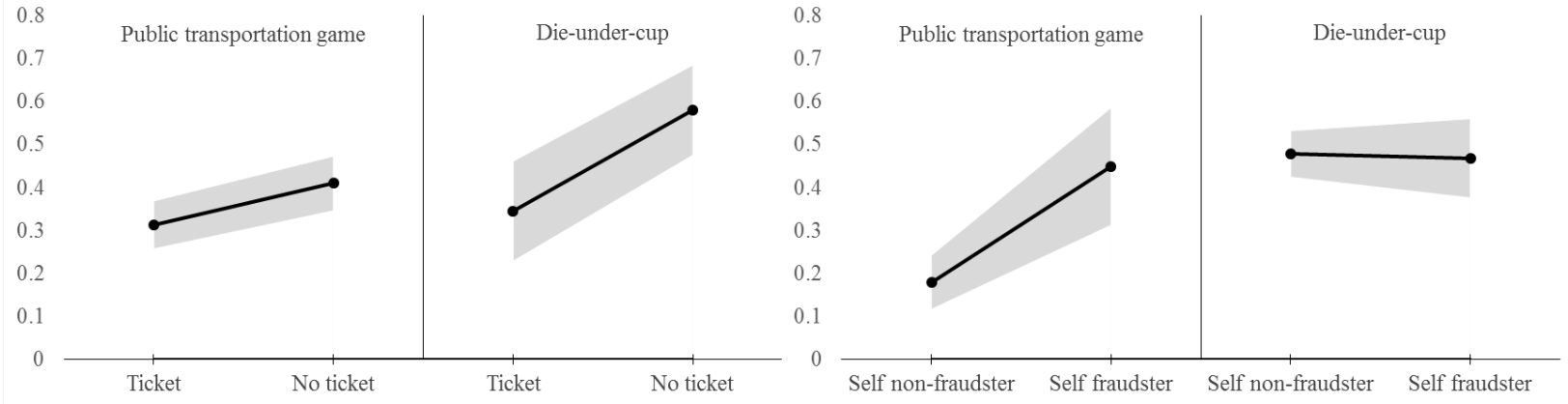


\section{Panel B}

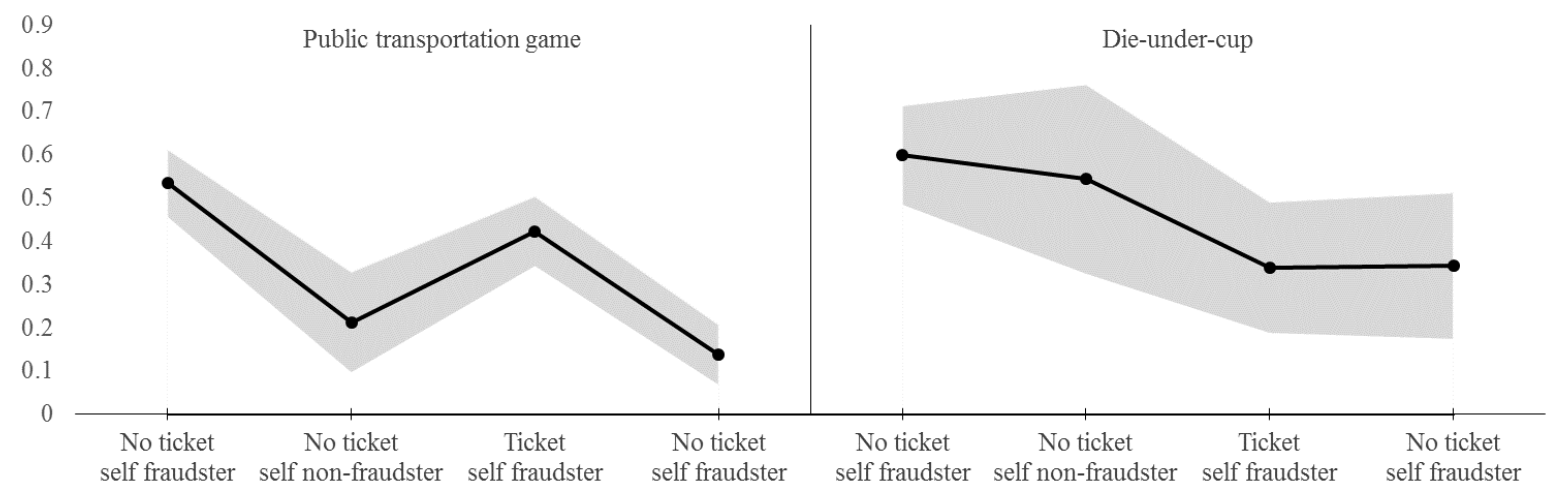

Notes: Average marginal effects. The shaded area identifies the $95 \%$ confidence intervals.

Figure 2. Average marginal effects of the standardized measure of dishonesty

\section{A COMPLEMENTARY STUDY WITH STUDENTS}

So far, we have provided evidence of the external validity of laboratory tasks performed by a pool of non-student subjects. Most lab experiments are, however, conducted with students. It is thus legitimate to ask whether our results hold with undergraduate students in a typical lab environment. To bridge our artefactual field experiment with a conventional lab experiment, we invited 192 University students to perform the same die-under-cup task in the context of a typical lab experiment. ${ }^{34}$ The procedures were similar to the field experiment, except for a few changes. First, subjects were recruited on-line using the H-root software (Bock et al., 2014). Second, the experiment was conducted at GATE-LAB, Lyon. Last, we collected a different measure of field dishonesty, which consists in overpaying subjects at the end of the session and see whether they report or not the "mistake" in the payment. This manipulation has been used by Gneezy et al. (2013) and Potters and Stoop (2016) in the lab and by Azar et al. (2013) in the field. ${ }^{35}$ Subjects were paid their earnings and 5 extra Euros at their computer station using envelopes. The earnings of the experiment (excluding the overpayment) remained displayed on the computer screen of each subject during the payment procedures. Subjects were also reminded to check the money they received before leaving the laboratory. Those who reported the mistake in the payment were classified as honest, and the others as dishonest. ${ }^{36}$

\footnotetext{
${ }^{34}$ The task was added at the beginning of another unrelated experiment. As in our artefactual field experiment, we collected data on the subjects' risk preferences before playing the die-under-cup task. Students are recruited from the local engineering and business schools.

${ }^{35}$ In fact, 12 of our 192 subjects were not treated (we did not pay them the extra 5 euros). Indeed, in the first two sessions (out of 13) we treated only half of the subjects to make sure that everything worked smoothly.

${ }^{36} \mathrm{We}$ acknowledge that this is a crude measure of dishonesty. First, lazy or naïve subjects could leave the lab without checking their money. Second, we measure a mild form of dishonesty that requires passive cheating (in contrast to the die task where cheating requires active misreporting). All this would, however, only make more difficult to detect a correlation between field and lab dishonesty. Hence, if we find one, as we do, this result is
} 
Result 6 summarizes our findings:

Result 6. A conventional lab experiment with undergraduate students replicates a) the diversity of cheating behavior in the die task observed with passengers of public transportation, and $b$ ) the relation between the lab task and a field measure of dishonesty.

Support for Result 6. The distribution of the die outcomes reported by the students is not uniform $\left(\chi^{2}\right.$ test, $p<0.001$ ): indeed, the percentages of reds, yellows and blues are $65.10 \%, 26.56 \%$ and $8.33 \%$, respectively, showing evidence of widespread cheating. This distribution is also statistically different than the one observed in our field experiment (Fisher's exact test, $p=0.018$ ). In particular, students report more reds $(p=0.06)$ and less yellows $(p=0.021)$ than people recruited in the field (but not blues, $p=0.352$ ).

Next, we test whether cheating in the die task is associated with our measure of dishonesty in the field. Figure 3 displays the distributions of the die outcomes reported by the students who do not return the extra earnings, on the left, and by those who return them, on the right. Of the 192 subjects who took part in the experiment, 12 (6.25\%) were not treated, 147 (76.56\%) did not return the extra earnings, and $33(17.19 \%)$ returned them. The distribution reported by those who do not return the overpayment differs significantly from a uniform distribution $\left(\chi^{2}\right.$ test, $\left.p<0.001\right)$. These students report more reds, less yellows, and less blues than the expected values of 33\% (Fisher's exact test, $p<0.001$ for reds and blues, and $p=0.003$ for yellows). Turning to those who return the overpayment, the distribution of their reported outcomes also differs from the uniform distribution $\left(\chi^{2}\right.$ test, $\left.p=0.023\right)$. In particular, they report less blues and more yellows than the expected values of 33\% (Fisher's exact test, $p=0.009$ for blues, and $p=0.094$ for yellows; for reds, the test gives insignificant results, $p=0.464$ ). However, their distribution is statistically different than the one reported by those who do not return the extra earnings $(p=0.002)$. In particular, the students who return the overpayment report significantly less reds $(39.39 \%$ vs. $70.75 \%)$ and more yellows (48.48\% vs. $21.77 \%)$ than those students who did not return the extra money ( $\mathrm{p}=0.001$ and 0.004 respectively). They also report more blues $(12.12 \%$ vs. $7.48 \%)$, but the difference does not achieve statistical significance $(\mathrm{p}=0.482)$.

even stronger. Moreover, passive cheating is relatively similar to fare-dodging where individuals do not buy a ticket if they want to cheat, and the monetary stake of the fraud is in the same range of values. 


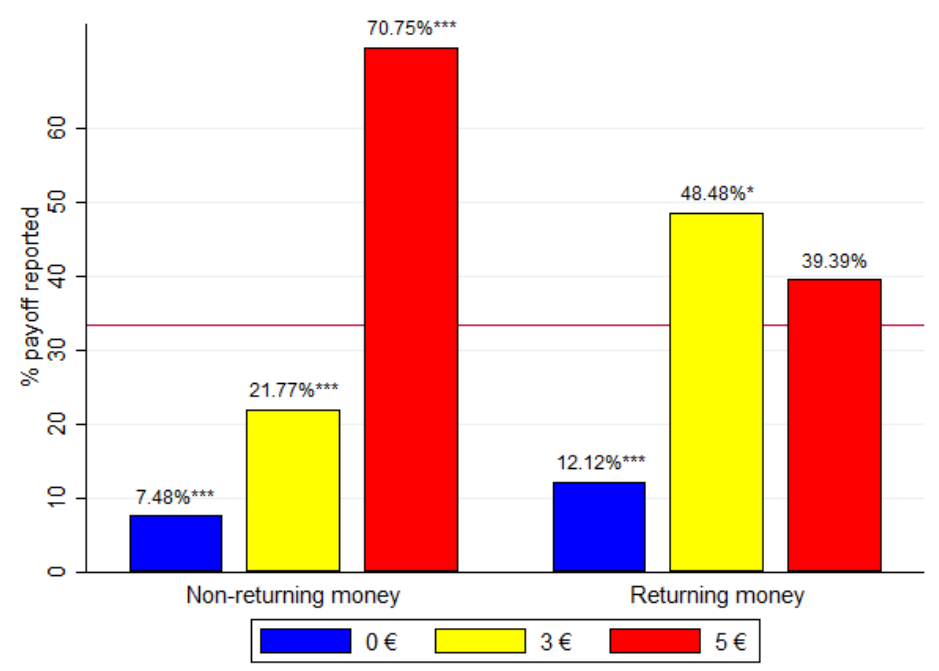

Figure 3. Reported outcomes of the first die roll and return of money by students

Notes: The horizontal line identifies the uniform distribution and is located at $33.33 \%{ }^{*} p<0.1, * * p<0.05, * * *$ $p<0.01$ (two-sided binomial tests that the observed percentage differs from $33.33 \%$.).

These results are similar to those obtained with the passengers of public transportation and they confirm that simple laboratory tasks measuring dishonesty are able to capture important aspects of moral flexibility in the field.

\section{DISCUSSION AND CONCLUSION}

The data from our artefactual field experiment with a diversified sample of passengers of a public transport service confirm that, when given the opportunity to increase their earnings by behaving dishonestly in laboratory tasks without any risk of detection, some individuals follow the moral principle of honesty, while others act partially dishonestly and others cheat fully to maximize their earnings. This diversity of moral behavior is observed regardless of whether the laboratory task is abstract (die task) or contextualized (public transportation game). It confirms previous studies (Fischbacher and Föllmi-Heusi, 2013; Gibson et al., 2013). The novelty of our study is to provide evidence that this diversity of behavior in the laboratory tasks replicates the diversity of the degrees of moral firmness of the same individuals in their day-to-day life, for incentives to fraud of comparable monetary value. Indeed, at the aggregate level, the group of passengers who cannot present a validated ticket and who self-report as frequent fare-dodgers tends to act fully dishonestly in the die task. In contrast, the group of passengers who hold a validated ticket and self-report as never evading fares reports honestly the die outcomes more frequently than the other groups. At the individual level, we show that fare-dodgers in real life behave also less honestly in the transportation game, while people who self-report as non fare-dodgers are less likely to evade. These major findings indicate that simple lab experiments can deliver externally valid results on rule violation by ordinary populations. They suggest that norm violators have lower intrinsic ethical values than others (since when they cheat they are more likely to do it in our different contexts). However, we are cautious not to conclude that context 
does not matter in general. In particular, in our study we consider cheating for a given level of incentives that is relatively similar in the field and in the lab. An interesting extension would be to measure the robustness of our findings to a manipulation of the level of incentives. The meta-analysis of Abeler et al. (2016) on studies based on reports of a random draw (dice or coins) concludes that reporting behavior is not affected by the manipulation of the incentive to lie. On the other hand, Kajackaite and Gneezy (2015) show that the insensitivity of lying to incentives results from the subjects' concern about being exposed as cheaters. In contrast, the impact of variations of incentives on cheating behavior in real settings is not well understood yet. Exploring the influence of parallel manipulations of the incentives to lie in the lab and in the field is beyond the scope of this study but would be extremely useful. It would be also interesting to test whether the correlation that we observe still holds when individuals have benefited from positive income shocks in their life.

We chose a public transportation environment because of its economic relevance (i.e., faredodging concerns ordinary people and entails dramatic revenue losses for transport companies) and of the possibility to obtain a relatively simple and reliable measure of dishonesty in the field. One can naturally wonder whether our results could generalize to other environments. This is why we conducted a complementary experiment with students. In contrast to studies on cooperation in social dilemma conducted with both fishermen and students in the lab and in the field (Stoop et al., 2012), but consistently with most studies on other-regarding preferences, preferences for efficiency, peer effects or market behavior (see the survey of Frechette, 2015, and Herbst and Mas, 2015), we find that the students' dishonest behavior largely replicates that of ordinary people. Indeed, our second study confirms the within-subject correlation between dishonesty in the laboratory and in a real setting. Future studies could test to which extent our findings might extend to other domains of dishonesty.

In terms of methodological implications, by showing that cheating in the lab and cheating in the field -as measured by objective measures of dishonesty and self-reports- are correlated for ordinary people as well as for students, our findings provide support to the external validity of lab experiments in a domain that is not easily observable in the field because of its secretive nature. There is, however, an important caveat. As image-concerned people are reluctant to admit they are cheaters, in the lab the same persons may inflate their degree of honesty if they feel scrutinized. This is similar to what may happen in experiments studying pro-social behavior (e.g., List, 2006, Alpizar et al., 2008, Benz and Meier, 2008). Our results emphasize the importance of preserving the confidentiality of decisions, especially when studying honesty. Indeed, we found that self-reports have a higher predictive value in the transportation game than in the die task. This may be driven by the fact that in the former the experimenter is able, ex post, to detect dishonesty at the individual level. Subjects who self-reported as never cheating although they were not able to show a valid ticket behaved like self-reported faredodgers in the die task (where there is no scrutiny), but like ticket holders in the transportation game. Using tasks where decisions can be verified may underestimate the dishonesty of image-concerned 
individuals who conceal their preferences when dishonesty can be identified even with no risk of sanction.

We have also shown that individuals who have just been fined in a real setting behave more honestly in the die task than other fare-dodgers, which goes against the notion that people try to recover their loss. This could be driven by self-selection (those who come to the FCO are more "honest" than other fare-dodgers who never pay their fines), by the reactivation of the moral norm of honesty, or by the fact that having just paid a fine emphasized the cost of cheating. Our design and the small size of the sample do not allow us to disentangle precisely between these various explanations. Moreover, we ignore the reason of their sanction and the level of their fine. However, the fact that these subjects cheat as often as other fare-dodgers in the transportation game does not support the first explanation. It also suggests that the reactivation of the moral norm, if it exists, does not resist the priming of the identity of fare-dodgers by the introduction of context in the transportation game. While the role of identity has already been shown (Cohn et al., 2014, 2015), an extension could usefully investigate the dynamics of self-image and identity in the domain of dishonesty.

If the lab results can identify reliable both directional and quantitative effects regarding rule violation in the field, this is very useful to inform on the underlying mechanisms of dishonesty but this is certainly even more important to predict how people react to policy interventions. As developed by Camerer (2005), the generalizability of lab results is crucial if one adopts a policy view. The parallelism that we have identified in this study should increase our confidence in the use of laboratory methods to investigate which manipulation of incentives, sanctions, and moral appeals in the lab is better able at deterring dishonest behavior in the field.

\section{References}

Abeler, J., Becker, A., Falk, A. (2014). Representative evidence on lying costs. Journal of Public Economics 113: 96-104.

Abeler, J., Nosenzo, D., Raymond, D. (2016). Preferences for truth-telling - a meta-study. Mimeo.

Alm, J., Bloomquist, K.M., McKee, M. (2015). On the external validity of laboratory tax compliance experiments. Economic Inquiry 53(2): 1170-1186.

Alpizar, F., Carlsson, F., Johansson-Stenman, O. (2008). Anonymity, reciprocity, and conformity: Evidence from voluntary contributions to a national park in Costa Rica. Journal of Public Economics 92: 1047-1060.

Armantier, O., Boly, A. (2013). Comparing corruption in the laboratory and in the field in Burkina Faso and in Canada. The Economic Journal 123: 1168-1187.

Azar, O.H., Shira, Y., Bar-Eli, M. (2013). Do customers return excessive change in a restaurant?, Journal of Economic Behavior \& Organization 93: 219-226.

Barfort, S., Harmon, N., Hjorth, F., Olsen A.L. (2015). Dishonesty and selection into public service in Denmark: Who runs the world's lest corrupt public sector? Working paper, University of Copenhagen. 
Becker, G. S. (1968). Crime and punishment: An economic approach. Journal of Political Economy 76: 169-217.

Benz, M., Meier, S. (2008). Do people behave in experiments as in the field? Evidence from donations. Experimental Economics 11(3): 268-281.

Bock, O., Baetge, I., Nicklisch, A. (2014). Hroot: Hamburg Registration and Organization Online Tool. European Economic Review 71: 117-120.

Bonfanti, G., Wagenknecht, T. (2010). Human factors reduce aggression and fare evasion. Public Transport International 59: 28-32.

Boyd, C., Martini, C., Rickard, J., Russell, A. (1989). Fare Evasion and Non-Compliance. Journal of Transport Economics and Policy, 23(2), 189-197.

Brandts, J., Charness, G. (2003). Truth or consequence: an experiment. Management Science: 116-130.

Bucciol, A., Landini, F., Piovesan, M. (2013). Unethical behavior in the field: Demographic characteristics and beliefs of the cheater. Journal of Economic Behavior \& Organization 93: 248257.

Bucciol, A., Piovesan, M. (2011). Luck or cheating? A field experiment on honesty with children. Journal of Economic Psychology 32(1): 73-78.

Buehler, S., Halbheer, D., Lechner, M. (2014). Payment evasion. Working paper, University of St. Gallen.

Burton, R.V. (1963). Generality of honesty reconsidered. Psychological Review 70(6): 481-499.

Camerer, C.F. (2015). The Promise and Success of Lab-Field Generalizability in Experimental Economics: A Critical Reply to Levitt and List. In Frechette, G.R., and Schotter, A. (Eds.). Handbook of Experimental Economic Methodology, Oxford: Oxford University Press, 249-295.

Cardenas, J. C., Carpenter, J. (2013). Risk attitudes and economic well-being in Latin America. Journal of Development Economics 103: 52-61.

Charness, G., Dufwenberg, M. (2006). Promises and partnership. Econometrica 74(6), 1579-1601.

Charness, G., Masclet, D., Villeval M.C. (2014). The dark side of competition for status. Management Science 60 (1) : 38-55.

Charness, G., Fehr, E. (2015). From the lab to the real world. Science 350(6260): 512-513.

Choo, L., Fonseca, M.A., Myles, G.D. (2014). Do Students Behave Like Real Taxpayers? Experimental Evidence on Taxpayer Compliance From the Lab and From the Field. Working Paper, University of Exeter.

Cohn, A., Fehr, E., Maréchal, M.A. (2014). Business Culture and Dishonesty in the Banking Industry. Nature 516: 86-89.

Cohn, A., Maréchal, M.A. (2015). Laboratory Measure of Cheating Predict Misbehavior at School. Working Paper 205, University of Zurich.

Cohn, A., Maréchal, M.A., Noll, T. (2016). Bad Boys: How Criminal Identity Salience Affects Rule Violation. Forthcoming in Review of Economic Studies.

Conrads, J., Irlenbusch, B., Rilke, R. M., Walkowitz, G. (2013). Lying and team incentives. Journal of Economic Psychology 34: 1-7.

Conrads, J., Irlenbusch, B., Rilke, R. M., Schielke, A., Walkowitz, G. (2014). Honesty in tournaments. Economics Letters 123 : 90-93.

Cooper, D. J., J. H. Kagel, W. Lo and Q. L. Gu (1999). Gaming Against Managers in Incentive Systems: Experimental Results with Chinese Students and Chinese Managers. American Economic Review 89(4): 781-804.

Cour des Comptes (2016). La lutte contre la fraude dans les transports urbains en Île-de-France : un échec collectif, in Rapport public annuel 2016. 537-577.

Crawford, V., Sobel, J. (1982). Strategic information transmission. Econometrica 50(6) : 1431-1451.

Dai, Z., Hogarth, R.M., Villeval, M.C. (2015). Ambiguity on Audits and Cooperation in a Public Goods Game. European Economic Review 74: 146-162. 
Dai, Z., Galeotti, F., Villeval, M.C. (2016). The Efficiency of Crackdowns: A Lab-in-the-Field Experiment in Public Transportations. Mimeo, GATE, Lyon.

Dohmen, T., Falk, A., Huffman, D., Sunde, U., Schupp, J., Wagner, G.G. (2011). Individual Risk Attitudes: Measurement, Determinants, And Behavioral Consequences. Journal of the European Economic Association 9(3), 522-550.

Donohue, P. (2010). Millions of fare-beaters take MTA for an $\$ 8$ million bus ride. Daily News, 17 March. http://www.nydailynews.com/news/crime/millions-fare-beaters-mta-8-million-bus-ridearticle-1.175537 (accessed 30 December 2015).

Eckel, C.C., Grossman, P.J. (2008). Forecasting risk attitudes: an experimental study using actual and forecast gamble choices. Journal of Economic Behavior \& Organization 68(1)/ 1-17.

Eckel, C.C., Grossman, P.J., Johnson, C.A., de Oliveira, A.C., Rojas, C., Wilson, R.K. (2012). School environment and risk preferences: Experimental evidence. Journal of Risk and Uncertainty 45(3): 265-292.

Ellingsen, T., Johannesson, M., Tjøtta, S., Torsvik G. (2010). Testing guilt aversion. Games and Economic Behavior 68: 95-107.

Erat, S., Gneezy, U. (2012). White lies. Management Science 58, 723-733.

Falk, A., Heckman, J. (2009). Lab Experiments are a Major Source of Knowledge in the Social Sciences. Science 326(5952): 535-538.

Fischbacher, U., Föllmi-Heusi, F. (2013). Lies in disguise: An experimental study on cheating. Journal of the European Economic Association 11(3): 525-547.

Fréchette, G.R. (2015). Laboratory experiments: professionals versus students. In Fréchette, G.R., Schotter A. (Eds.). Handbook of Experimental Economic Methodology. Oxford: Oxford University Press: 360-390.

Fréchette, G.R., Schotter A. (Eds.) (2015). Handbook of Experimental Economic Methodology. Oxford: Oxford University Press. 477 p.

Fürst, E. (2015). Free Riders and Ticket Fraud in Public Transport: A Delphi Analysis. Association for European Transport Papers Repository.

Gächter, S., Schultz, J.F. (2016). Intrinsic honesty and the prevalence of rule violations across societies. Nature 531, 24 March: 496-499.

Gibson, R., Tanner, C., Wagner, A. F. (2013). Preferences for truthfulness: Heterogeneity among and within individuals. American Economic Review 103, 532-548.

Gino, F., Ayal, S., Ariely, D. (2009). Contagion and differentiation in unethical behavior: the effect of one bad apple on the barrel. Psychological Science 20(3): 393-398.

Gneezy, U. (2005). Deception: The role of consequences. American Economic Review 95: 384-394.

Gneezy, U., Imas, A., Madarasz, K., 2013. Conscience accounting. Working paper.

Halevy, R., Shalvi, S., Verschuere, B. (2014). Being Honest About Dishonesty: Correlating SelfReports and Actual Lying. Human Communication Research 40(1): 54-72.

Hanna, R., Wang, S.Y. (2015). Dishonesty and Selection into Public Service. Working paper, Harvard University.

Hao, L., Houser, D. (2013). Perceptions, Intentions, and Cheating. Working Paper, ICES.

Harrison, G.W., List, J.A. (2004). Field experiments. Journal of Economic Literature 1009-1055.

Hartshorne, H., May, M. A. (1928). Studies in the nature of character. Vol. 1. Studies in deceit. New York: Macmillan.

Hauber, A., Hofstra, B., Toornvliet, L., Zandbergen, A. (1996). Some new forms of functional social control in the Netherlands and their effects. British Journal of Criminology 36 (2): 199-219.

Herbst, D., Mas, A. (2015). Peer effects on worker output in the laboratory generalize to the field. Science 350(6260): 545-549.

Houser, D., Vetter, S., Winter, J. (2012). Fairness and cheating. European Economic Review 56 (8), 1645-1655. 
Irlenbusch, B., Villeval, M.C. (2015). Behavioral ethics: how psychology influenced economics and how economics might inform psychology? Current Opinion in Psychology 6: 87-92.

Jiang, T. (2013). Cheating in Mind Games: The Subtlety of Rules Matters. Journal of Economic Behavior \& Organization 93: 328-336.

Kajackaite, A., Gneezy (U.) (2015). Lying costs and incentives. UC San Diego Discussion Paper.

Kastlunger, B., Kirchler, E., Mittone, L., Pitters, J. (2009). Sequences of audits, tax compliance, and tax paying strategies. Journal of Economic Psychology 30 :405-418.

Keolis (2014). Fraude: comment lutter? Keo', February. Available online at http://www.keolis.com/fileadmin/documents/medias/publications/keo/KEO1402.pdf (accessed 28 December 2015).

Killias, M., Scheidegger, D., Nordenson, P. (2009). The Effects of Increasing the Certainty of Punishment: A Field Experiment on Public Transportation. European Journal of Criminology, 6 (5) $387-400$.

Kooreman, P. (1993). Fare Evasion as a Result of Expected Utility Maximization. Journal of Transport Economics and Policy 27(1): 69-74.

Levitt, S., List, J.A. (2007). What Do Laboratory Experiments Social Preferences Reveal About the Real World. Journal of Economic Perspectives 21(2): 153-174.

List, J.A. (2006). The Behavioralist Meets the Market: Measuring Social Preferences and Reputation Effects in Actual Transactions. Journal of Political Economy 114(1): 1-37.

List, J.A. (2009). The economics of open air markets. NBER Working Paper 15420.

Lundquist, T., Ellingsen, T., Gribbe, E., Johannesson, M. (2009). The aversion to lying. Journal of Economic Behavior \& Organization 70: 81-92.

Maggian, V., Villeval, M.C. (2016). Social preferences and lying aversion in children. Forthcoming in Experimental Economics.

Mazar, N., Ariely, D. (2006). Dishonesty in everyday life and its policy implications. Journal of Public Policy \& Marketing 25(1): 117-126.

Mazar, N., Amir, O., Ariely, D. (2008). The dishonesty of honest people: A theory of self-concept maintenance. Journal of Marketing Research 45(6): 633-644.

Nikiforakis, N. (2007). Fines for Young Public Transport Offenders: Insights from the Economics Literature. Unpusblished manuscript.

Potters, J., Stoop, J. (2016). Do cheaters in the lab also cheat in the field? Forthcoming in European Economic Review.

Pruckner, G. J., Sausgruber, R. (2013). Honesty on the streets: A field study on newspaper purchasing. Journal of the European Economic Association 11 (3): 661-679.

Rosaz, J., Villeval, M.C. (2012). Lies and Biased Evaluation: A Real-Effort Experiment. Journal of Economic Behavior \& Organization 84 (2), 537-549.

Shalvi, S., Dana, J., Handgraaf, M.J.J., De Dreu, C.K.W. (2011). Justified ethicality: observing desired counterfactuals modifies ethical perceptions and behavior. Organizational Behavior and Human Decision Processes 115: 181-190.

Smith, M.J., Clarke, R.V. (2000). Crime and Public Transport. Crime and Justice: A Review of Research 27: 169-233.

Stoop, J., Noussair, C. N., Van Soest, D. (2012). From the lab to the field: Cooperation among fishermen. Journal of Political Economy 120(6): 1027-1056.

Sutter, M. (2009). Deception Through Telling the Truth?! Experimental Evidence From Individuals and Teams. The Economic Journal 119: 47-60.

Torgler, B. (2007). Tax Compliance and Tax Morale. A Theoretical and Empirical Analysis. Cheltenham: Edward Elgar.

Utikal, V., Fischbacher, U. (2013). Disadvantageous lies in individual decisions. Journal of Economic Behavior \& Organization, 85: 108-111. 
van Andel, H. (1989). Crime Prevention that works: The care of public transport in the Netherlands. British Journal of Criminology 29 (1): 47-56.

Vanberg, C. (2008). Why do people keep their promises? An experimental test of two explanations. Econometrica 76 (6): 1467-1480.

Zimerman, L., Shalvi, S., Bereby-Meyer, Y. (2014). Self-reported ethical risk taking tendencies predict actual dishonesty. Judgment and Decision Making 9(1): 58-64.

Zizzo, D.J. (2012). Inducing Natural Group Identity: A RDP Analysis. CBESS Working Paper 12-01. 


\section{Cheating in the Lab Predicts Fraud in the Field}

\section{An Experiment in Public Transportations}

\section{On-line appendices}

1. Location of the experiment and the mobile laboratory

2. Background information on subjects

3. Experimental instructions

4. Non-parametric estimation of the proportions of dishonest and honest subjects

5. An analysis of the determinants of fare-dodging

6. Full regression of Table 4 (Determinants of the 1 st roll outcome reported in the die task)

7. An analysis of self-justification in the die task

8. Full regression of Table 6 (Determinants of fraud in the public transportation game)

9. Relationship between the public transportation game and the die-under-cup task

10. Determinants of the $1^{\text {st }}$ roll outcome reported in the die task (ordered logit regressions) 
Appendix 1. Location of the experiment and the mobile laboratory

Figure A1: Location of the field experiment

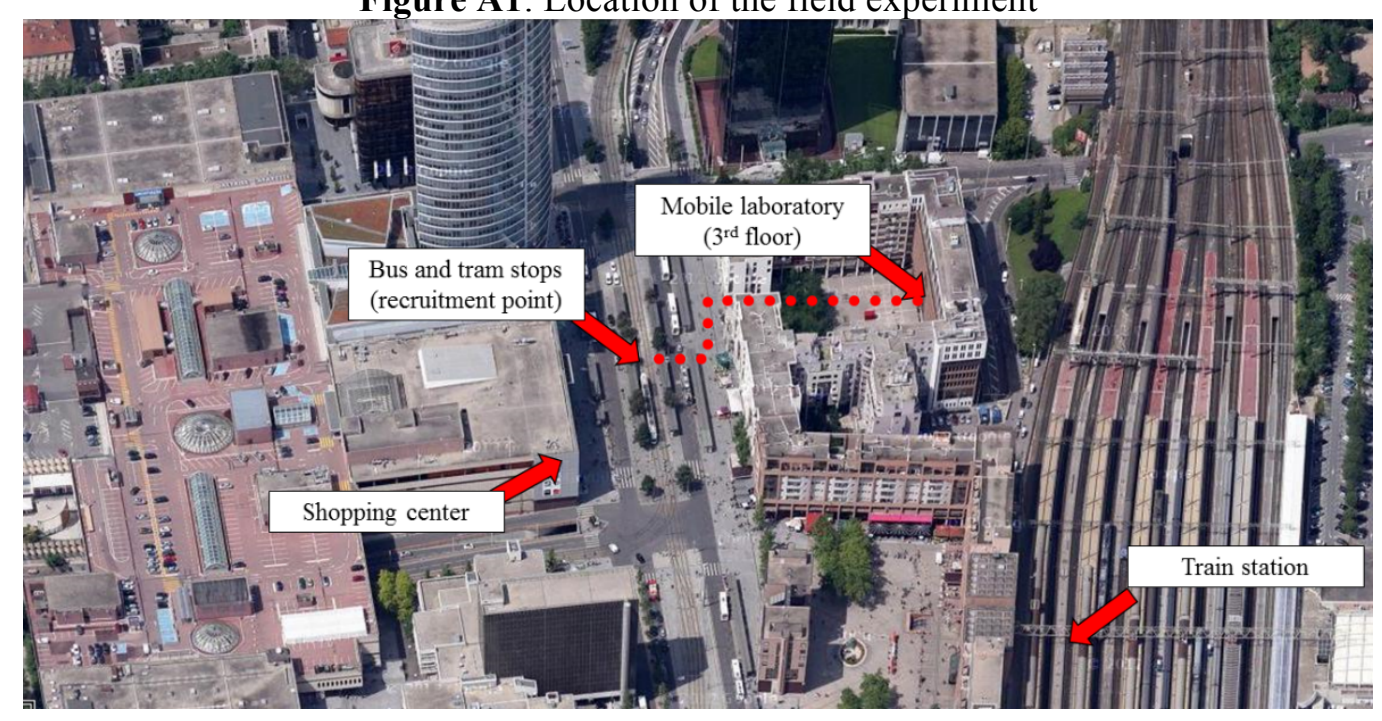

Note: The distance between the recruitment point and the mobile laboratory (red dotted line) is about 60 meters.

Figure A2: The mobile laboratory on the experimental site

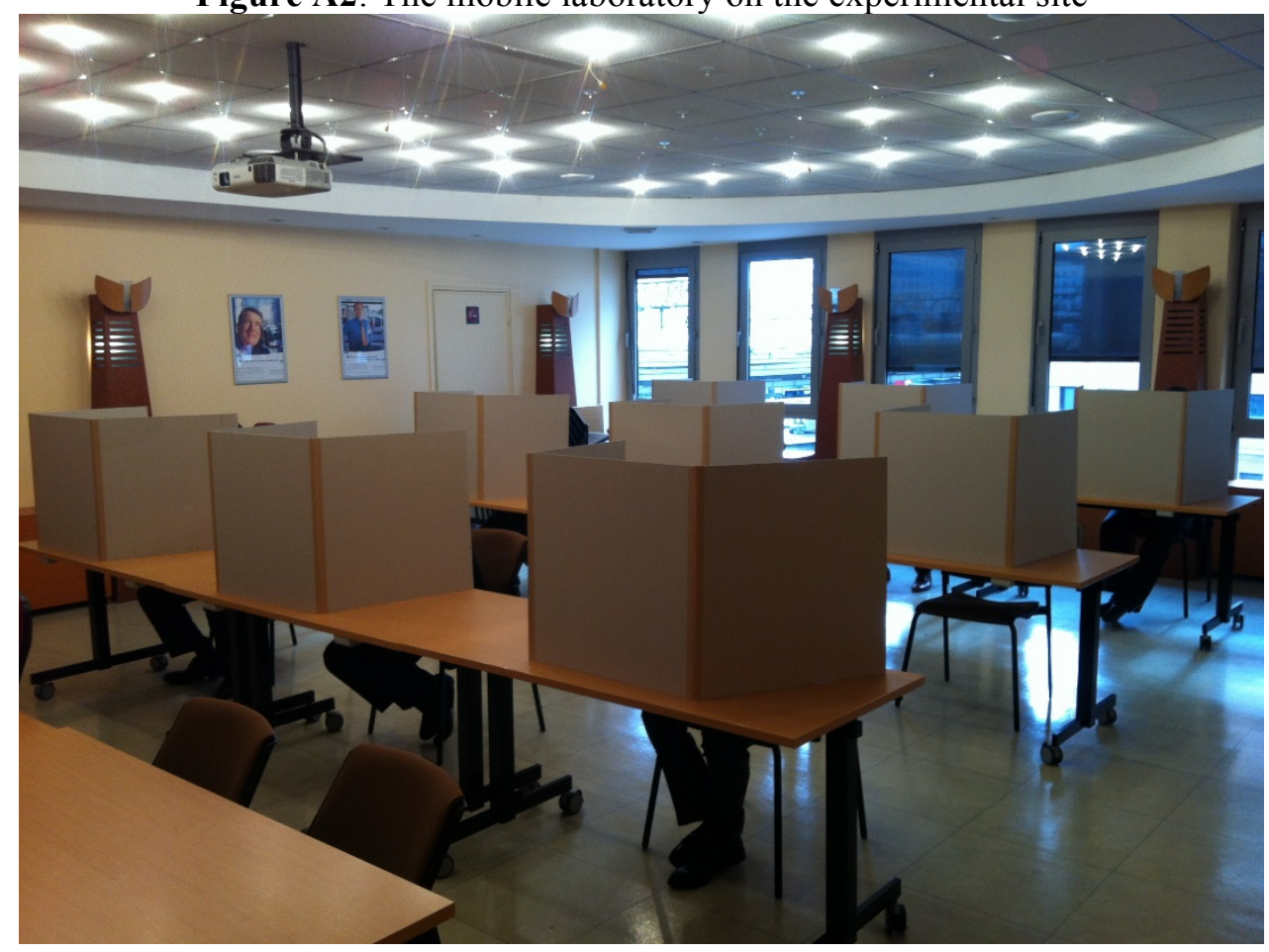


Figure A3: Die-under-cup task

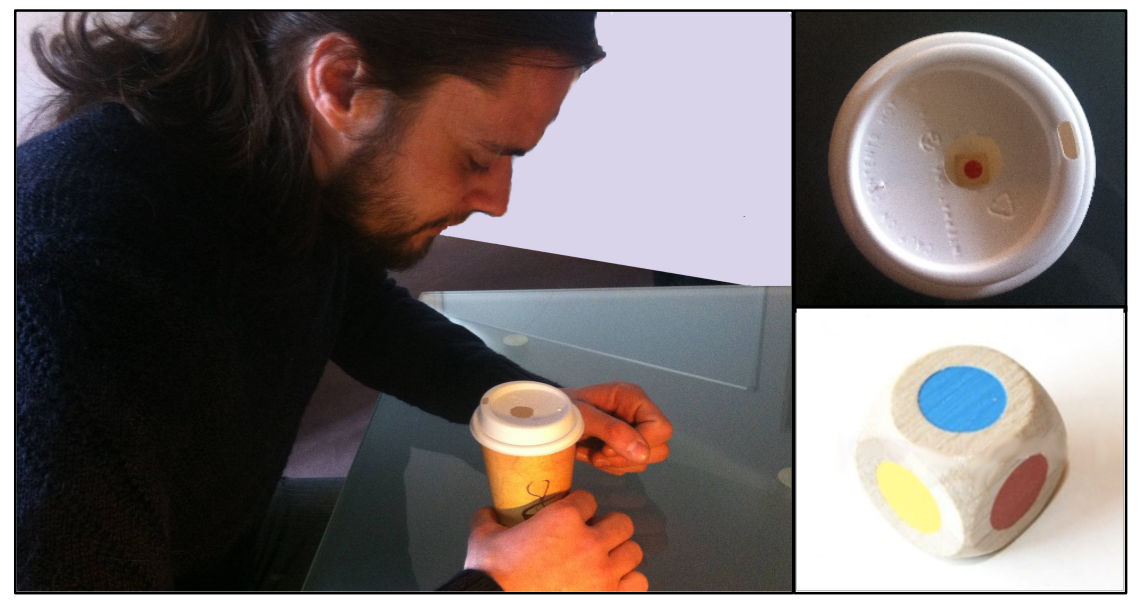


Appendix 2. Table A1: Background information on subjects and comparison of the subject pool with the 2014 TCL Sytral fraud survey in Lyon

\begin{tabular}{|c|c|c|c|c|c|}
\hline \multirow{2}{*}{ Characteristics } & \multicolumn{2}{|c|}{$\begin{array}{c}\text { TCL Sytral Fraud survey } \\
01-2014\end{array}$} & \multicolumn{2}{|c|}{ Our experiment } & \multirow{2}{*}{$\begin{array}{l}\text { Binomial test } \\
\quad(p \text {-value })\end{array}$} \\
\hline & $\%$ & $\begin{array}{c}\text { Corrected } \\
\%\end{array}$ & $\%$ & $\begin{array}{l}\mathrm{Nb} \text { of } \\
\text { obs. }\end{array}$ & \\
\hline \multicolumn{6}{|l|}{ Gender (18444) } \\
\hline Males & $47.45 \%$ & & $46.24 \%$ & 129 & \multirow[b]{2}{*}{0.719} \\
\hline Females & $52.55 \%$ & & $53.76 \%$ & 150 & \\
\hline \multicolumn{6}{|l|}{ Age (17344) } \\
\hline-18 & $13.54 \%$ & - & $0.36 \%$ & 1 & - \\
\hline $18-24$ & $31.63 \%$ & $36.59 \%$ & $42.65 \%$ & 119 & 0.029 \\
\hline $25-34$ & $21.03 \%$ & $24.33 \%$ & $26.88 \%$ & 75 & 0.329 \\
\hline $35-44$ & $12.69 \%$ & $14.67 \%$ & $12.19 \%$ & 34 & 0.271 \\
\hline $45-59$ & $13.20 \%$ & $15.27 \%$ & $13.62 \%$ & 38 & 0.505 \\
\hline 60 and more & $7.91 \%$ & $9.14 \%$ & $4.30 \%$ & 12 & 0.003 \\
\hline \multicolumn{6}{|l|}{ Status (17476) } \\
\hline High school & $15.05 \%$ & $1.86 \%$ & 0 & 0 & - \\
\hline Student & $24.06 \%$ & $27.79 \%$ & $29.03 \%$ & 81 & 0.640 \\
\hline Unemployed & $5.73 \%$ & $6.62 \%$ & $22.22 \%$ & 62 & $<0.001$ \\
\hline Blue collar & $3.50 \%$ & $4.04 \%$ & $3.58 \%$ & 10 & 0.879 \\
\hline White collar & $33.37 \%$ & $38.55 \%$ & $29.74 \%$ & 83 & 0.003 \\
\hline Manager & $7.86 \%$ & $9.08 \%$ & $9.32 \%$ & 26 & 0.835 \\
\hline Retired & $6.72 \%$ & $7.76 \%$ & $3.58 \%$ & 10 & 0.007 \\
\hline Inactive & $2.50 \%$ & $2.89 \%$ & $2.51 \%$ & 7 & 0.858 \\
\hline Others & $1.21 \%$ & $1.40 \%$ & 0 & 0 & - \\
\hline \multicolumn{6}{|l|}{$\begin{array}{l}\text { Usage of public } \\
\text { transports (17663) }\end{array}$} \\
\hline $4 /$ day or + & $20.24 \%$ & & $22.22 \%$ & 62 & 0.412 \\
\hline 2- 3 /day & $58.85 \%$ & & $42.29 \%$ & 118 & $<0.001$ \\
\hline At least 1 /week & $13.09 \%$ & & $26.88 \%$ & 75 & $<0.001$ \\
\hline $1-3 /$ month & $3.63 \%$ & & $6.09 \%$ & 17 & 0.036 \\
\hline Less frequently & $4.19 \%$ & & $2.51 \%$ & 7 & 0.180 \\
\hline TOTAL & $100 \%$ & $100 \%$ & $100 \%$ & 279 & \\
\hline
\end{tabular}

Notes: The 2014 TCL Sytral fraud survey ("Etude de mesure de la fraude") aims at measuring the rate of fraud on the public transportation network in Lyon. The rate of refusal is $2.8 \%$, the number of persons interviewed is 18845 . This is a representative survey of passengers. The numbers in italics and in parentheses indicates the number of responders for each category of questions. The last column reports the p-value of binomial tests comparing our subject pool with the TCL Sytral fraud survey. 


\section{Appendix 3. Experimental instructions}

We report below a reproduction of the instructions of Parts 1, 2 and 3 (only Period 1) which appeared on participants' computer screens (translated from French). The instructions of the remaining parts are available upon request.

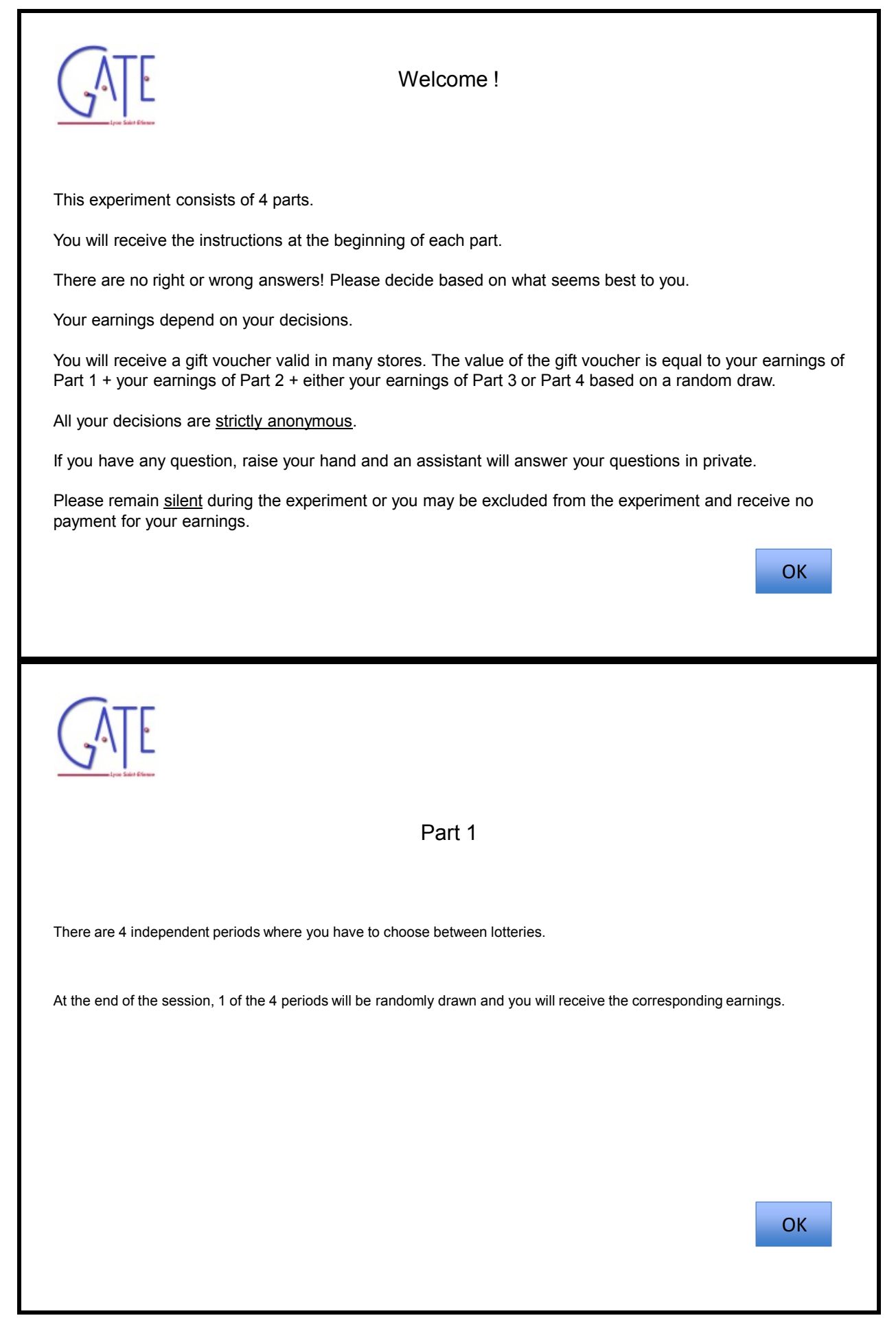




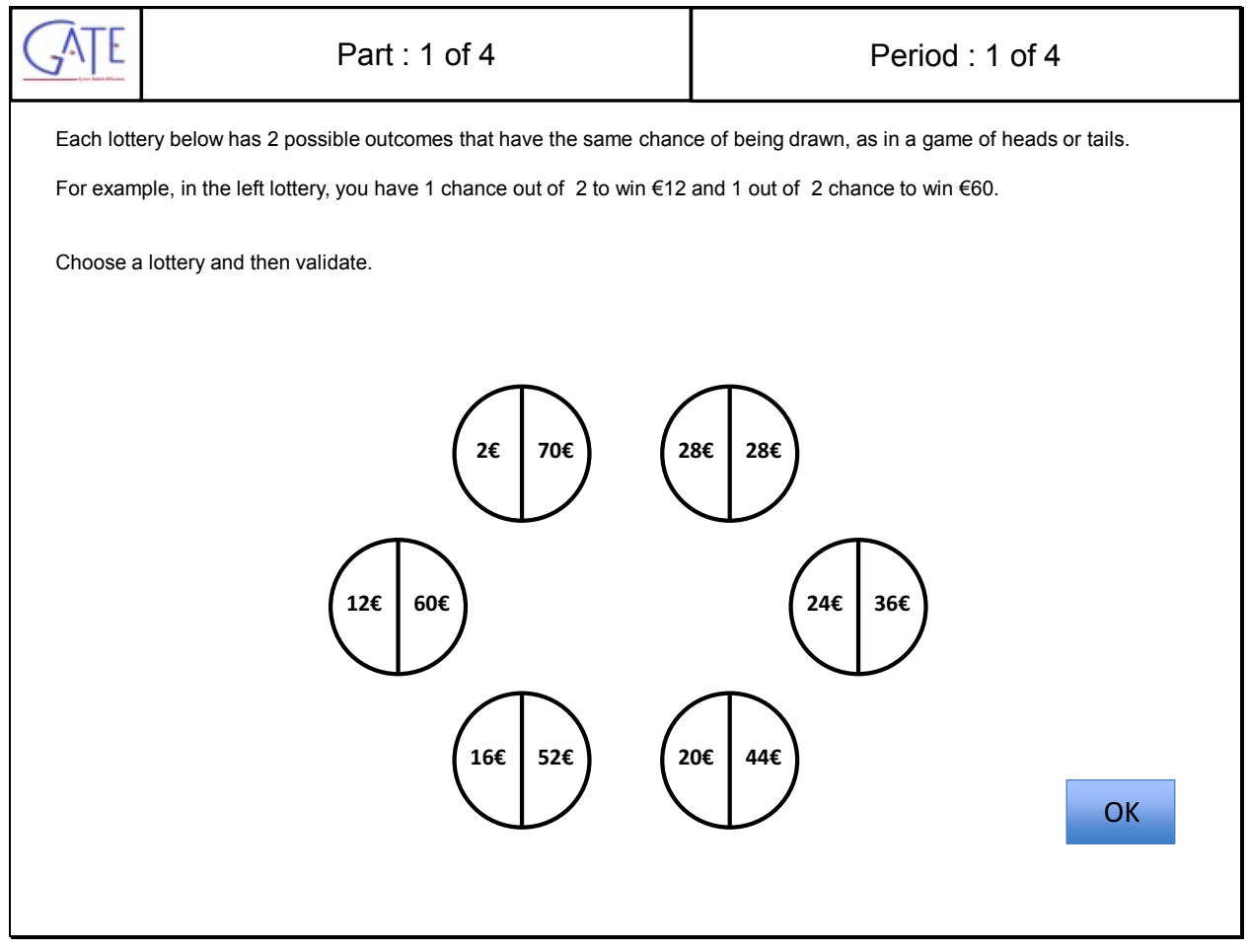

\begin{tabular}{|l|l|l|}
\hline GTE & Part : 1 of 4 & Period : 2 of 4 \\
\hline
\end{tabular}

You receive an endowment of $€ 40$

Choose one lottery. Unlike the previous period, a loss is possible. If you make a loss, it will be deducted from your endowment.

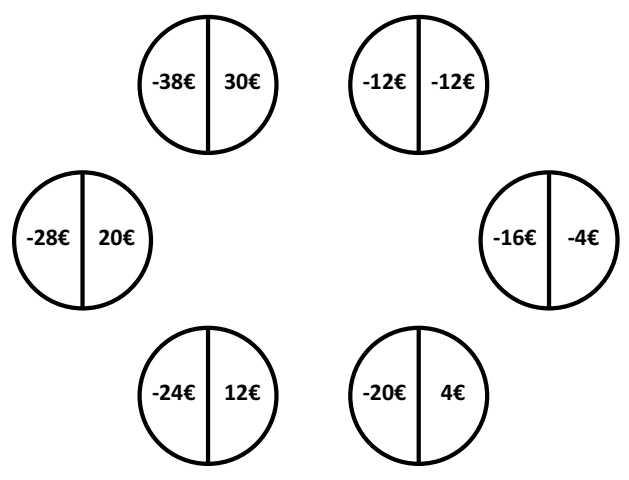




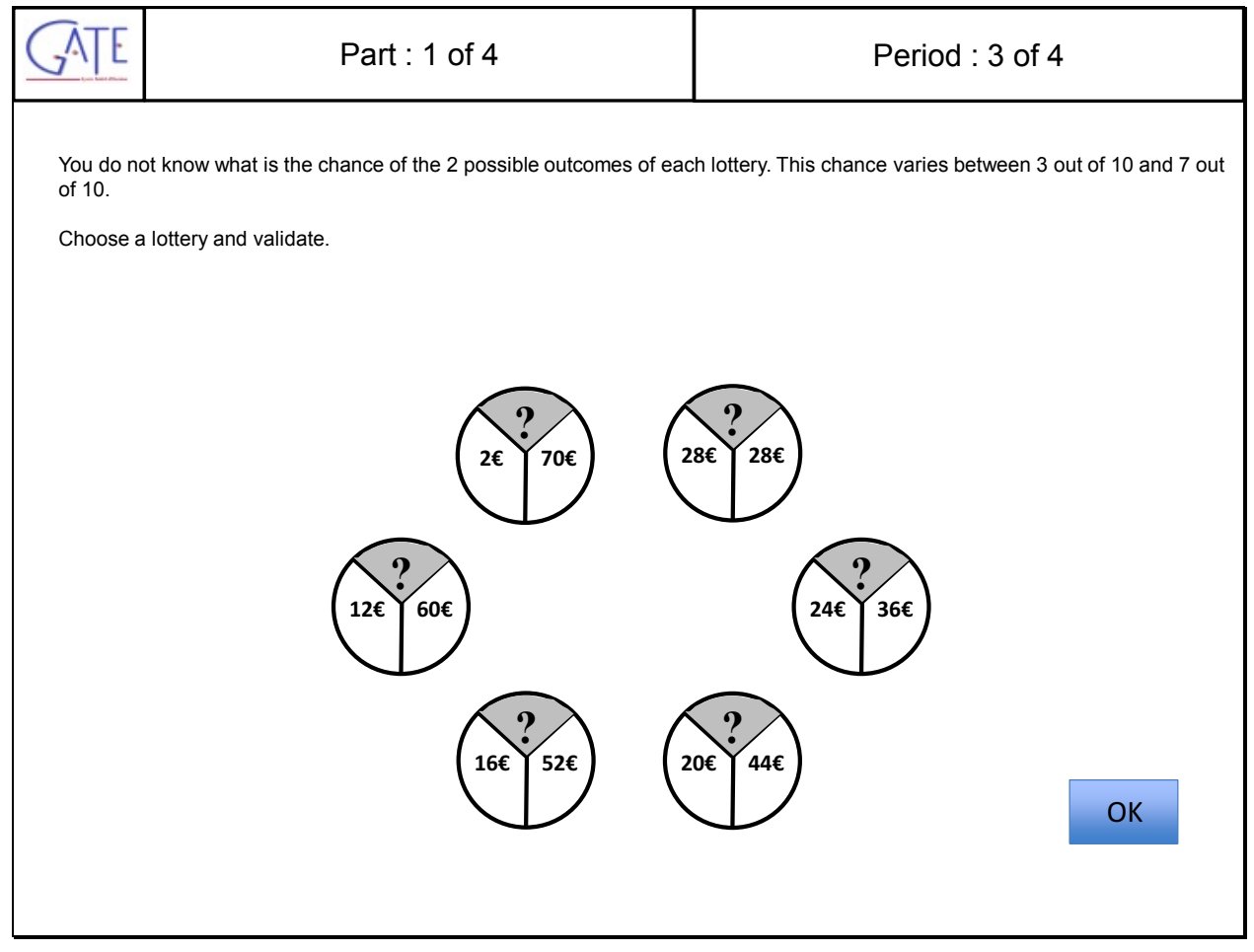

\begin{tabular}{|l|l|l|}
\hline GTE & Part : 1 of 4 & Period : 4 of 4 \\
\hline
\end{tabular}

You receive an endowment of $€ 40$. In case of a loss, it will be deducted from the endowment.

Choose a lottery and validate.

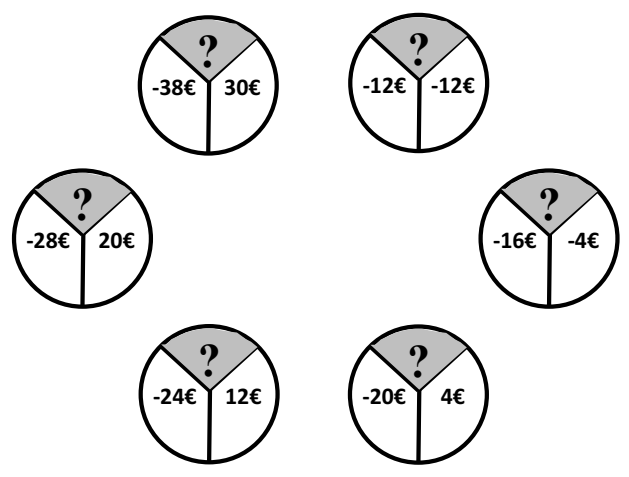




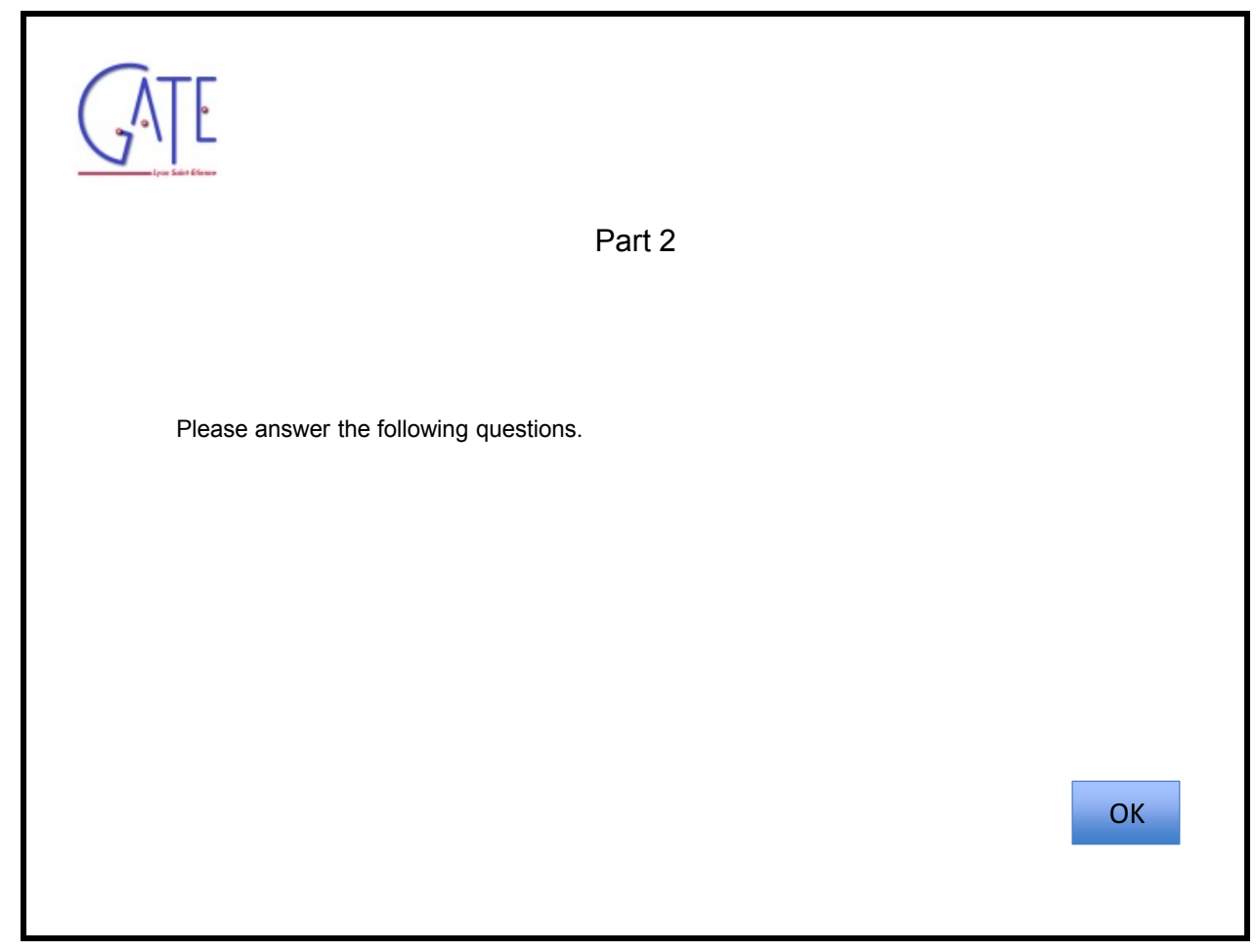

\begin{tabular}{|l|l|l|}
\hline GTE & Part : 2 of 4 & \\
\hline
\end{tabular}

Are you generally a person who is fully prepared to take risks or do you try to avoid taking risks?

Give an answer between 0 and 10, with 0 meaning "not at all willing to take risks" and 10 meaning "fully prepared to take risks," and then validate. 


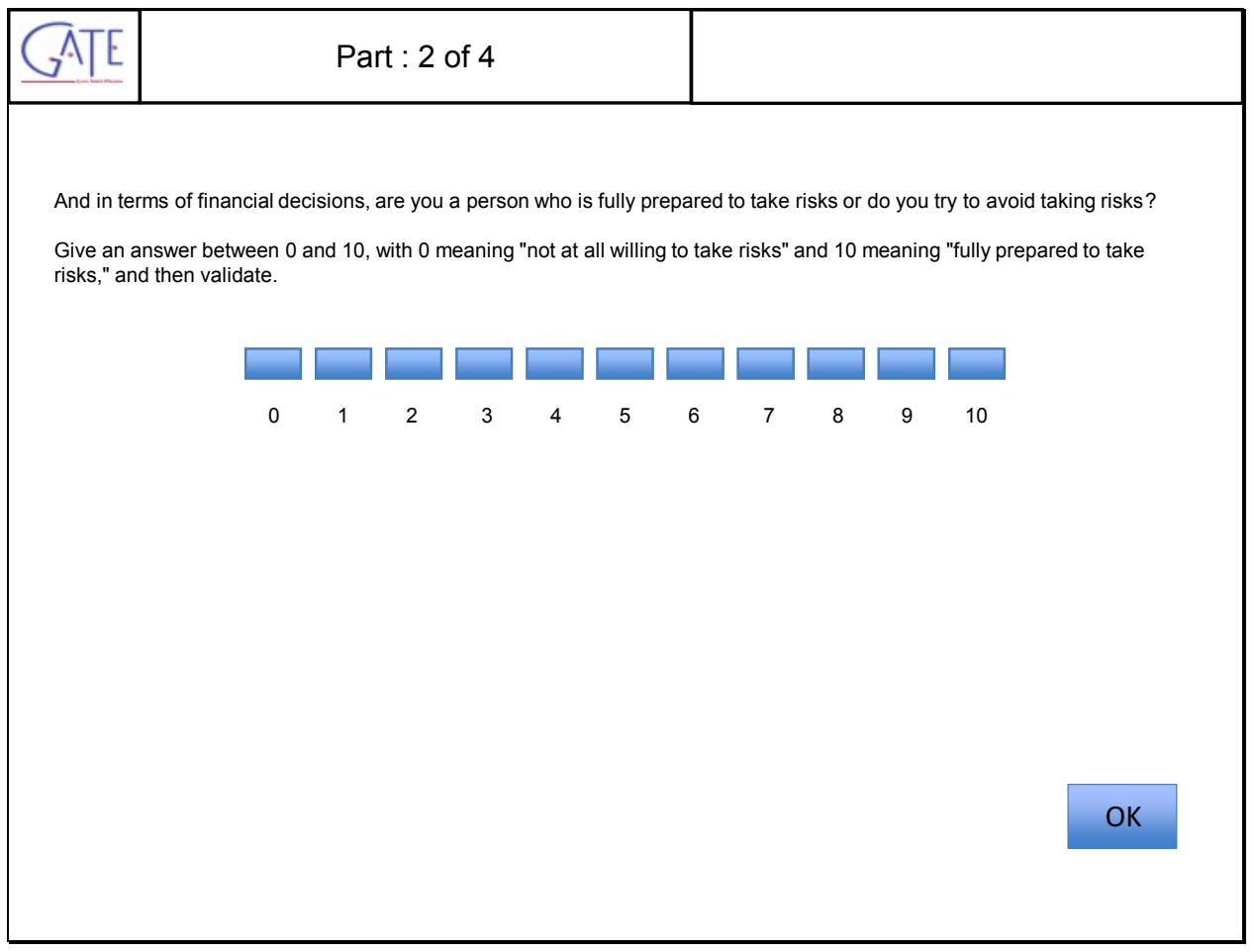

\begin{tabular}{|l|l|l|}
\hline G.TE & Part : 2 of 4 & \\
\hline
\end{tabular}

For having answered the previous questions, you will receive an additional gain of $€ 0, € 3$ or $€ 5$.

This gain depends on a roll of a dice which is contained in the cup on your table. 


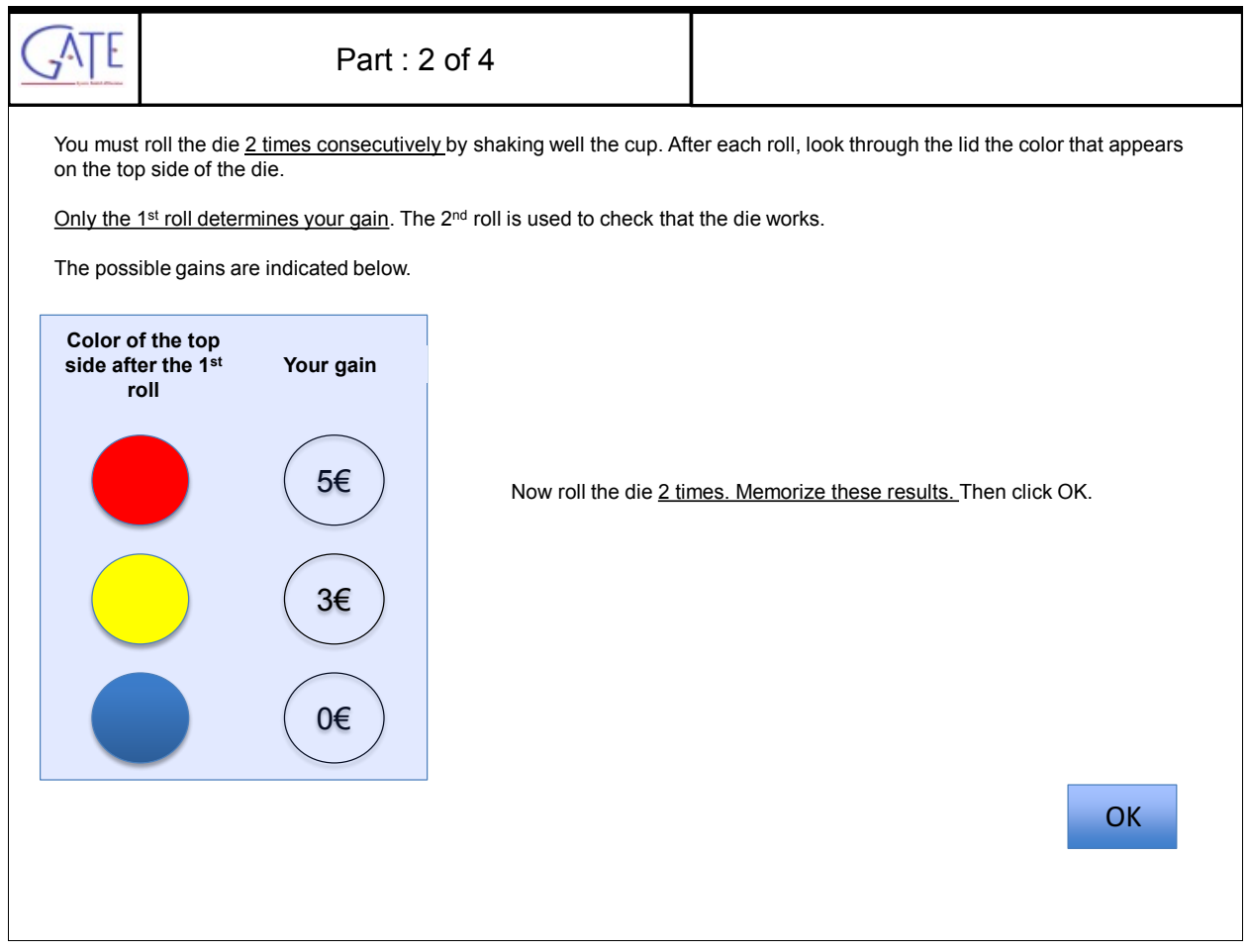

\begin{tabular}{|l|l|l|}
\hline GTE & Part : 2 of 4 & \\
\hline
\end{tabular}

Click on the color observed on the top side of the die after the $1^{\text {st }}$ roll. This determines your gain. 

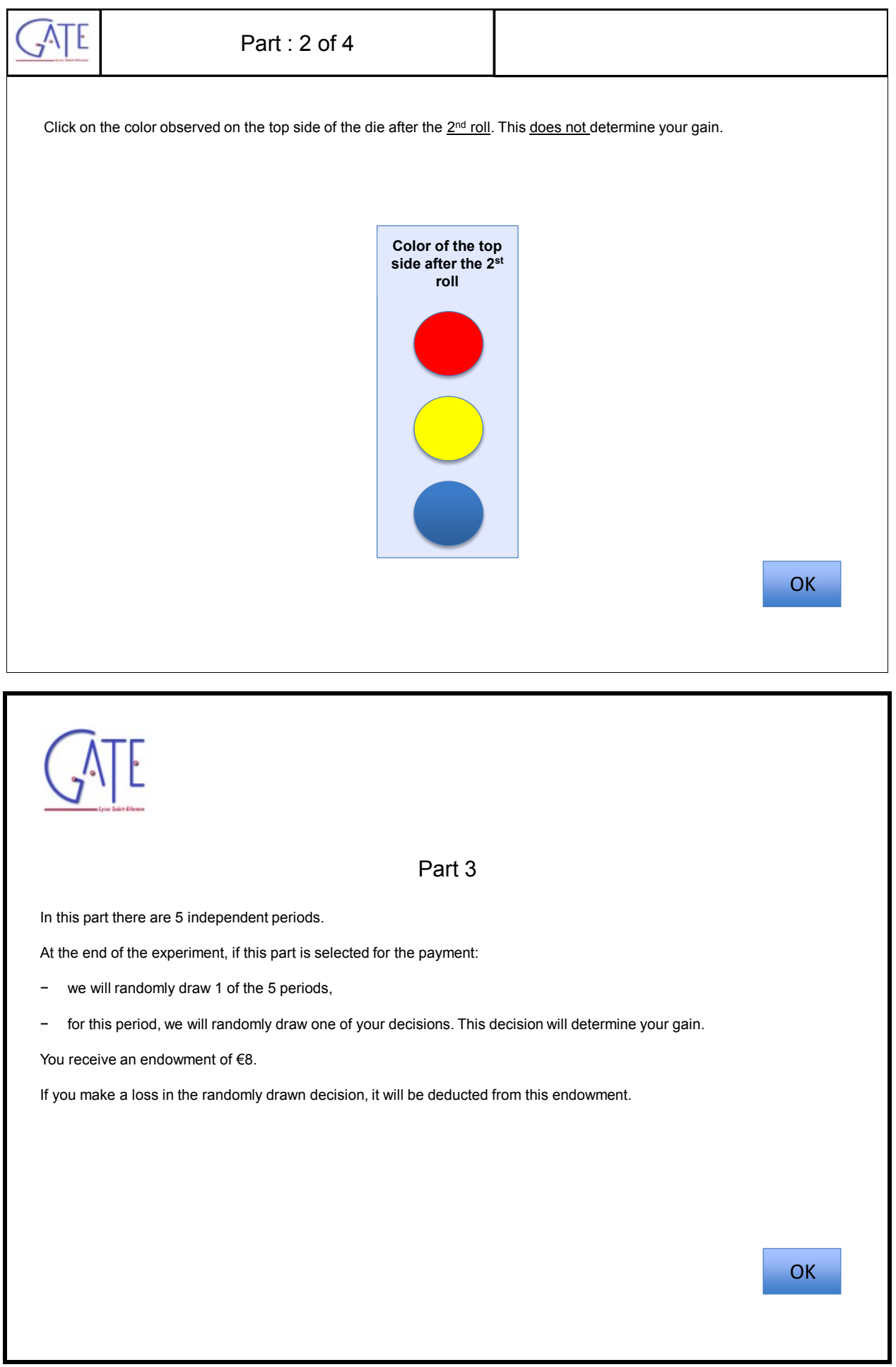
Variable treatment:

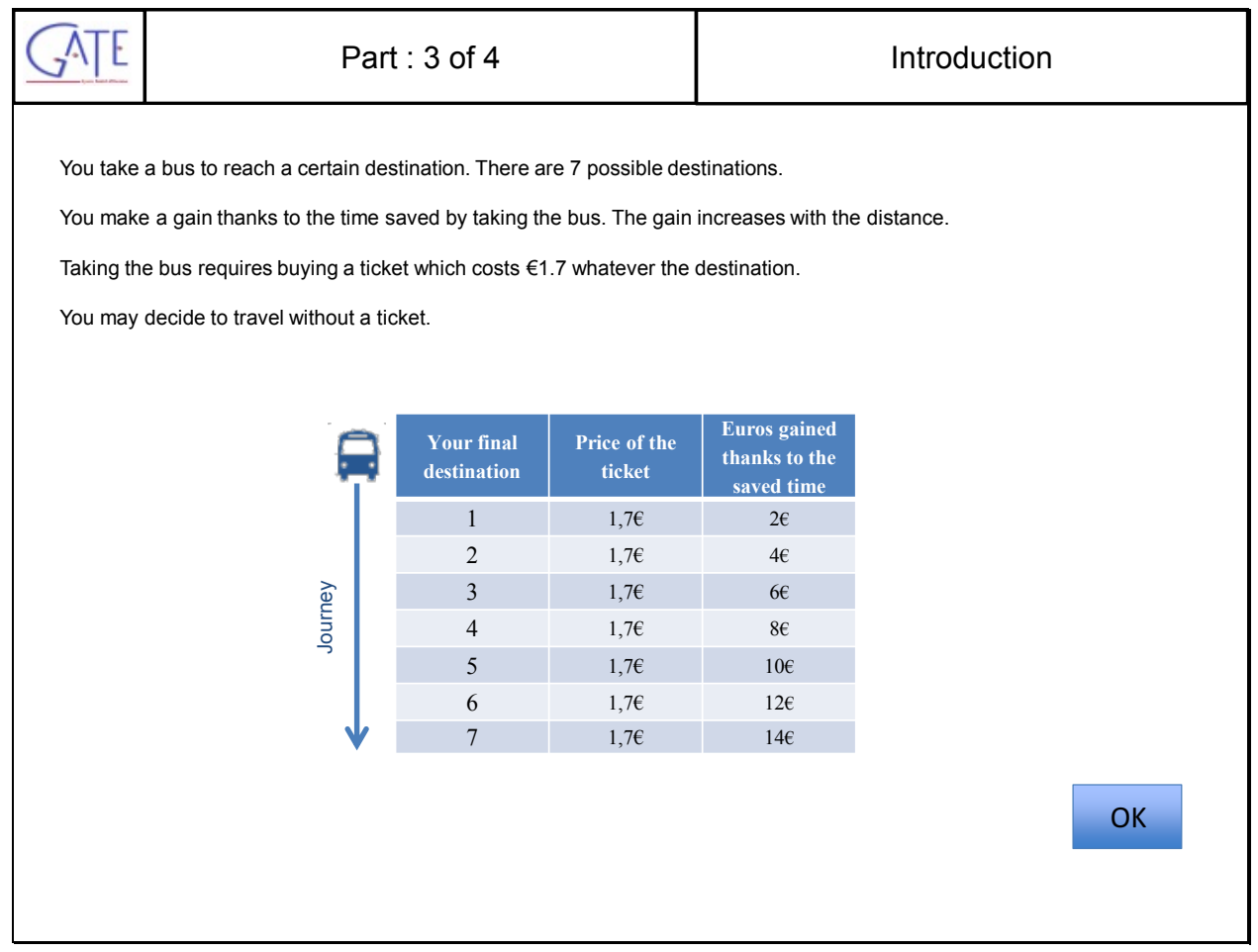

\begin{tabular}{|l|l|l|}
\hline GTE & Part : 3 of 4 & Period $: 1$ of 5 \\
\hline
\end{tabular}

Decide for each of the 7 possible final destinations if you buy a ticket or not.

There is no inspection.

The program will randomly draw your final destination. Your gain depends on your situation

- You have bought a ticket:

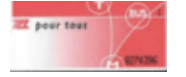

Your gain $=8 €$ of the endowment + the Euros earned $-1,7 €$

- You have not bought a ticket :

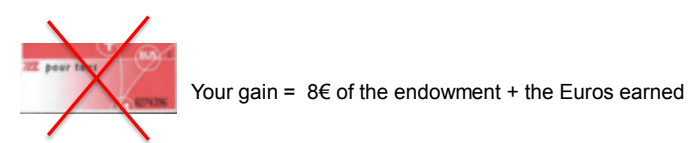




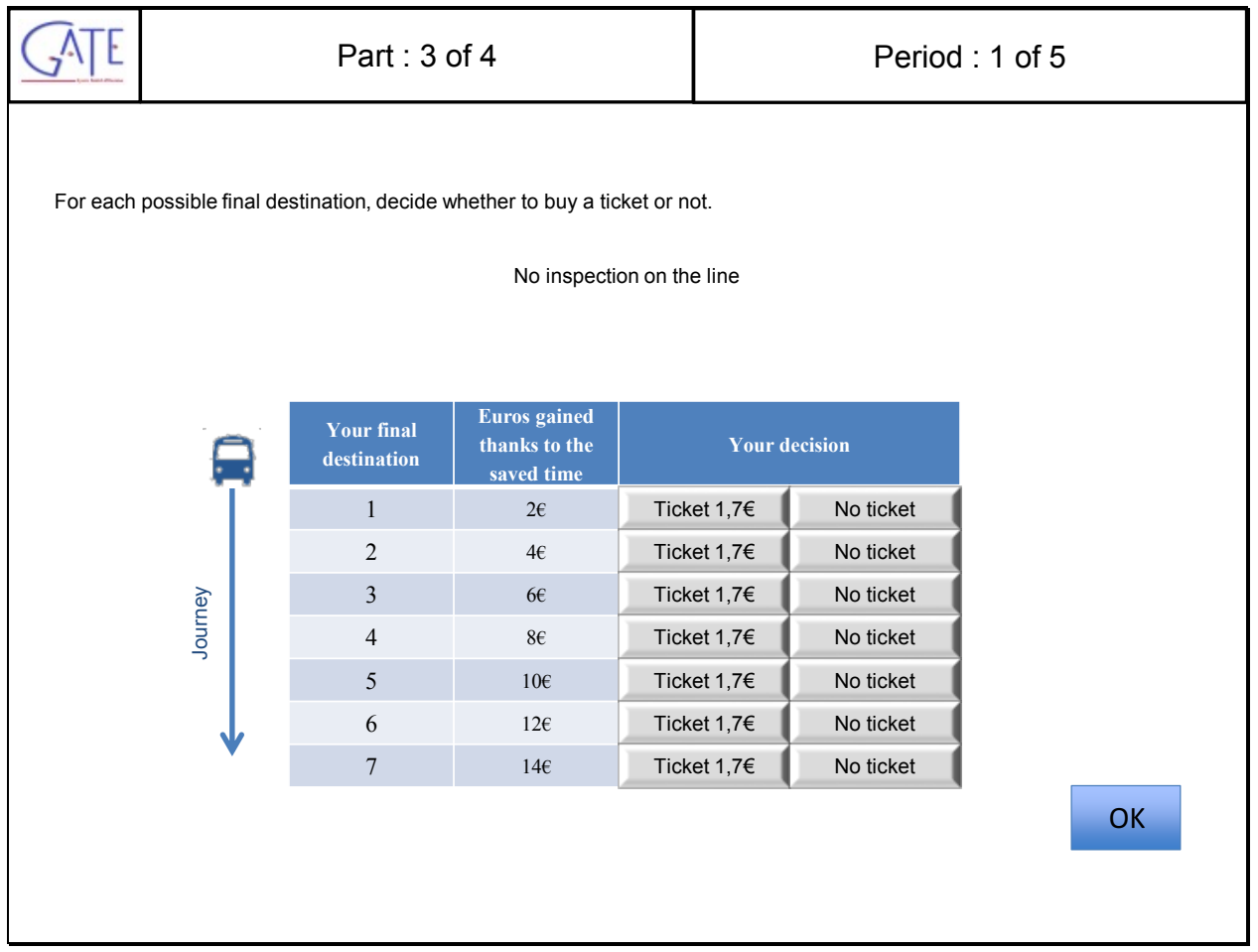

\section{$\underline{\text { Constant treatment: }}$}

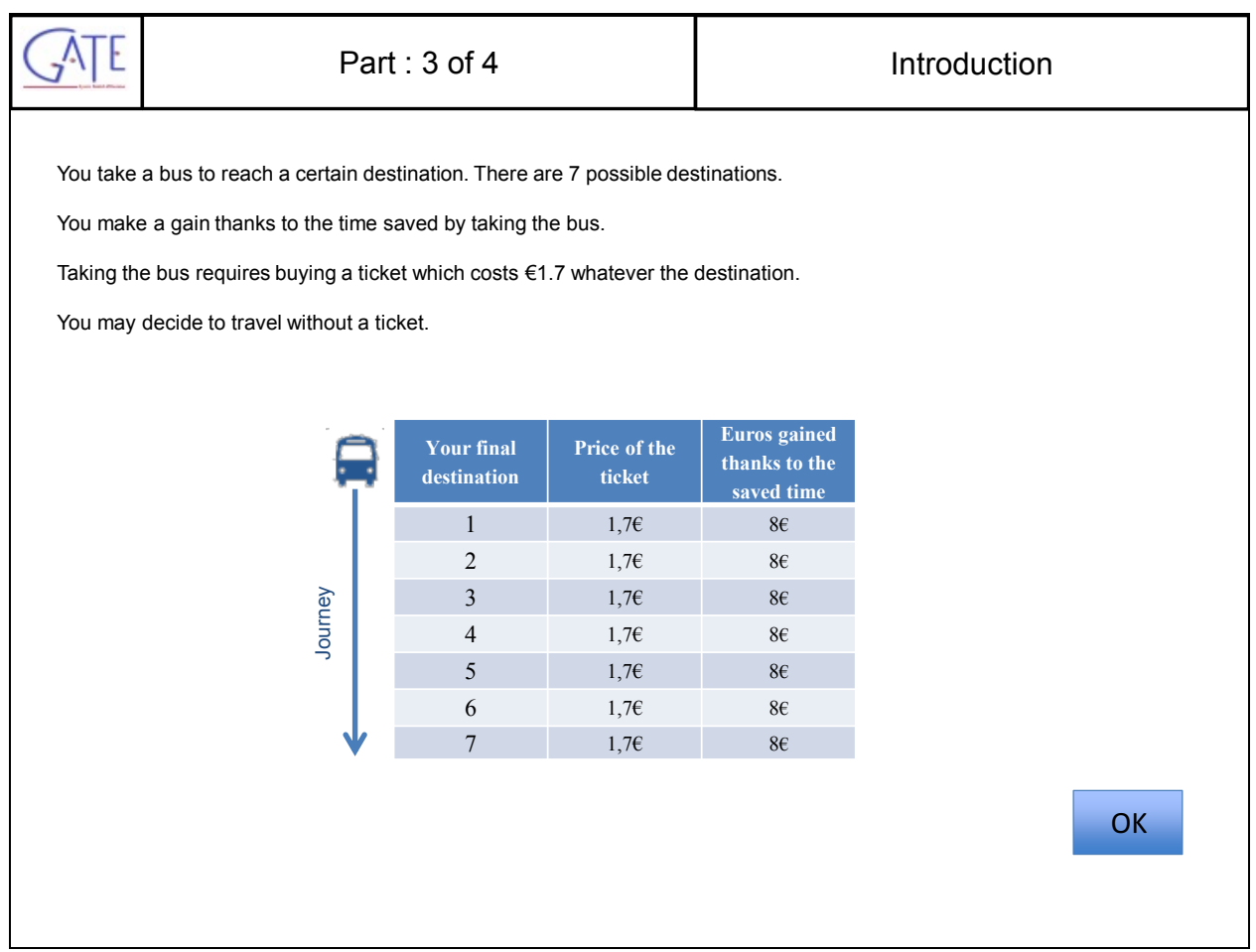




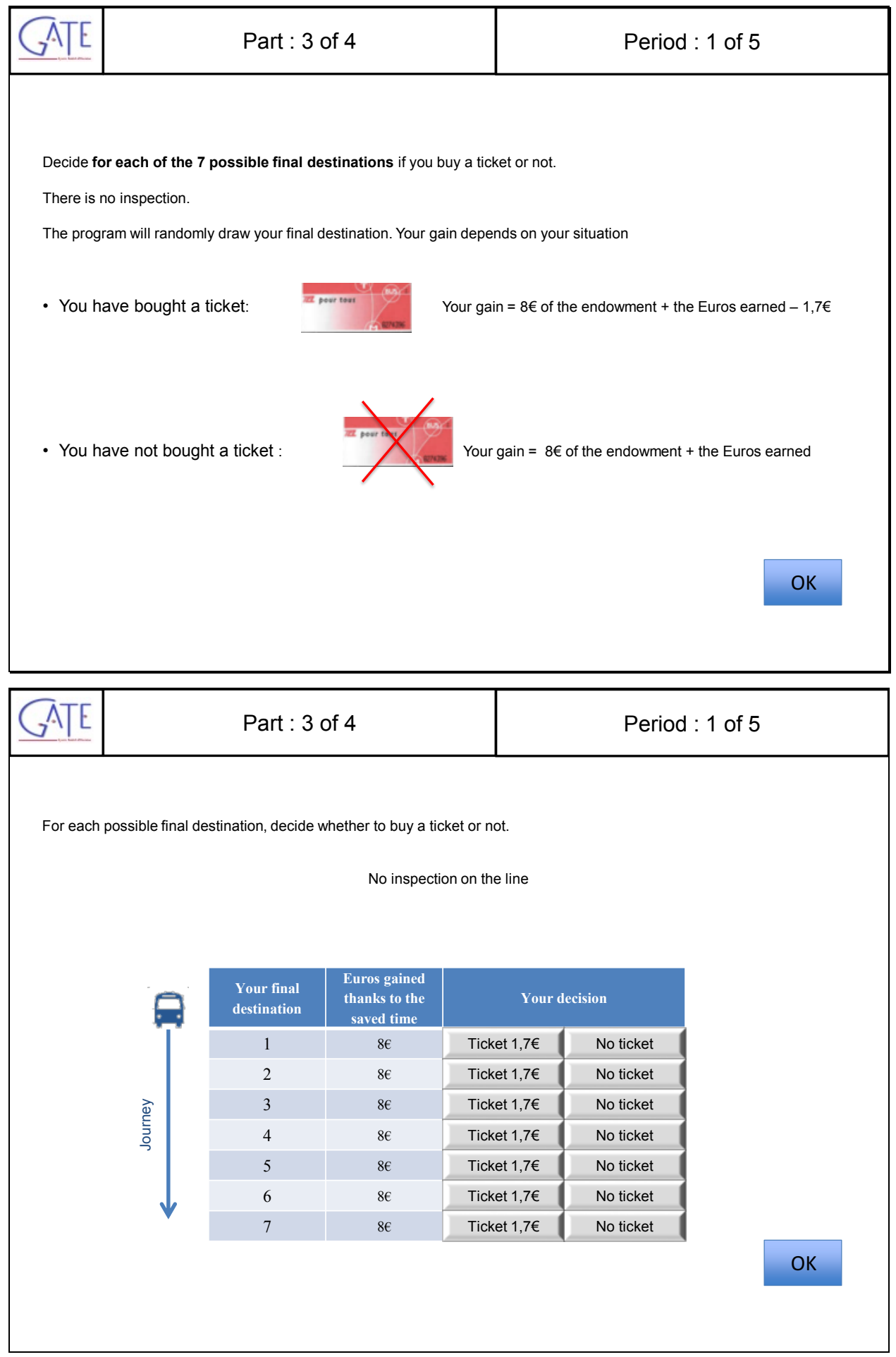




\section{Appendix 4. Non-parametric estimation of the proportions of dishonest and honest subjects}

Assuming that subjects never misreport the outcome of the dice roll at their disfavor, a dishonest person will always report an outcome which gives positive earnings ( $€ 3$ or $€ 5$ ). Indeed, for a dishonest subject, a 0 is reported as 3 or 5 , a 3 is reported as 3 or 5 and a 5 is reported as 5 . We assume that a dishonest subject who gets a 5 should never report 0 or 3 , i.e. we exclude downward lying. ${ }^{37}$ A honest subject will instead report a positive payoff only in two out of three cases (if he/she rolls the yellow or the red face). The proportion of positive payoffs $(p)$ that we should observe is thus equal to:

$$
p=\gamma \cdot 1+(1-\gamma) \cdot \frac{2}{3}=\frac{1}{3} \cdot \gamma+\frac{2}{3}
$$

where $\gamma$ is the proportion of dishonest subjects, and $1-\gamma$ is the proportion of honest subjects. From our data, we observe the proportion of positive payoffs reported by the subjects. We can then compute the proportion of dishonest subjects as:

$$
\gamma=3 \cdot p-2
$$

We can go one step further and distinguish between fully and partially dishonest subjects. The interpretation of the fully dishonest subjects is straightforward: fully dishonest subjects are those who always report the most favorable payoff $(€ 5)$. More difficult is the interpretation of the partially dishonest subjects. There are two possibilities. A lower-bound interpretation is that these subjects are those who behaves dishonestly only when they roll the worst outcome (€0), and report the middle payoff $(€ 3)$. An upper-bound interpretation is that these subjects are those who always lie a bit by reporting the next superior payoff. That is they report the middle payoff $(€ 3)$ if they roll the worst payoff $(€ 0)$, and they report the best payoff $(€ 5)$ if they roll the middle payoff $(€ 3) .{ }^{38}$ Based on these definitions, we can calculate the proportions of fully and partially dishonest subjects in the population. Combining the definition of fully dishonest subjects with the lower-bound definition of partially dishonest subjects, we can compute the proportions of best payoffs $\left(p_{1}\right)$ and middle payoffs $\left(p_{2}\right)$ respectively that we should observe in the experiment as:

$$
\left\{\begin{array}{l}
p_{1}=\gamma_{H} \cdot 1+\gamma_{M} \cdot \frac{1}{3}+\left(1-\gamma_{H}-\gamma_{M}\right) \cdot \frac{1}{3} \\
p_{2}=\gamma_{H} \cdot 0+\gamma_{M} \cdot \frac{2}{3}+\left(1-\gamma_{H}-\gamma_{M}\right) \cdot \frac{1}{3}
\end{array}\right.
$$

where $\gamma_{H}$ is the proportion of fully dishonest subjects, $\gamma_{M}$ is the proportion of partially dishonest subjects, and $1-\gamma_{H}-\gamma_{M}$ the proportion of honest subjects. From our data, we observe the proportion of best and middle payoffs respectively. We can then solve the system above for $\gamma_{H}$ and $\gamma_{M}$. The solution is:

$$
\left\{\begin{array}{c}
\gamma_{M}^{L}=\frac{3}{2} p_{1}-\frac{3}{2}+3 p_{2} \\
\gamma_{H}^{U}=\frac{3}{2} p_{1}-\frac{1}{2}
\end{array}\right.
$$

Combining the definition of fully dishonest subjects with the upper-bound definition of partially dishonest subjects, we can obtain a different measure for $\gamma_{H}$ and $\gamma_{M}$. The proportions of best payoffs $\left(p_{1}\right)$ and middle payoffs $\left(p_{2}\right)$ should be:

$$
\left\{\begin{array}{l}
p_{1}=\gamma_{H} \cdot 1+\gamma_{M} \cdot \frac{2}{3}+\left(1-\gamma_{H}-\gamma_{M}\right) \cdot \frac{1}{3} \\
p_{2}=\gamma_{H} \cdot 0+\gamma_{M} \cdot \frac{1}{3}+\left(1-\gamma_{H}-\gamma_{M}\right) \cdot \frac{1}{3}
\end{array}\right.
$$

We can then solve the system for $\gamma_{H}$ and $\gamma_{M}$, and obtain:

\footnotetext{
${ }^{37}$ This is consistent with previous literature (Houser, Vetter and Winter, 2012; Fischbacher and Föllmi-Heusi, 2013; Abeler et al., 2014; and Cohn, Fehr and Marechal, 2015) who acknowledge that downward lying may occur (for example because of altruism toward the experimenter, a fear of being detected, or a willingness to signal that one is not greedy), but assume that this behavior is very unlikely to occur, especially in the lab. Utikal and Fischbacher (2012) find that nuns are lying downward, but this is a very specific population. ${ }^{38}$ This definition is also consistent with the case where partially dishonest subjects behaves dishonestly only when they roll the worst outcome (€0), and report the best payoff $(€ 5)$.
} 


$$
\left\{\begin{array}{c}
\gamma_{M}^{U}=3 p_{1}-3+6 p_{2} \\
\gamma_{H}^{L}=1-3 p_{2}
\end{array}\right.
$$

Note that our data may not fully support the upper-bound definition of partially dishonest subjects. In particular, this definition is valid only if the data satisfy the following condition:

$$
p_{2} \leq \frac{1}{3}
$$

That is, the proportion of middle payoffs reported is not greater than $33 \%{ }^{39}$ If this condition is not satisfied, we can still provide an upper-bound proportion of partially dishonest subjects assuming that there are no fully dishonest subjects, and some partially dishonest subjects behave in line with the lowerbound interpretation of partial dishonesty. This equivalent to solve the following system of equations:

$$
\left\{\begin{array}{l}
p_{1}=\gamma_{M}^{l} \cdot \frac{1}{3}+\gamma_{M}^{u} \cdot \frac{2}{3}+\left(1-\gamma_{M}^{l}-\gamma_{M}^{u}\right) \cdot \frac{1}{3} \\
p_{2}=\gamma_{M}^{l} \cdot \frac{2}{3}+\gamma_{M}^{u} \cdot \frac{1}{3}+\left(1-\gamma_{M}^{l}-\gamma_{M}^{u}\right) \cdot \frac{1}{3}
\end{array}\right.
$$

Where $\gamma_{M}^{l}\left(\gamma_{M}^{u}\right)$ is the proportion of partially dishonest subjects who behave according to the lowerbound (upper-bound) interpretation of partial dishonesty. The solution is:

$$
\left\{\begin{array}{l}
\gamma_{M}^{u}=3 p_{1}-1 \\
\gamma_{M}^{l}=3 p_{2}-1
\end{array}\right.
$$

The total number of partially dishonest subjects is thus:

$$
\gamma_{M}^{U}=\gamma_{M}^{u}+\gamma_{M}^{l}=3 p_{1}+3 p_{2}-2
$$

${ }^{39}$ This is equivalent to say that the proportion of fully dishonest subjects is at least $0 \%$. 


\section{Appendix 5. An analysis of the determinants of fare-dodging}

To investigate the determinants of fare-dodging, we ran a logit regression with robust standard errors (see Table A2 below). The dependent variable is equal to 1 if a subject is either recruited at the FCO, does not hold a valid ticket at the end of the experiment or self reports as fare dodger. In all these cases, for reasons that we already discuss in the paper (see Section 3.3), we can confidently classify a subject as fare-dodger. Among the explanatory variables, we include dummy variables for being male, having a monthly income lower than $€ 1000$, being a student, being employed, having a high school education or lower (Education lower than Bac), having children, residing in downtown Lyon, residing in a upper class neighborhood, residing in other departments (the baseline for the latter three variables is residing in a lower class neighborhood), using the public transport after $7 \mathrm{pm}$, travelling on average less than 15 minutes per trip, using exclusively the bus, the tram, a combination of the two (the baseline for the latter three variables is using the metro), overestimating the fine, and underestimating the fine; we also include non-dichotomous variables for age (18-24, 25-34, 35-44, 45-59, 60 and over), number of social networks, degree of risk seeking, loss aversion and ambiguity aversion (as they are measured in our risk lottery tasks), number of trips during the last month, degree of approval of fare-dodging (measured on a scale from 1, i.e. "I very strongly disapprove", to 7, i.e. "I very strongly approve"), number of trips out of 10 without a ticket for a person to be considered dishonest (weakness of moral norm), belief about the proportion of fare-dodgers amongst travelers, and belief about the probability of being inspected.

The results of the regression show that being a male, having an income lower than $€ 1000$, having a high school education or lower, leaving in the center or in a lower class neighborhood all increase the probability to be a fare-dodger. Actual fare-dodgers have also weaker moral norms of honesty. In particular, subjects who approve more fare-dodging and those who are more flexibility in the definition of dishonesty (i.e. weakness of moral norm) are more likely to fraud. Finally, subjects who believe that there is a higher proportion of fare-dodgers in the population and people who think that the probability of being inspected is lower are more likely fare-dodgers.

To test whether there are potential differences between the fare-dodgers who were recruited at the FCO and other fare-dodgers, we ran a logit regression with robust standard errors on the sample of fare dodgers (202 subjects). The dependent variable is equal to 1 if a fare dodgers is recruited at the FCO, and 0 otherwise. The explanatory variables are the same as in the previous regression. The marginal effects are reported in Table A3. We find that the fare dodgers recruited at the FCO are less likely to be students and employees. They also believe that there is a smaller proportion of fare-dodgers in the population, think that the probability of being inspected is higher, and tend to underestimate less the amount of the fine compared to other fare-dodgers. This latter result may be due to the fact that the faredodgers recruited at FCO had just paid the fine, and, therefore, had a better idea of its amount.

These findings indicate that there are few slight differences between fare-dodgers who were recruited at the FCO and other fare-dodgers. However, none of these individual characteristics seems to explain the lab behavior of fare-dodgers recruited at the FCO. Note in fact that we control directly for these individual characteristics in the regression analysis of Tables 4 and 6 , and this does not change our results regarding the behavior of the subjects recruited at the FCO. 
Table A2: Determinants of fraud in real life (Logit regression)

\begin{tabular}{|c|c|c|}
\hline & $\mathrm{dy} / \mathrm{dx}$ & se \\
\hline \multicolumn{3}{|l|}{ Individual characteristics } \\
\hline Male & $0.085^{*}$ & 0.048 \\
\hline Age & -0.042 & 0.026 \\
\hline Monthly income $<1000 €$ & $0.129 * *$ & 0.059 \\
\hline Student & 0.076 & 0.069 \\
\hline Unemployed & \multicolumn{2}{|l|}{ Ref. } \\
\hline Employee & 0.052 & 0.062 \\
\hline Education lower than Bac & $0.163 * *$ & 0.063 \\
\hline With children & 0.057 & 0.063 \\
\hline Residence: lower class neighborhood & \multicolumn{2}{|c|}{ Ref. } \\
\hline Downtown & -0.01 & 0.053 \\
\hline Upper class neighborhood & $-0.187 * * *$ & 0.066 \\
\hline Non local & -0.088 & 0.078 \\
\hline Number social networks & -0.001 & 0.017 \\
\hline \multicolumn{3}{|l|}{ Attitudes towards risk } \\
\hline Risk seeking & 0.024 & 0.019 \\
\hline Loss aversion & 0.004 & 0.013 \\
\hline Aversion to uncertainty & 0.015 & 0.014 \\
\hline \multicolumn{3}{|l|}{ Usage of public transportation } \\
\hline Frequency of trips in previous month & -0.001 & 0.001 \\
\hline Trip after $7 \mathrm{pm}$ & 0.062 & 0.124 \\
\hline Mean duration of trips $<15$ minutes & 0.043 & 0.062 \\
\hline Usage of metro & \multicolumn{2}{|l|}{ Ref. } \\
\hline Bus exclusively & 0.142 & 0.144 \\
\hline Tram exclusively & $0.179 *$ & 0.096 \\
\hline Various modes excluding metro & 0.059 & 0.097 \\
\hline \multicolumn{3}{|l|}{ Norms and beliefs } \\
\hline Degree of approval of fraud (1 to 7) & $0.033 * *$ & 0.015 \\
\hline Weakness of moral norm & $0.032 * * *$ & 0.01 \\
\hline Belief on fraud rate in transportations & $0.002 *$ & 0.001 \\
\hline Belief on control probability & $-0.001 *$ & 0.001 \\
\hline Correct belief on fine $(=€ 50)$ & \multicolumn{2}{|l|}{ Ref. } \\
\hline Overestimate fine & 0.01 & 0.072 \\
\hline Underestimate fine & -0.094 & 0.063 \\
\hline Obs & \multicolumn{2}{|c|}{279} \\
\hline Pseudo R2 & \multicolumn{2}{|c|}{0.310} \\
\hline Df & \multicolumn{2}{|c|}{26} \\
\hline Prob $>$ F & \multicolumn{2}{|c|}{$<0.001$} \\
\hline
\end{tabular}

Notes: Logit regressions with robust standard errors. The Table reports the marginal effects. Independent variables include individual characteristics, attitudes towards risk, usage of public transportation, norms, beliefs. $* p<0.1,{ }^{* *} p<0.05,{ }^{* * *} p<0.01$. 
Table A3: Determinants of fare dodgers recruited at the FCO (Logit regression)

\begin{tabular}{|c|c|c|}
\hline & $\mathrm{dy} / \mathrm{dx}$ & se \\
\hline \multicolumn{3}{|l|}{ Individual characteristics } \\
\hline Male & 0.078 & 0.056 \\
\hline Age & -0.039 & 0.041 \\
\hline Monthly income $<1000 €$ & -0.044 & 0.07 \\
\hline Student & $-0.129 *$ & 0.071 \\
\hline Unemployed & \multicolumn{2}{|l|}{ Ref. } \\
\hline Employee & $-0.163^{* *}$ & 0.076 \\
\hline Education lower than Bac & 0.003 & 0.056 \\
\hline With children & 0.019 & 0.079 \\
\hline Residence: lower class neighborhood & \multicolumn{2}{|l|}{ Ref. } \\
\hline Downtown & -0.014 & 0.062 \\
\hline Upper class neighborhood & 0.113 & 0.083 \\
\hline Non local & -0.084 & 0.154 \\
\hline Number social networks & 0 & 0.019 \\
\hline \multicolumn{3}{|l|}{ Attitudes towards risk } \\
\hline Risk seeking & -0.024 & 0.02 \\
\hline Loss aversion & 0.01 & 0.015 \\
\hline Aversion to uncertainty & -0.008 & 0.015 \\
\hline \multicolumn{3}{|l|}{ Usage of public transportation } \\
\hline Frequency of trips in previous month & 0.001 & 0.001 \\
\hline Trip after $7 \mathrm{pm}$ & -0.083 & 0.09 \\
\hline Mean duration of trips $<15$ minutes & -0.002 & 0.073 \\
\hline Usage of metro & \multicolumn{2}{|l|}{ Ref. } \\
\hline Bus exclusively & 0.032 & 0.092 \\
\hline Tram exclusively & -0.079 & 0.112 \\
\hline Various modes excluding metro & 0.07 & 0.072 \\
\hline \multicolumn{3}{|l|}{ Norms and beliefs } \\
\hline Degree of approval of fraud (1 to 7) & -0.008 & 0.017 \\
\hline Weakness of moral norm & -0.002 & 0.009 \\
\hline Belief on fraud rate in transportations & $-0.004 * *$ & 0.002 \\
\hline Belief on control probability & $0.002 * *$ & 0.001 \\
\hline Correct belief on fine $(=€ 50)$ & \multicolumn{2}{|l|}{ Ref. } \\
\hline Overestimate fine & -0.121 & 0.074 \\
\hline Underestimate fine & $-0.232 * * *$ & 0.078 \\
\hline Obs & \multicolumn{2}{|l|}{202} \\
\hline Pseudo R2 & \multicolumn{2}{|c|}{0.228} \\
\hline Df & \multicolumn{2}{|c|}{26} \\
\hline Prob $>$ F & \multicolumn{2}{|c|}{0.044} \\
\hline
\end{tabular}

Notes: Logit regressions with robust standard errors. The Table reports the marginal effects. Independent variables include individual characteristics, attitudes towards risk, usage of public transportation, norms, beliefs. $* p<0.1,{ }^{* *} p<0.05, * * * p<0.01$. 
Appendix 6. Tables A4 and A5: Full regression of Table 4 (Determinants of the 1st roll outcome reported in the die task)

\begin{tabular}{|c|c|c|c|c|c|c|}
\hline & \multicolumn{6}{|c|}{ (2) } \\
\hline & \multicolumn{2}{|c|}{ Blue $(€ 0)$} & \multicolumn{2}{|c|}{ Yellow $(€ 3)$} & \multicolumn{2}{|c|}{ Red $(€ 5)$} \\
\hline & $\mathrm{dy} / \mathrm{dx}$ & $\mathrm{se}$ & $\mathrm{dy} / \mathrm{dx}$ & se & $\mathrm{dy} / \mathrm{dx}$ & se \\
\hline Ticket & $0.092 *$ & 0.051 & $0.127 *$ & 0.068 & $-0.218 * * *$ & 0.069 \\
\hline Self-reported non-fraudster & $0.146^{* *}$ & 0.059 & $-0.186 * *$ & 0.074 & 0.04 & 0.08 \\
\hline Fine Collection Office & $0.127^{* *}$ & 0.053 & 0.02 & 0.092 & -0.146 & 0.094 \\
\hline \multicolumn{7}{|l|}{ Individual characteristics } \\
\hline Male & 0.004 & 0.037 & $0.116^{*}$ & 0.061 & $-0.121 *$ & 0.064 \\
\hline Age & -0.023 & 0.028 & 0.034 & 0.041 & -0.01 & 0.043 \\
\hline Monthly income $<1000 €$ & $0.097 *$ & 0.059 & 0.009 & 0.082 & -0.106 & 0.085 \\
\hline Student & -0.01 & 0.052 & -0.053 & 0.086 & 0.063 & 0.089 \\
\hline Unemployed & \multicolumn{2}{|c|}{ Ref. } & \multicolumn{2}{|c|}{ Ref. } & \multicolumn{2}{|l|}{ Ref. } \\
\hline Employee & 0.036 & 0.054 & -0.033 & 0.086 & -0.003 & 0.09 \\
\hline Education lower than Bac & 0.009 & 0.042 & $-0.123 *$ & 0.069 & 0.113 & 0.069 \\
\hline With children & 0.084 & 0.063 & 0.048 & 0.089 & -0.132 & 0.094 \\
\hline Residence: lower class neighborhood & \multicolumn{2}{|c|}{ Ref. } & \multicolumn{2}{|c|}{ Ref. } & \multicolumn{2}{|c|}{ Ref. } \\
\hline Downtown & 0.002 & 0.044 & -0.004 & 0.068 & 0.002 & 0.068 \\
\hline Upper class neighborhood & -0.012 & 0.054 & 0.13 & 0.088 & -0.118 & 0.092 \\
\hline Non local & -0.015 & 0.066 & 0.132 & 0.1 & -0.117 & 0.105 \\
\hline Number social networks & -0.012 & 0.014 & 0.018 & 0.019 & -0.006 & 0.02 \\
\hline \multicolumn{7}{|l|}{ Attitudes towards risk } \\
\hline Risk seeking & 0.003 & 0.014 & $-0.044 *$ & 0.023 & $0.041 *$ & 0.024 \\
\hline Loss aversion & 0.013 & 0.01 & -0.008 & 0.017 & -0.005 & 0.017 \\
\hline Aversion to uncertainty & -0.014 & 0.012 & 0.002 & 0.018 & 0.012 & 0.018 \\
\hline \multicolumn{7}{|l|}{ Usage of public transportation } \\
\hline Frequency of trips in previous month & -0.001 & 0 & 0.001 & 0.001 & -0.001 & 0.001 \\
\hline Trip after $7 \mathrm{pm}$ & $0.194 * * *$ & 0.055 & -0.07 & 0.132 & -0.123 & 0.131 \\
\hline Mean duration of trips $<15$ minutes & -0.045 & 0.06 & -0.101 & 0.087 & $0.145^{*}$ & 0.085 \\
\hline Usage of metro & \multicolumn{2}{|l|}{ Ref. } & \multicolumn{2}{|c|}{ Ref. } & \multicolumn{2}{|l|}{ Ref. } \\
\hline Bus exclusively & -0.031 & 0.12 & 0.082 & 0.149 & -0.052 & 0.139 \\
\hline Tram exclusively & 0.111 & 0.081 & -0.22 & 0.173 & 0.109 & 0.151 \\
\hline Various modes excluding metro & 0.019 & 0.086 & -0.011 & 0.121 & -0.008 & 0.119 \\
\hline \multicolumn{7}{|l|}{ Norms and beliefs } \\
\hline Degree of approval of fraud (1 to 7) & 0.003 & 0.011 & 0.017 & 0.02 & -0.019 & 0.021 \\
\hline Weakness of moral norm & $0.011 * *$ & 0.005 & 0.014 & 0.011 & $-0.024 * *$ & 0.011 \\
\hline Belief on fraud rate in transportations & 0.001 & 0.001 & -0.002 & 0.002 & 0.001 & 0.002 \\
\hline Belief on control probability & 0.001 & 0.001 & 0.001 & 0.001 & $-0.002 *$ & 0.001 \\
\hline Correct belief on fine $(=€ 50)$ & \multicolumn{2}{|c|}{ Ref. } & \multicolumn{2}{|c|}{ Ref. } & \multicolumn{2}{|l|}{ Ref. } \\
\hline Overestimate fine & -0.01 & 0.052 & 0.003 & 0.084 & 0.006 & 0.085 \\
\hline Underestimate fine & -0.043 & 0.057 & 0.012 & 0.081 & 0.031 & 0.084 \\
\hline Number of observations & \multicolumn{6}{|c|}{279} \\
\hline Pseudo R2 & \multicolumn{6}{|c|}{0.145} \\
\hline Df & \multicolumn{6}{|c|}{58} \\
\hline Prob $>$ F & & & 0.0 & & & \\
\hline
\end{tabular}

Notes: Multinomial logit regressions with robust standard errors. Dependent variable $=$ outcome of the $1^{\text {st }}$ die roll. The table reports the marginal effects. Independent variables include individual characteristics, attitudes towards risk, usage of public transportation, norms, beliefs. ${ }^{*} \mathrm{p}<0.1,{ }^{* *} \mathrm{p}<0.05,{ }^{* * *} \mathrm{p}<0.01$. 


\begin{tabular}{|c|c|c|c|c|c|c|}
\hline & \multicolumn{6}{|c|}{ (4) } \\
\hline & \multicolumn{2}{|c|}{ Blue $(€ 0)$} & \multicolumn{2}{|c|}{ Yellow $(€ 3)$} & \multicolumn{2}{|c|}{ Red $(€ 5)$} \\
\hline & $\mathrm{dy} / \mathrm{dx}$ & se & $\mathrm{dy} / \mathrm{dx}$ & se & $\mathrm{dy} / \mathrm{dx}$ & se \\
\hline No ticket and self non-fraudster & 0.128 & 0.078 & -0.044 & 0.106 & -0.085 & 0.11 \\
\hline Ticket and self fraudster & 0.086 & 0.075 & $0.209 * *$ & 0.085 & $-0.295 * * *$ & 0.092 \\
\hline Ticket and self non-fraudster & $0.234 * * *$ & 0.068 & -0.063 & 0.088 & $-0.171 *$ & 0.09 \\
\hline Fine Collection Office & $0.122 * *$ & 0.059 & 0.055 & 0.094 & $-0.178^{*}$ & 0.097 \\
\hline \multicolumn{7}{|l|}{ Individual characteristics } \\
\hline Male & 0.005 & 0.037 & $0.112^{*}$ & 0.06 & $-0.117^{*}$ & 0.063 \\
\hline Age & -0.023 & 0.028 & 0.036 & 0.04 & -0.012 & 0.043 \\
\hline Monthly income $<1000 €$ & $0.099 *$ & 0.058 & 0.001 & 0.08 & -0.1 & 0.084 \\
\hline Student & -0.007 & 0.052 & -0.083 & 0.088 & 0.091 & 0.09 \\
\hline Unemployed & \multicolumn{2}{|c|}{ Ref. } & \multicolumn{2}{|c|}{ Ref. } & \multicolumn{2}{|l|}{ Ref. } \\
\hline Employee & 0.037 & 0.056 & -0.047 & 0.084 & 0.01 & 0.09 \\
\hline Education lower than Bac & 0.01 & 0.042 & $-0.136^{* *}$ & 0.069 & $0.126^{*}$ & 0.069 \\
\hline With children & 0.085 & 0.063 & 0.038 & 0.088 & -0.123 & 0.093 \\
\hline Residence: lower class neighborhood & \multicolumn{2}{|c|}{ Ref. } & \multicolumn{2}{|c|}{ Ref. } & \multicolumn{2}{|l|}{ Ref. } \\
\hline Downtown & 0.003 & 0.044 & -0.006 & 0.068 & 0.003 & 0.067 \\
\hline Upper class neighborhood & -0.013 & 0.054 & $0.153^{*}$ & 0.089 & -0.14 & 0.094 \\
\hline Non local & -0.015 & 0.066 & 0.135 & 0.1 & -0.12 & 0.105 \\
\hline Number social networks & -0.013 & 0.014 & 0.018 & 0.019 & -0.005 & 0.02 \\
\hline \multicolumn{7}{|l|}{ Attitudes towards risk } \\
\hline Risk seeking & 0.003 & 0.014 & $-0.042 *$ & 0.023 & $0.039^{*}$ & 0.024 \\
\hline Loss aversion & 0.013 & 0.01 & -0.005 & 0.016 & -0.008 & 0.017 \\
\hline Aversion to uncertainty & -0.014 & 0.012 & 0.001 & 0.018 & 0.014 & 0.018 \\
\hline \multicolumn{7}{|l|}{ Usage of public transportation } \\
\hline Frequency of trips in previous month & -0.001 & 0 & 0.001 & 0.001 & -0.001 & 0.001 \\
\hline Trip after $7 \mathrm{pm}$ & $0.193 * * *$ & 0.055 & -0.078 & 0.13 & -0.115 & 0.13 \\
\hline Mean duration of trips $<15$ minutes & -0.045 & 0.057 & -0.102 & 0.084 & $0.146^{*}$ & 0.082 \\
\hline Usage of metro & \multicolumn{2}{|c|}{ Ref. } & \multicolumn{2}{|c|}{ Ref. } & \multicolumn{2}{|l|}{ Ref. } \\
\hline Bus exclusively & -0.032 & 0.119 & 0.085 & 0.15 & -0.053 & 0.143 \\
\hline Tram exclusively & 0.11 & 0.081 & -0.207 & 0.173 & 0.098 & 0.152 \\
\hline Various modes excluding metro & 0.019 & 0.086 & -0.021 & 0.114 & 0.002 & 0.114 \\
\hline \multicolumn{7}{|l|}{ Norms and beliefs } \\
\hline Degree of approval of fraud & 0.002 & 0.011 & 0.017 & 0.02 & -0.019 & 0.021 \\
\hline Weakness of moral norm & $0.011^{* *}$ & 0.005 & 0.012 & 0.011 & $-0.023 * *$ & 0.011 \\
\hline Belief on fraud rate in transportations & 0.001 & 0.001 & -0.002 & 0.002 & 0.001 & 0.002 \\
\hline Belief on control probability & 0.001 & 0.001 & 0.001 & 0.001 & $-0.002 * *$ & 0.001 \\
\hline Correct belief on fine $(=€ 50)$ & \multicolumn{2}{|c|}{ Ref. } & \multicolumn{2}{|c|}{ Ref. } & \multicolumn{2}{|l|}{ Ref. } \\
\hline Overestimate fine & -0.009 & 0.052 & 0.002 & 0.083 & 0.006 & 0.085 \\
\hline Underestimate fine & -0.042 & 0.056 & 0.01 & 0.081 & 0.032 & 0.083 \\
\hline Number of observations & \multicolumn{6}{|c|}{279} \\
\hline Pseudo R2 & \multicolumn{6}{|c|}{0.151} \\
\hline Df & \multicolumn{6}{|c|}{60} \\
\hline Prob $>$ F & & & 0.0 & & & \\
\hline
\end{tabular}

Notes: Multinomial logit regressions with robust standard errors. Dependent variable $=$ outcome of the $1^{\text {st }}$ die roll. The table reports the marginal effects. Independent variables include individual characteristics, attitudes towards risk, usage of public transportation, norms, beliefs. The omitted category is "No Ticket and self-reported fraudster". $* \mathrm{p}<0.1,{ }^{* *} \mathrm{p}<0.05, * * * \mathrm{p}<0.01$. 


\section{Appendix 7. An analysis of self-justification in the die task}

Do people need a self-justification to lie? Shalvi et al. (2011) found that, in the die-under-cap paradigm, if subjects can roll the dice several times, they tend to lie more by reporting the best outcome they see across all the rolls. The interpretation is that people use the desired counterfactual as a self-justification to lie. In our experiment, subjects were asked to roll the die twice. Hence, they could feel legitimate to report, for the first roll, the outcome of the second roll if this was more desired. We call this the selfjustification hypothesis. To test it, we construct the theoretical distribution of reporting the best outcome of any of the two rolls, ${ }^{40}$ and compare it to the actual distribution of the reported payoffs from the first die roll.

We find that, pooling all the subjects together, the actual distribution is not statistically different from the theoretical distribution ( $\chi^{2}$ goodness-of-fit test, $p=0.423$ ). This evidence supports the selfjustification hypothesis. We can also explore whether fraudsters and non-fraudsters need more or less self-justification to lie (see Figure A1). We find an opposite pattern between ticket and non-ticket holders. While a self-justification is not sufficient to motivate ticket holders to lie (the distribution of the reported payoffs is different from the theoretical distribution at $p=0.064)$, non-ticket holders appeared to need less self-justification to lie, although not significantly so $(p=0.135)$. More specifically, ticket holders reported significantly less yellows and reds than what it is predicted by the selfjustification hypothesis (Binomial tests, $p=0.062$ and 0.022 respectively). Non-ticket holders reported less blues and more reds than predicted but the differences are not statistically significant ( $p=0.113$ and 0.111 , respectively). The behavior of self-reported non-fraudsters is consistent with the self-justification hypothesis $\left(\chi^{2}\right.$ test, $\left.p=0.501\right)$. Self-reported fraudsters needed instead less self-justification to lie (the distribution of the reported payoffs is different from the theoretical distribution at $p=0.083)$. In particular, they reported more yellows than predicted by the self-justification hypothesis (Binomial test, $p=0.066$ ). Finally, if we consider subjects recruited at the FCO, their behavior is fully consistent with the self-justification hypothesis ( $\chi^{2}$ test, $\left.p=0.269\right)$.

To summarize these findings, subjects, in general, behave as if they report the highest outcome of the two die rolls, which could denote a strategy of self-justification. This search for self-justification is however weaker for actual fare-dodgers, and potential self-justification is not sufficient to motivate non-fare-dodgers (especially ticket holders) to lie.

\footnotetext{
${ }^{40}$ If subjects report the best outcome of two rolls, we should observe $11.11 \%$ of blues, $33.33 \%$ of yellows, and $55.56 \%$ of reds.
} 
Figure A1: Comparison with theoretical distribution of choosing the highest payoff
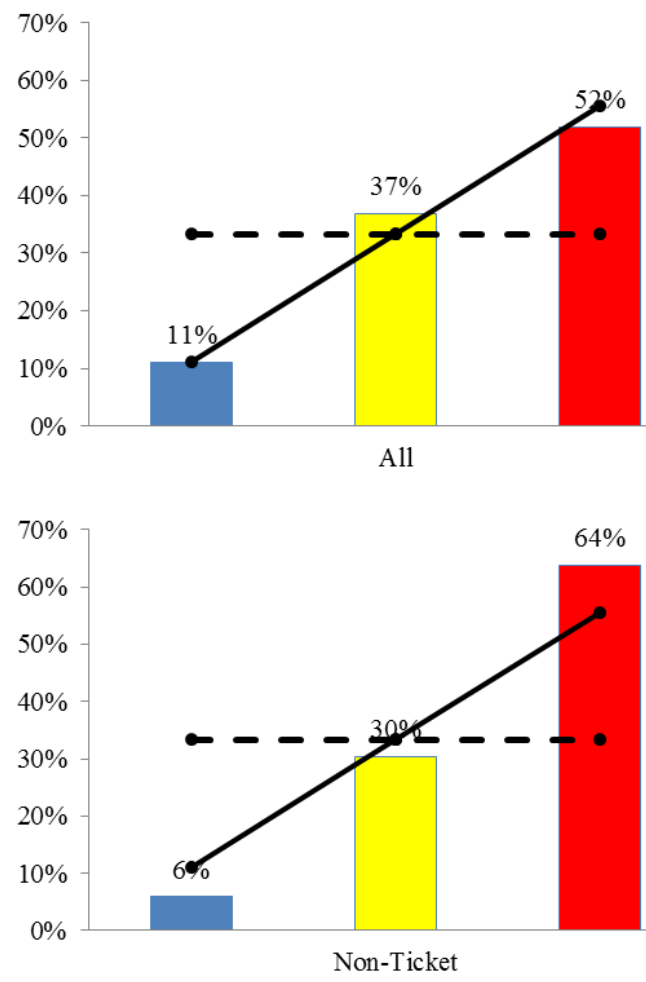

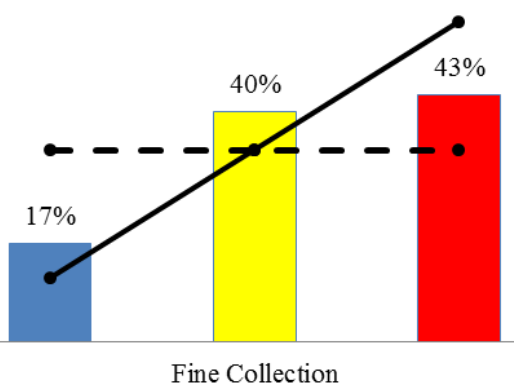

Office

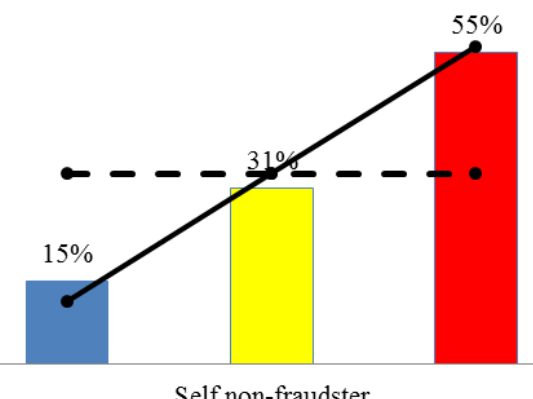

Self non-fraudster

-•—Uniform $\rightarrow$ Highest payoff
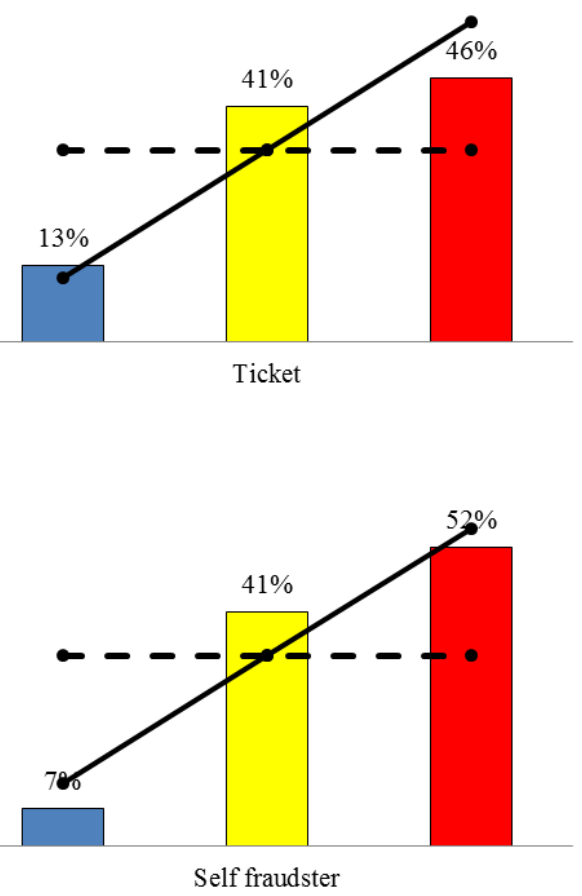
Appendix 8. Tables A6 and A7: Full regression of Table 6 (Determinants of fraud in the public transportation game)

\begin{tabular}{|c|c|c|c|c|}
\hline & \multicolumn{2}{|l|}{ (1) } & \multicolumn{2}{|l|}{ (2) } \\
\hline & $\mathrm{dy} / \mathrm{dx}$ & se & $d y / d x$ & $\mathrm{se}$ \\
\hline Ticket & $-0.093 * *$ & 0.042 & -0.063 & 0.043 \\
\hline Self-reported non-fraudster & $-0.292 * * *$ & 0.04 & $-0.155^{* * *}$ & 0.05 \\
\hline Fine Collection Office & -0.096 & 0.069 & 0 & 0.064 \\
\hline \multicolumn{5}{|l|}{ Treatment variables } \\
\hline Variable treatment & -0.043 & 0.041 & -0.044 & 0.041 \\
\hline Destination (1 to 7$)$ & $-0.041 * * *$ & 0.005 & $-0.041 * * *$ & 0.005 \\
\hline \multicolumn{5}{|l|}{ Individual characteristics } \\
\hline Male & & & 0.008 & 0.043 \\
\hline Age & & & 0.021 & 0.025 \\
\hline Monthly income $<1000 €$ & & & -0.013 & 0.057 \\
\hline Student & & & -0.006 & 0.058 \\
\hline Unemployed & & & \multicolumn{2}{|l|}{ Ref. } \\
\hline Employee & & & 0.011 & 0.058 \\
\hline Education lower than Bac & & & -0.063 & 0.049 \\
\hline With children & & & $-0.159 * * *$ & 0.057 \\
\hline Residence: lower class neighborhood & & & \multicolumn{2}{|l|}{ Ref. } \\
\hline Downtown & & & -0.044 & 0.04 \\
\hline Upper class neighborhood & & & -0.064 & 0.064 \\
\hline Non local & & & $-0.126 * *$ & 0.061 \\
\hline Number social networks & & & 0.008 & 0.012 \\
\hline \multicolumn{5}{|l|}{ Attitudes towards risk } \\
\hline Risk seeking & & & $0.031 *$ & 0.016 \\
\hline Loss aversion & & & 0.01 & 0.011 \\
\hline Aversion to uncertainty & & & -0.007 & 0.012 \\
\hline \multicolumn{5}{|l|}{ Usage of public transportation } \\
\hline Frequency of trips in previous month & & & 0 & 0 \\
\hline Trip after $7 \mathrm{pm}$ & & & -0.076 & 0.064 \\
\hline Mean duration of trips $<15$ minutes & & & -0.013 & 0.049 \\
\hline Usage of metro & & & \multicolumn{2}{|c|}{ Ref. } \\
\hline Bus exclusively & & & 0.003 & 0.108 \\
\hline Tram exclusively & & & 0.031 & 0.103 \\
\hline Various modes excluding metro & & & -0.004 & 0.071 \\
\hline \multicolumn{5}{|l|}{ Norms and beliefs } \\
\hline Degree of approval of fraud ( 1 to 7 ) & & & 0.015 & 0.014 \\
\hline Weakness of moral norm & & & $0.031 * * *$ & 0.007 \\
\hline Belief on fraud rate in transportations & & & $0.002 * *$ & 0.001 \\
\hline Belief on control probability & & & $-0.002 * * *$ & 0.001 \\
\hline Correct belief on fine $(=€ 50)$ & & & \multicolumn{2}{|l|}{ Ref. } \\
\hline Overestimate fine & & & 0.028 & 0.052 \\
\hline Underestimate fine & & & 0.036 & 0.053 \\
\hline Obs & \multicolumn{2}{|l|}{1953} & \multicolumn{2}{|c|}{1953} \\
\hline Pseudo R2 & \multicolumn{2}{|l|}{0.113} & \multicolumn{2}{|l|}{0.22} \\
\hline Df & \multirow{2}{*}{\multicolumn{2}{|c|}{$\begin{array}{c}5 \\
<0001\end{array}$}} & \multicolumn{2}{|c|}{31} \\
\hline Prob $>$ F & & & \multicolumn{2}{|c|}{$<0.001$} \\
\hline
\end{tabular}

Notes: Logit regressions with clustered standard errors. Dependent variable $=$ decision to not buy a ticket for a given destination. The Table reports the marginal effects. Independent variables include individual characteristics, attitudes towards risk, usage of public transportation, norms, beliefs. $* p<0.1, * * p<0.05,{ }^{* * *}$ $p<0.01$ 


\begin{tabular}{|c|c|c|c|c|}
\hline & \multicolumn{2}{|l|}{ (3) } & \multicolumn{2}{|l|}{ (4) } \\
\hline & $\mathrm{dy} / \mathrm{dx}$ & se & $\mathrm{dy} / \mathrm{dx}$ & se \\
\hline No Ticket and self non-fraudster & $-0.286 * * *$ & 0.072 & $-0.173 * * *$ & 0.066 \\
\hline Ticket and self fraudster & $-0.090 *$ & 0.048 & -0.073 & 0.053 \\
\hline Ticket and self non-fraudster & $-0.386^{* * *}$ & 0.054 & $-0.214 * * *$ & 0.066 \\
\hline Fine Collection Office & -0.094 & 0.071 & -0.004 & 0.065 \\
\hline \multicolumn{5}{|l|}{ Treatment variables } \\
\hline Variable treatment & -0.043 & 0.041 & -0.044 & 0.041 \\
\hline Destination (1 to 7$)$ & $-0.041 * * *$ & 0.005 & $-0.041 * * *$ & 0.005 \\
\hline \multicolumn{5}{|l|}{ Individual characteristics } \\
\hline Male & & & 0.008 & 0.043 \\
\hline Age & & & 0.021 & 0.025 \\
\hline Monthly income $<1000 €$ & & & -0.012 & 0.057 \\
\hline Student & & & -0.002 & 0.058 \\
\hline Unemployed & & & \multicolumn{2}{|l|}{ Ref. } \\
\hline Employee & & & 0.013 & 0.057 \\
\hline Education lower than Bac & & & -0.061 & 0.049 \\
\hline With children & & & $-0.158 * * *$ & 0.057 \\
\hline Residence: lower class neighborhood & & & \multicolumn{2}{|l|}{ Ref. } \\
\hline Lower class neighborhood & & & -0.044 & 0.04 \\
\hline Upper class neighborhood & & & -0.067 & 0.065 \\
\hline Non local & & & $-0.126 * *$ & 0.061 \\
\hline Number social networks & & & 0.008 & 0.012 \\
\hline \multicolumn{5}{|l|}{ Attitudes towards risk } \\
\hline Risk seeking & & & $0.031^{*}$ & 0.016 \\
\hline Loss aversion & & & 0.01 & 0.011 \\
\hline Aversion to uncertainty & & & -0.007 & 0.012 \\
\hline \multicolumn{5}{|l|}{ Usage of public transportation } \\
\hline Frequency of trips in previous month & & & 0 & 0 \\
\hline Trip after $7 \mathrm{pm}$ & & & -0.075 & 0.064 \\
\hline Mean duration of trips $<15$ minutes & & & -0.012 & 0.049 \\
\hline Usage of metro & & & \multicolumn{2}{|c|}{ Ref. } \\
\hline Bus exclusively & & & 0.002 & 0.107 \\
\hline Tram exclusively & & & 0.031 & 0.103 \\
\hline Various modes excluding metro & & & -0.002 & 0.073 \\
\hline \multicolumn{5}{|l|}{ Norms and beliefs } \\
\hline Degree of approval of fraud ( 1 to 7 ) & & & 0.015 & 0.014 \\
\hline Weakness of moral norm & & & $0.031 * * *$ & 0.007 \\
\hline Belief on fraud rate in transportations & & & $0.002 * *$ & 0.001 \\
\hline Belief on control probability & & & $-0.002 * * *$ & 0.001 \\
\hline Correct belief on fine $(=€ 50)$ & & & \multicolumn{2}{|l|}{ Ref. } \\
\hline Overestimate fine & & & 0.028 & 0.052 \\
\hline Underestimate fine & & & 0.037 & 0.053 \\
\hline Obs & \multicolumn{2}{|l|}{1953} & \multicolumn{2}{|c|}{1953} \\
\hline Pseudo R2 & \multicolumn{2}{|l|}{0.113} & \multicolumn{2}{|c|}{0.22} \\
\hline Df & \multicolumn{2}{|c|}{6} & \multicolumn{2}{|c|}{32} \\
\hline Prob $>$ F & \multicolumn{2}{|c|}{$<0.001$} & \multicolumn{2}{|c|}{$<0.001$} \\
\hline
\end{tabular}

Notes: Logit regressions with clustered standard errors. Dependent variable $=$ decision to not buy a ticket for a given destination. The Table reports the marginal effects. Independent variables include individual characteristics, attitudes towards risk, usage of public transportation, norms, beliefs. The omitted category is "No ticket and self-reported fraudster". ${ }^{*} p<0.1,{ }^{* *} p<0.05, * * * p<0.01$. 


\section{Appendix 9. Relationship between the public transportation game and the die-under-cup task}

In this section, we investigate the extent to which the behavior in the public transportation game relates to the one in the die task. A priori, we should expect very little correlation between the two measures for two main reasons. First, the measure obtained from the die task is very noisy at the individual level. Second, as we reported in the main paper, potential scrutiny by the experimenter in the public transportation game reduces the willingness to cheat of image-concerned individuals who, conversely, fare dodge in the field and cheat in the die task.

If we look at the mean fraud rate in the public transportation game of those who, in the die task, report a blue, yellow and red respectively (see Table A8), we find that it is on average higher for those who report yellow or red compared to those who report blue. The differences are however not statistically significant (Kruskal-Wallis test, $p=0.292$; Mann-Whitney tests, $p>0.1$ for all pairwise comparisons).

Table A8. Fraud rate in the public transportation game based on the first die's report

\begin{tabular}{ccc}
\hline \multirow{2}{*}{ Report in the die-under-cup task } & $\begin{array}{c}\text { Fraud rate in the public transportation game } \\
\text { Mean }\end{array}$ & St. dev. \\
\hline Blue $(€ 0)$ & 0.300 & 0.335 \\
Yellow $(€ 3)$ & 0.390 & 0.359 \\
Red $(€ 5)$ & 0.354 & 0.388 \\
\hline
\end{tabular}

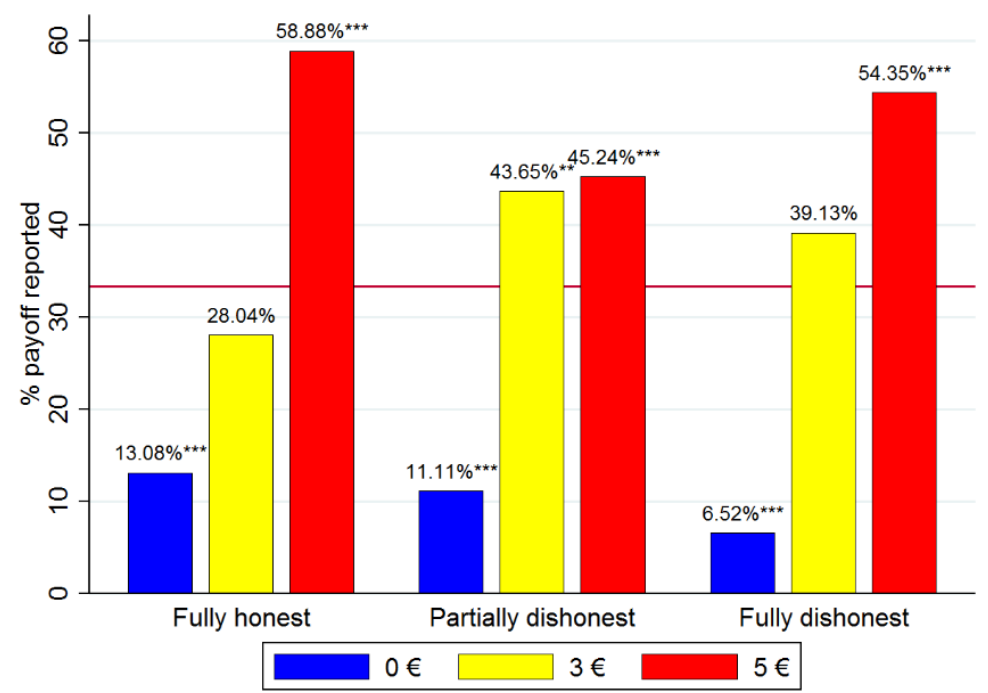

Figure A2. Reported outcomes of the first die roll and behavior in the public transportation game

Notes: The horizontal line identifies the uniform distribution and is located at $33.33 \%{ }^{*} p<0.1, * * p<0.05$, *** $p<0.01$ (two-sided binomial tests that the observed percentage differs from $33.33 \%$.).

We can also look at the first die's reports of those who, in the public transportation game, always buy a ticket (fully honest), never buy one (fully dishonest), and do not buy a ticket at least once but not systematically (partially dishonest). Figure A2 displays the distributions of the die outcomes reported by fully honest, fully dishonest, and partially dishonest subjects respectively. All categories of subjects tend to misreport the first die roll to their advantage. More specifically, the distributions of the outcomes reported by fully honest, fully dishonest, and partial dishonest subjects differ significantly from a uniform distribution $\left(\chi^{2}\right.$ tests, $\left.\mathrm{p}<0.001\right)$. Binomial tests indicate that all subjects report significantly more reds and less blues than the expected value of $33 \%(\mathrm{p}<0.01)$. Partial dishonest subjects also report significantly more yellows than expected $(\mathrm{p}=0.018)$. 
Comparing the distributions of the outcomes reported by each category of subjects, we only find significant differences between fully honest and partial dishonest subjects (Fisher's exact test, $p=0.044)$. In particular, fully honest subjects report more reds $(p=0.048)$ and less yellows $(p=0.014)$ than partial dishonest subjects. This is not surprising given our results reported in the paper. Note in fact that many actual fare dodgers (non-ticket holders) who self-report as non-fraudsters were classified as fully honest in the public transportation game.

Table A9. Determinants of fraud in the public transportation game (Logit regressions)

\begin{tabular}{|c|c|c|c|c|}
\hline & \multicolumn{2}{|l|}{$(1)$} & \multicolumn{2}{|l|}{$(2)$} \\
\hline & $\mathrm{dy} / \mathrm{dx}$ & se & $\mathrm{dy} / \mathrm{dx}$ & se \\
\hline Ticket holder & $-0.096 * *$ & 0.043 & -0.069 & 0.044 \\
\hline Self-reported non fraudster & $-0.292 * * *$ & 0.039 & $-0.157 * * *$ & 0.05 \\
\hline Fine Collection Office & -0.099 & 0.069 & -0.004 & 0.064 \\
\hline $1^{\text {st }}$ die report & -0.005 & 0.013 & -0.009 & 0.012 \\
\hline Controls for individual characteristics & \multicolumn{2}{|c|}{ No } & \multicolumn{2}{|c|}{ Yes } \\
\hline Controls for the treatment variables & \multicolumn{2}{|l|}{ Yes } & \multicolumn{2}{|l|}{ Yes } \\
\hline Number of observations & \multicolumn{2}{|l|}{1953} & \multicolumn{2}{|l|}{1953} \\
\hline Pseudo R2 & \multicolumn{2}{|l|}{0.114} & \multicolumn{2}{|l|}{0.22} \\
\hline Df & \multicolumn{2}{|c|}{6} & \multicolumn{2}{|l|}{32} \\
\hline Prob $>$ F & \multicolumn{2}{|c|}{$<0.001$} & \multicolumn{2}{|c|}{$<0.001$} \\
\hline & \multicolumn{2}{|l|}{ (3) } & \multicolumn{2}{|l|}{ (4) } \\
\hline & $\mathrm{dy} / \mathrm{dx}$ & se & $\mathrm{dy} / \mathrm{dx}$ & se \\
\hline No Ticket and self-reported non-fraudster & $-0.286 * * *$ & 0.072 & $-0.177 * * *$ & 0.067 \\
\hline Ticket and self-reported fraudster & $-0.093 *$ & 0.049 & -0.081 & 0.053 \\
\hline Ticket and self-reported non-fraudster & $-0.389 * * *$ & 0.054 & $-0.224 * * *$ & 0.067 \\
\hline Fine Collection Office & -0.098 & 0.071 & -0.009 & 0.066 \\
\hline $1^{\text {st }}$ die report & -0.005 & 0.013 & -0.01 & 0.012 \\
\hline Controls for individual characteristics & \multicolumn{2}{|l|}{ No } & \multicolumn{2}{|c|}{ Yes } \\
\hline Controls for the treatment variables & \multicolumn{2}{|l|}{ Yes } & \multicolumn{2}{|l|}{ Yes } \\
\hline Number of observations & \multicolumn{2}{|l|}{1953} & \multicolumn{2}{|l|}{1953} \\
\hline Pseudo R2 & \multicolumn{2}{|c|}{0.114} & \multicolumn{2}{|l|}{0.221} \\
\hline Df & \multirow{2}{*}{\multicolumn{2}{|c|}{$\begin{array}{c}7 \\
<0001\end{array}$}} & \multicolumn{2}{|l|}{33} \\
\hline Prob $>$ F & & & \multicolumn{2}{|c|}{$<0.001$} \\
\hline
\end{tabular}

Notes: Logit regressions with clustered standard errors. The Table reports the marginal effects. Independent variables include individual characteristics, attitudes towards risk, usage of public transportation, norms, beliefs. The full regressions are contained in Appendix 9. In models (3) and (4) the omitted category is "No ticket and self-reported fraudster". ${ }^{*} p<0.1,{ }^{* *} p<0.05,{ }^{* *} p<0.01$.

As an additional test of the relationship between the behavior in the public transportation game and the die task, we report, in Table A9, the regressions relative to cheating in the public transportation game with the inclusion of the reported die roll among the explanatory variables. The regression confirms the results above that the behavior in the die task is not a good predictor of the behavior in the public transportation game. 
Appendix 10. Table A10: Determinants of the $1^{\text {st }}$ roll outcome reported in the die task (ordered logit regressions)

\begin{tabular}{|c|c|c|c|c|c|c|c|c|c|c|c|c|}
\hline & \multicolumn{6}{|c|}{ (1) } & \multicolumn{6}{|c|}{ (2) } \\
\hline & \multicolumn{2}{|c|}{ Blue $(€ 0)$} & \multicolumn{2}{|c|}{ Yellow $(€ 3)$} & \multicolumn{2}{|c|}{ Red $(€ 5)$} & \multicolumn{2}{|c|}{ Blue $(€ 0)$} & \multicolumn{2}{|c|}{ Yellow $(€ 3)$} & \multicolumn{2}{|c|}{ Red $(€ 5)$} \\
\hline & $\mathrm{dy} / \mathrm{dx}$ & se & $\mathrm{dy} / \mathrm{dx}$ & se & $\mathrm{dy} / \mathrm{dx}$ & se & $\mathrm{dy} / \mathrm{dx}$ & $\mathrm{se}$ & $\mathrm{dy} / \mathrm{dx}$ & se & $\mathrm{dy} / \mathrm{dx}$ & $\mathrm{se}$ \\
\hline Ticket holder & $0.075 * * *$ & 0.028 & $0.111 * * *$ & 0.036 & $-0.187 * * *$ & 0.059 & $0.089 * * *$ & 0.032 & $0.123 * * *$ & 0.04 & $-0.212 * * *$ & 0.068 \\
\hline Self-reported non-fraudster & 0.052 & 0.038 & $-0.108^{*}$ & 0.059 & 0.056 & 0.064 & $0.073 *$ & 0.043 & -0.096 & 0.062 & 0.022 & 0.076 \\
\hline Fine Collection Office & $0.090 * *$ & 0.045 & $0.132 * *$ & 0.057 & $-0.222 * *$ & 0.098 & $0.080^{*}$ & 0.042 & $0.110^{* *}$ & 0.055 & $-0.190 * *$ & 0.094 \\
\hline Individual characteristics & \multicolumn{2}{|c|}{ No } & \multicolumn{2}{|c|}{ No } & \multicolumn{2}{|l|}{ No } & \multicolumn{4}{|c|}{ Yes } & \multicolumn{2}{|l|}{ Yes } \\
\hline Number of observations & \multicolumn{6}{|c|}{279} & \multicolumn{6}{|c|}{279} \\
\hline Pseudo R2 & \multicolumn{6}{|c|}{0.028} & \multicolumn{6}{|c|}{0.095} \\
\hline Df & \multicolumn{6}{|c|}{4} & \multicolumn{6}{|c|}{30} \\
\hline Prob $>$ F & \multicolumn{6}{|c|}{0.006} & \multicolumn{6}{|c|}{0.037} \\
\hline & \multicolumn{6}{|c|}{ (3) } & \multicolumn{6}{|c|}{ (4) } \\
\hline & \multicolumn{2}{|c|}{ Blue $(€ 0)$} & \multicolumn{2}{|c|}{ Yellow $(€ 3)$} & \multicolumn{2}{|c|}{ Red $(€ 5)$} & \multicolumn{2}{|c|}{ Blue $(€ 0)$} & \multicolumn{2}{|c|}{ Yellow $(€ 3)$} & \multicolumn{2}{|c|}{$\operatorname{Red}(€ 5)$} \\
\hline & $\mathrm{dy} / \mathrm{dx}$ & se & $\mathrm{dy} / \mathrm{dx}$ & se & $\mathrm{dy} / \mathrm{dx}$ & se & $\mathrm{dy} / \mathrm{dx}$ & se & $\mathrm{dy} / \mathrm{dx}$ & se & $\mathrm{dy} / \mathrm{dx}$ & se \\
\hline No ticket and self non-fraudster & 0.008 & 0.043 & 0.011 & 0.063 & -0.019 & 0.106 & 0.042 & 0.047 & 0.058 & 0.064 & -0.101 & 0.11 \\
\hline Ticket and self fraudster & $0.085 * * *$ & 0.032 & $0.124 * * *$ & 0.044 & $-0.209 * * *$ & 0.073 & $0.111 * * *$ & 0.039 & $0.154 * * *$ & 0.049 & $-0.265 * * *$ & 0.082 \\
\hline Ticket and self non-fraudster & $0.067 *$ & 0.036 & $0.098 * *$ & 0.046 & $-0.165^{* *}$ & 0.079 & $0.097 * *$ & 0.044 & $0.134 * * *$ & 0.05 & $-0.231 * *$ & 0.09 \\
\hline Fine Collection Office & $0.092 * *$ & 0.043 & $0.135 * *$ & 0.056 & $-0.227 * *$ & 0.095 & $0.086^{* *}$ & 0.041 & $0.119 * *$ & 0.054 & $-0.204 * *$ & 0.092 \\
\hline Individual characteristics & \multicolumn{2}{|c|}{ No } & \multicolumn{2}{|c|}{ No } & No & & Yes & & Yes & & Yes & \\
\hline Number of observations & & & 27 & & & & & & 279 & & & \\
\hline Pseudo R2 & & & 0.0 & & & & & & 0.08 & & & \\
\hline Df & & & 4 & & & & & & 30 & & & \\
\hline Prob $>$ F & & & 0.0 & & & & & & 0.02 & & & \\
\hline
\end{tabular}

Notes: (1) and (2) are partial ordered logit regressions, while (3) and (4) are generalized ordered logit regressions. "Self-reported non-fraudster" violates the proportional odds assumption (Brant test, $p=0.023$ ). For this reason, we employ a partial ordered model in (1) and (2). This model relaxes the proportional odds assumption for those variables that violate it. All regressions have robust standard errors. The table reports the marginal effects. Independent variables include individual characteristics, attitudes towards risk, usage of public transportation, norms, beliefs. The full regressions are available from the authors upon request. In models (3) and (4) the omitted category is "No Ticket and self-reported fraudster". $* p<0.1, * * p<0.05, * * * p<0.01$. 